\title{
Erkrankungen der Atemwege und der Lunge
}

\section{Kopp, W. Leupold}

22.1 Anatomische und physiologische Besonderheiten - 473 W. Leupold

22.2 Angeborene Fehlbildungen - 473

M. Kopp

22.2.1 Angeborene Fehlbildungen von Larynx, Trachea und Bronchien - 473

22.2.2 Angeborene Fehlbildungen der Lunge - 474

22.2.3 Angeborene Fehlbildungen des Zwerchfells - 475

22.3 Angeborene Lungenerkrankungen - 475

K. Kopp

22.3.1 Primäre ziliäre Dyskinesie $\quad-475$

22.3.2 Alpha-1-Antitrypsinmangel -476

22.4 Akute und chronische Entzündung der oberen Luftwege - 477 M. Kopp

22.4.1 Akute Rhinitis -477

22.4.2 Chronische Rhinitis -477

22.5 Akute und chronische Entzündung der mittleren Atemwege - 477 W. Leupold, M. Kopp

22.5.1 Stenosierende Laryngotracheitis (Pseudokrupp) - 477

22.5.2 Epiglottitis -478

22.5.3 Akute Bronchitis -479

22.5.4 Chronische Bronchitis - 479

22.5.5 Bronchiolitis -480

22.5.6 Rezidivierende Infekte der Atemwege - Infektanfälligkeit - 481

22.6 Akute und chronische Entzündung der Lunge - 481

M. Kopp, W. Leupold

22.6.1 Pneumonie - 481

22.6.2 Asthma bronchiale -485

22.6.3 Exogen-allergische Alveolitis - 491

22.7 Bronchiolitis obliterans -493

M. Kopp

22.8 Bronchiektasen -493

W. Leupold 
22.9 Interstitielle Lungenerkrankungen $\quad-494$

M. Kopp

22.10 Systemkrankheiten mit Beteiligung der Lunge - 495

M. Kopp, W. Leupold

22.10.1 Sarkoidose -495

22.10.2 Neuromuskuläre Erkrankungen und Ateminsuffizienz - 496

22.11 Aspiration - 497

M. Kopp

22.11.1 Fremdkörperaspiration -498

22.11.2 Aspiration von Flüssigkeiten - 499

22.12 Thoraxtrauma und Erkrankungen der Pleura - 499 W. Leupold

22.12.1 Geschlossene Brustkorbverletzungen - 499

22.12.2 Pneumothorax -499

22.12.3 Pleuritis -500

22.13 Tumoren der Lunge und der Pleura - 501 M. Kopp

22.13.1 Gutartige Neoplasien - 501

22.13.2 MaligneTumoren -502

Literatur - 502 
$>$ Einleitung

Der italienische Arzt Girolamo Cardano (1501-1576), der zu seiner Zeit als einer der größten Gelehrten und Ärzte in ganz Europa galt, wurde im Jahre 1552 von John Hamilton, dem Erzbischof von St. Andrews in Edinburgh, zur Konsultation eingeladen. Hamilton, der Bruder des Regenten von Schottland, litt seit mehreren Jahren an Husten, Dyspnoe und Expektoration, die nach Ansicht der königlichen Leibärzte von einem kalten und feuchten Hirn herrührten, in dem sich durch Destillation Phlegma anhäufte, das anschließend durch die Luftröhre in die Lunge absank.

Cardano beobachtete seinen Patienten 40 Tage lang und kam zu dem Schluss, dass asthmatische Beschwerden durch eine Unverträglichkeit von Bettfedern mitverursacht werden. Heute ist bekannt, dass Allergien - wie in diesem Fall die Hausstaubmilbenallergie - oft an der Auslösung des kindlichen Asthma bronchiale beteiligt sind. Da in Mitteleuropa mittlerweile das Asthma die häufigste chronische Erkrankung des Kindes ist, sind Maßnahmen der Allergenkarenz somit auch heute noch von essenzieller Bedeutung.

\subsection{Anatomische und physiologische Besonderheiten}

\section{$W$. Leupold}

Je jünger ein Kind ist, umso höher ist seine Atemfrequenz. Neugeborene atmen 35- bis 55-mal pro Minute, 6-Jährige noch etwa 25-mal pro Minute. Der noch weitgehend horizontale Verlauf der Rippen lässt eine wirksame Erweiterung des Thorax nicht zu, sodass Neugeborene und Säuglinge auf Zwerchfellatmung angewiesen sind und eine Regulation im Wesentlichen nur über die Frequenz möglich ist. Einziehungen beim Neugeborenen mit Atemnot entstehen dann, wenn die Lungen weniger beweglich als die Brustwand werden. Während der Inspiration entwickelt das Kind kräftige diaphragmatische Kontraktionen, um die Lunge mit Luft zu füllen. Dies lässt einen starken negativen intrapleuralen Druck entstehen; als Folge kollabiert die Brustwand nach innen an Punkten kleinsten Widerstandes: Einziehungen interkostal, subkostal, substernal und jugulär resultieren.

C Cave

Neugeborene und Säuglinge sind obligate Nasenatmer. Damit kann ein Schnupfen im Säuglingsalter zu einer erheblichen Beeinträchtigung des Kindes führen und wird gelegentlich sogar Anlass zur Krankenhausaufnahme.

Stöhnen wird dann gehört, wenn das Neugeborene - aber auch Patienten mit einer Kollapsneigung der intrathorakalen Atemwege - zur Steigerung des endobronchialen Drucks am Beginn der Ausatmung kurz die Glottis verschließt und nach deren Öffnung die Luft mit einem »stöhnenden « Geräusch entweicht.

In Abhängigkeit vom Voranschreiten der Entwicklung des bronchopulmonalen Systems ergeben sich bei Kindern altersspezifische physiologische Besonderheiten der Lungenfunktion, die auch für die weitere Entstehung und den Verlauf von Erkrankungen von besonderer Bedeutung sind.

Vorrangig zu nennen ist dabei die Tatsache, dass bis etwa zum 5. Lebensjahr die peripheren Atemwege (ab 15. Generation) disproportional eng sind und dementsprechend ihre Durchlassfähigkeit [Conductance $\left(\mathrm{G}_{\mathrm{aw}}\right)$ ] gegenüber den zentralen Atemwegen unerwartet niedrig ist. Sie tragen in diesem Alter noch zu ca. 50\% zum gesamten Atemwegswiderstand bei. Erst nach dem 4. Lebensjahr kommt es zu einer raschen Größenzunahme der Atemwege (Vergrößerung des Radius!), die mit einer sprunghaften Vergrößerung der Conductance bzw. Verringerung der Resistance der peripheren Atemwege verbunden ist.

Auf der Basis dieser Besonderheit wird jeder Infekt der Atemwege bei Säuglingen und Kleinkindern einen größeren Einfluss auf die Conductance der peripheren Atemwege haben als im späteren Leben. Es kommt zu erheblichen Störungen hinsichtlich Belüftung (Giemen!) und Gasaustausch. Beim größeren Kind bzw. beim Erwachsenen werden Störungen mit gleicher Lokalisation (z. B. im Rahmen von Bronchitis, Bronchiektasen oder Mukoviszidose) dagegen oft »stumm« bleiben. Die Tendenz der jungen Kinder zur schnellen Obstruktion der kleinen Atemwege ist auch der Grund dafür, dass in diesem Altersbereich Atelektasen und rezidivierende Infektionen häufiger zu beobachten sind.

Als weitere entwicklungsabhängige Besonderheiten und Risikofaktoren für Entstehung und Verlauf von bronchopulmonalen Erkrankungen im frühen Kindesalter sind zu nennen:

- Weichheit des Knorpels von Larynx und großen Bronchien, sodass bei größeren Druckschwankungen in den Atemwegen Kollapsneigung besteht.

- Die Bronchien junger Kinder besitzen relativ viele Schleimdrüsen. Entzündungen oder Irritationen führen deshalb zu einer stärkeren sekretbedingten Obstruktion.

- Ein inadäquater Hustenmechanismus (= schwacher Reflex, horizontale Rippenstellung) und die beschriebene Kollapsneigung verhindern eine optimale Bronchialreinigung.

\subsection{Angeborene Fehlbildungen}

\author{
M. Kopp
}

\subsubsection{Angeborene Fehlbildungen von Larynx, Trachea und Bronchien}

\section{Stridor congenitus}

Pathogenese. Kongenitale Fehlbildungen, die den Kehlkopfeingang, das Kehlkopflumen oder die Trachea einengen, führen postnatal - bei geringerer Ausprägung auch erst im Rahmen des ersten Luftwegsinfektes - zu einem ziehenden, juchzenden oder schnarchenden Atemgeräusch.

D Dieser Stridor tritt bei extrathorakal gelegenen Hindernissen (häufigste Lokalisation) bei der Inspiration, bei unterhalb der oberen Thoraxapertur liegenden Stenosen (unteres Drittel der Trachea, Hauptbronchien) exspiratorisch auf.

Prinzipiell kann es sich um dynamische (Malazie) und fixierte Stenosen handeln. Weitere Ursachen eines kongenitalen Stridors, die differenzialdiagnostisch berücksichtigt werden müssen, sind in - Tabelle 22.1 dargestellt.

Klinik. Neben dem meist inspiratorischen, manchmal "gackernden« Stridor kann es in Abhängigkeit vom Grad der Einengung bis zum schweren inspiratorischen Ziehen mit tiefen jugulären, sternalen und epigastrischen Einziehungen kommen. Ein hinzukommender Luftwegsinfekt verschlimmert in der Regel die Situation. Der Stridor ist oft lageabhängig mit Besserung in Bauchlage oder beim Überstrecken des Halses. Eine Verschlechterung bei Nahrungsaufnahme kann auf eine Tracheomalazie hindeuten. 


\begin{tabular}{l|l|l}
$\begin{array}{l}\text { - Tabelle 22.1. Differenzialdiagnose des Stridors } \\
\text { Pharynxbereich }\end{array}$ & Angeboren & $\begin{array}{l}\text { Laryngomalazie } \\
\text { Laryngozele oder -zyste } \\
\text { Hämangiom, Lymphangiom }\end{array}$ \\
\cline { 2 - 3 } & Erworben & $\begin{array}{l}\text { Krupp } \\
\text { Epiglotittis } \\
\text { Rekurrensparese }\end{array}$ \\
\hline Trachea-Bronchien & Angeboren & $\begin{array}{l}\text { Tracheomalazie } \\
\text { Bronchomalazie } \\
\text { Hämangiom, Lymphangiom } \\
\text { Gefäßfehlbildung }\end{array}$ \\
\hline & Erworben & $\begin{array}{l}\text { Fremdkörper } \\
\text { Tumoren }\end{array}$ \\
\cline { 2 - 3 } & Angeboren & $\begin{array}{l}\text { Makroglossie, Glossoptose } \\
\text { Mikrognathie }\end{array}$ \\
\hline Andere & Erworben & \begin{tabular}{l} 
Tonsillenhyperplasie \\
\hline
\end{tabular}
\end{tabular}

Diagnose. Bei einer leichten Form des Stridor congenitus mit Beginn in den ersten Lebenswochen, der nicht mit einer Gedeihstörung einhergeht, ist eine weitere Diagnostik zunächst verzichtbar. Die Babyplethysmographie ist eine sensitive Untersuchungsmethode, um eine reine Laryngomalazie mit einem typischen »Sägezahnmuster« bei der Inspiration von anderen Ursachen eines Stridors zu differenzieren. Bleibt die Interpretation unklar, so muss mittels flexibler Bronchoskopie, Echokardiographie und ggf. Schnittbildgebung die Ätiologie eines persistierenden Stridors zweifelsfrei geklärt werden.

Therapie. Leichte bis mittelschwere Verläufe auf der Basis einer Malazie von Epiglottis, Kehlkopf oder Trachea bedürfen keiner besonderen Therapie. Verschlechterungen im Rahmen akuter Infekte sollten u. U. stationär überwacht werden. Schwere Verläufe machen eine Beatmung oder in seltenen Fällen eine Tracheotomie nötig. Eine nicht-invasive nächtliche CPAP-Atemunterstützung (= continuous positive airway pressure) kann in Einzelfällen die Tracheotomie umgehen. Andere Ursachen (z. B. primäre und sekundäre Stenosen, Tumoren, Zysten) können operativ beseitigt werden. Bei Hämangiomen kann eine laserchirurgische Abtragung erfolgen.

D Cave

Bei der Bronchoskopie müssen Hämangiome aufgrund der Blutungsgefahr mit äußerster Vorsicht inspiziert werden.

Prognose. Die Weichheit des Knorpels von Kehlkopf oder Trachea nimmt mit zunehmendem Lebensalter ab, sodass der Stridor bei den meisten Kindern nach 6-18 Monaten abklingt.

Stenosen durch Fehlbildungen von großen Gefäßen ( $\triangleright$ Kap. 24).

\subsubsection{Angeborene Fehlbildungen der Lunge}

\section{Agenesie, Hypoplasie, Separation}

Pathogenese. Die Agenesie/Aplasie einer Lunge (meist links) ist mit dem Leben vereinbar, geht aber oft mit gehäuften bronchopulmonalen Infekten einher. Die Kinder sind vermindert belastbar. Begleitende Fehlbildungen (besonders Herz, Ösophagus u. a.) finden sich in 50-75\% der Fälle. Die Therapie beschränkt sich auf die Bekämpfung der rezidivierenden Infektionen in dem fehlgebildeten Lungenabschnitt.

Eine Hypoplasie ( $\triangleright$ Kap. 8.7.5) der Lunge kann sowohl durch primäre teratogene Schädigungen, eine Hypo- oder Aplasie der A. pulmonalis wie aber auch durch Einwirkungen von außen entstehen, die die weitere Entwicklung einer primär normal angelegten Lunge behindern (z. B. Zysten, Zwerchfellhernien). Fast immer wird die Hypoplasie des Lungengewebes von einer Hypoplasie der zuständigen Arterie begleitet, und oft bestehen Fehlbildungen in anderen Organen (Herz, Zwerchfell, Niere). Die verminderte Durchblutung und Belüftung des hypoplastischen Areals bedingt eine erhöhte Gefahr für virale und bakterielle Infektionen, deren Behandlung (Antibiotika, Physiotherapie, Inhalationen) die wesentlichste Aufgabe bei der Betreuung dieser Patienten ist.

Die Separation von Lungengewebe kann in Form einer Nebenlunge vorliegen, die man als normales Lungenparenchym mit Bronchusanlagen intrathorakal aber auch intraabdominal finden kann.

Bei der Lungensequestration besitzt der vom normalen Lungengewebe anatomisch und funktionell völlig getrennte Teil eine amorphe histologische Struktur. Besteht keine Verbindung zur gleichseitigen Lunge und ist eine eigene Pleura vorhanden, spricht man von extralobärer - im Gegensatz zur intralobären Sequestration.

\section{$>$ Bedeutsam ist für Diagnose und Operation, dass die versor- gende Arterie immer direkt aus der Aorta entspringt! (in 25\% dabei aus der Aorta abdominalis).}

Diagnose. Klinisch machen sich diese Fehlbildungen durch rezidivierende Pneumonien, Lungenabszesse oder unter dem Bild von Bronchiektasen bemerkbar, die meist im Unterlappen (links > rechts) ablaufen. Mithilfe von Thoraxröntgenbild, CT, retrograder Aortographie (wichtig für den Operateur) und eventueller Bronchographie kann die Diagnose gesichert werden (• Abb. 22.1).

Therapie. Die Behandlung ist chirurgisch, wobei meist chronisch entzündetes umgebendes Lungengewebe mit entfernt werden muss.

\section{Zystische Lungenfehlbildungen}

Beim vorsprossenden Wachstum der embryonalen Anlage für Atemwege und Lunge kann es durch ungleichmäßiges Wachstum oder Versprengung von Zellen zu einer Vielzahl zystischer Fehlbildungen in den verschiedensten Bereichen kommen. In der frühen Entwicklungsphase entstehen Trachealzysten. Später entwickeln sich bronchogene Zysten und ein lobäres Emphysem, gefolgt von Zystenlunge, Wabenlunge und kongenitaler zystischadenomatoider Malformation der Lunge.

Bronchogene Zysten. Vom Bronchialsystem ausgehende Zysten sind intra- oder extrapulmonal gelegene, kugelförmige Hohlräume von wechselnder Größe. Sie können Luft oder Flüssigkeit enthalten und haben primär eine Verbindung zum Bronchialbaum, die meist aber obliteriert ist. Bronchogene Zysten machen etwa die Hälfte aller Lungenfehlbildungen aus.

Die extrapulmonalen Zysten (meist solitär) entstehen in der 4.-5., die intrapulmonalen (meist multipel) in der 8. Embryonalwoche wohl durch vermehrte Ausknospung oder Wachstum von versprengten Zellen. 

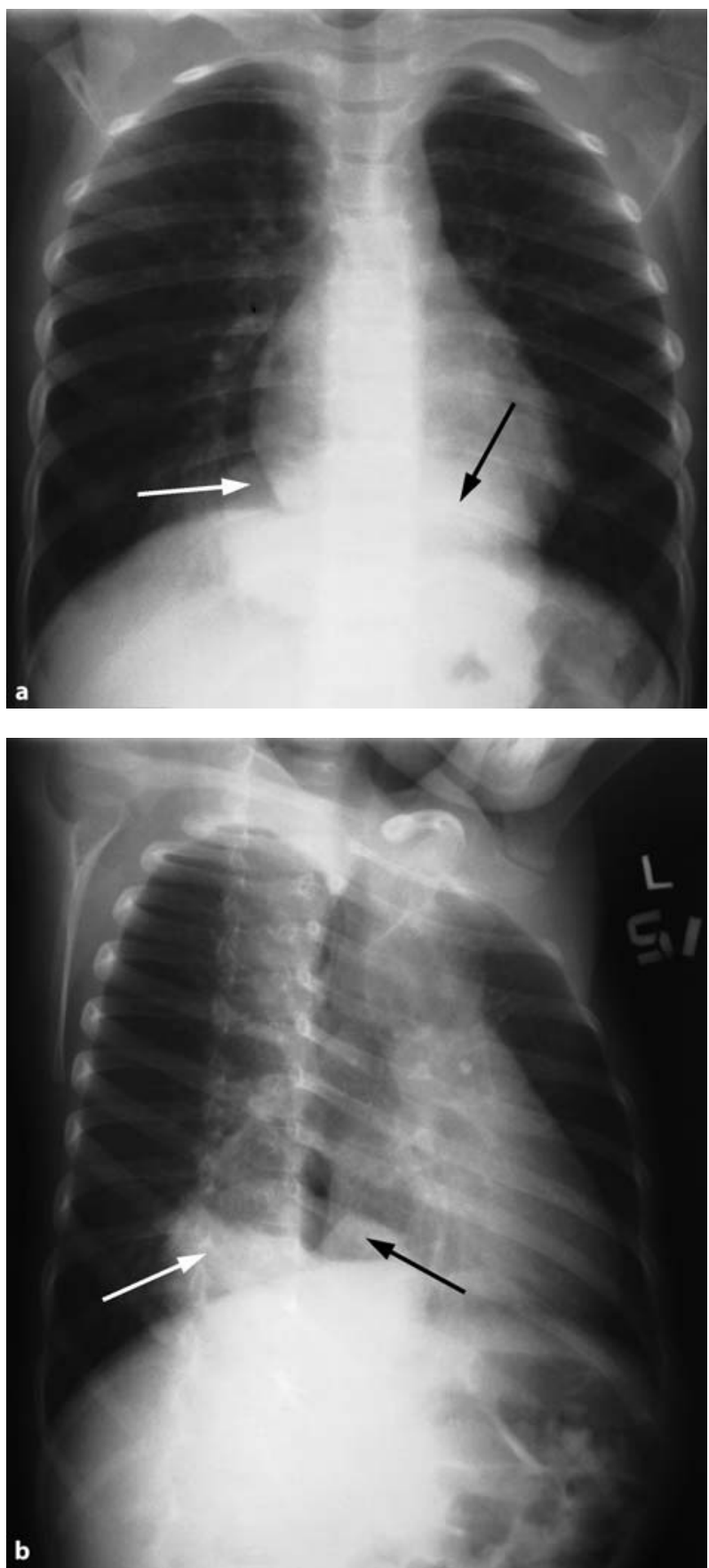

- Abb. 22.1a,b. Rundliche Verschattungen beidseits der Wirbelsäule (Pfeile) bei doppelseitiger Lungensequestration: a posterior-anteriorer, b schräger Strahlengang

Bronchogene Zysten können lange Zeit symptomlos bleiben und werden teilweise auch zufällig bei einer Röntgenaufnahme entdeckt. Bedeutung erlangen sie durch Kompression von Bronchien oder Lungenparenchym (Reizhusten, Stridor, chronische Bronchitis) bzw. durch rezidivierende Infektionen (Pneumonie).

Die Therapie erfolgt durch chirurgische Entfernung aller extrapulmonalen Zysten. Bei intrapulmonaler Lage ohne Zeichen für Kompression und Infektion kann unter Beobachtung abgewartet werden.
Kongenitales lobäres Emphysem. Unter einem lobären Emphysem versteht man eine Überblähung eines oder auch mehrerer Lungenlappen. Dies kommt durch einen Ventilmechanismus zustande: Bei der Inspiration tritt Luft in den betroffenen Bereich ein, die bei der Exspiration nicht mehr entweichen kann. Ursachen hierfür können u. a. eine Knorpeldysplasie, Gefäßanomalien oder Stenosierungen von außen z. B. durch eine bronchogene Zyste oder ein Teratom sein. Histologisch findet man eine normale Lungenarchitektur mit überblähten Alveolen.

Im Unterschied dazu findet man bei dem sog. Iobulären Emphysem alveoläre Strukturanomalien. Die klinische Symptomatik beginnt fast immer direkt in der Neonatalzeit, wenn die Kinder mit einer progredienten Tachypnoe und Dyspnoe auffallen.

\subsubsection{Angeborene Fehlbildungen des Zwerchfells}

Kongenitale Zwerchfellhernie. ( $\$$ Kap. 37, Kinderchirurgie)

\subsection{Angeborene Lungenerkrankungen}

$$
\text { M. Kopp }
$$

Zystische Fibrose $>$ Kap. 23.

\subsubsection{Primäre ziliäre Dyskinesie}

Definition. Die primäre Ziliendyskinesie (»primary ciliary dyskinesia«, PCD) ist eine phänotypisch und genetisch heterogene Erkrankung, die überwiegend autosomal-rezessiv vererbt wird. Die Erkrankung ist charakterisiert durch eine Fehlfunktion respiratorischer Flimmerhärchen (Zilien), embryonaler Zilien und Spermienschwänze. Im Respirationstrakt kommt es hierdurch zu einer gestörten Mukus-Clearance und rezidivierenden bzw. chronischen Infektionen der Atemwege. Männliche Infertilität auf Grund einer Spermiendysmotilität wird ebenfalls oft bei einer PCD beobachtet ( $60 \%)$. Die embryonale Ziliendysfunktion ist dafür verantwortlich, dass die Hälfte der PCDPatienten einen Situs inversus (Kartagener Syndrom) aufgrund einer zufälligen Anordnung der Links/Rechts-Körperasymmetrie aufweist. Neben den angeborenen Formen kann es im Rahmen von chronisch-entzündlichen Erkrankungen der Atemwege auch zu einer sekundären Fehlfunktion der Zilien kommen.

Epidemiologie. Die Inzidenz liegt zwischen 1:15.000 und 1: 20.000 in der weißen Bevölkerung.

Klinik. Der individuelle Krankheitsverlauf der PCD ist sehr heterogen. Die pulmonalen Beschwerden bei PCD Patienten sind durch die gestörte mukoziliären Clearance erklärbar. Hierdurch kommt es zu einem unzureichenden Transport von Mukus aus den Atemwegen. Dies führt schließlich zu einer Besiedelung mit verschiedenen Erregern. So kommt es zu rezidivierenden bzw. chronischen Infektionen wie Otitis media, Sinusitis, Bronchitiden und Pneumonien mit chronischem, oft produktivem Husten. Die pulmonalen Beschwerden und Veränderungen sind ähnlich wie bei der zystischen Fibrose. Im fortgeschrittenen Stadium kann es zur Emphysem- und zur Bronchiektasenbildung 
kommen. Die Männer sind oft infertil. Bei der Hälfte der Patienten mit PCD liegt ein Situs inversus vor. Der Befund des Situs inversus hat für den Patienten keinen zusätzlichen Krankheitswert, führt jedoch bei gleichzeitig vorliegenden respiratorischen Symptomen häufig zur früheren Diagnosestellung. Die klassische Trias des Kartagener-Syndroms besteht aus: Situs inversus, chronische Sinusitis und Bronchiektasen.

Diagnose. Rezidivierende oder chronische Erkrankungen der Atemwege wie Rhinitis, Otitis, Sinusitis oder Bronchitis sowie das Vorliegen eines Situs inversus können hinweisend auf eine PCD sein. Die Diagnose der PCD kann jedoch nur elektronenmikroskopisch an Hand von Schleimhautbiopsien oder an spezialisierten Zentren auch mit hochauflösenden immunfluorezenzmikroskopischen Untersuchungstechniken nach einfachem Bürstenabstrich des Nasenepithels gesichert werden.

PCD ist eine genetisch heterogene Erkrankung, die i. d. R. autosomal-rezessiv vererbt wird. Für autosomal-rezessiv vererbte PCD-Varianten mit Defekten des äußeren Dyneinarmes wurden bislang 4 Genorte auf den Chromosomen lokalisiert.

Differenzialdiagnostisch müssen andere schwere Lungenerkrankungen wie z. B. die zystische Fibrose ausgeschlossen werden.

Therapie. Eine kausale Therapie der PCD gibt es nicht. Ziel von symptomatischen Therapiemaßnahmen muss die Vermeidung von pulmonalen Komplikationen sein. Zu den zur Verfügung stehenden symptomatischen Maßnahmen zählen u. a. die Physiotherapie, Sekretolytika, Inhalationstherapie mit antiinflammatorischen und antiobstruktiven Medikamenten, Impfungen und eine gezielte antibiotische Therapie bei Infektionen. Patienten mit einer Zilienfunktionsstörung sollten in einer spezialisierten Ambulanz in regelmäßigen Abständen von einem Kinderpneumologen betreut werden.

\subsubsection{Alpha-1-Antitrypsinmangel}

Definition. Alpha-1-Antitrypsin (A1-AT) ist ein Akute-PhaseProtein, das in der Leber synthetisiert wird und verschiedene Proteinasen hemmt (• Abb. 22.2). Ein Mangel an Proteaseinhibitoren führt zur Leberzirrhose und zum Lungenemphysem. Das Strukturgen ist auf Chromosom 14q31-32.2 lokalisiert. Von dem Glykoprotein sind mehr als 75 Allele bekannt. Der Austausch von wenigen Aminosäuren führt zu einer veränderten Tertiärstruktur des Proteins; hierdurch wird offenbar die Ausschleußung aus den Hepatozyten gehemmt. Die genotypischen Varianten wurden nach ihrer elektrophoretischen Mobilität benannt (Pi-Typisierung). Der homozygote Pi-Typ ZZ hat in der mitteleuropäischen Bevölkerung eine Häufigkeit von etwa 1:20001:5000. Er geht mit einer Serumrestaktivität von 10-20\% der Norm einher (• Tab. 22.2).

Pathogenese. A1-AT inaktiviert Proteasen aus aktivierten Neutrophilen. Ein Überschuss an Proteasen, insbesondere der neutrophilen Elastase, führt zur Zerstörung extrazellulärer Strukturproteine wie dem Elastin. Ein Ungleichgewicht zwischen Proteasen und A1-AT führt daher zur Destruktion von Lungengewebe mit irreversiblem Verlust der elastischen Rückstellkraft, Überdehnung der Alveolarwände und Ausbildung eines Emphysems.

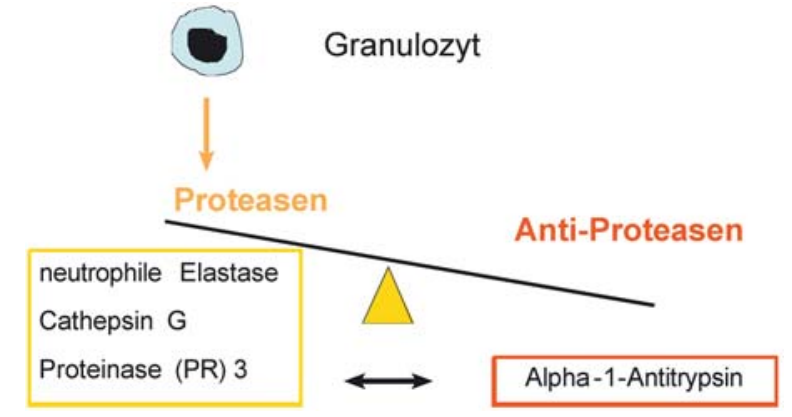

- Abb. 22.2. Pathophysiologie des A1-AT-Mangels

\begin{tabular}{l|l|l}
$\begin{array}{l}\text { - Tabelle 22.2. } \\
\text { semrisiko }\end{array}$ & A1-AT-Phänotyp, A1-AT-Serumspiegel und Emphy- \\
\hline Phänotyp & Serumspiegel in mg/dl & Emphysemrisiko \\
\hline MM & $150-350$ & Nicht erhöht \\
\hline SS & $100-140$ & Nicht erhöht \\
\hline MZ & $90-150$ & Nicht erhöht \\
\hline SZ & $45-80$ & $20-50 \%$ \\
\hline ZZ & $15-50$ & $80-100 \%$ \\
\hline Null-Null & 0 & $100 \%$ \\
\hline
\end{tabular}

Klinik. Die emphysematischen Veränderungen der Lunge führen erst dann zu Symptomen, wenn etwa bereits $25 \%$ der Lunge umgebaut sind. Dies ist in der Regel erst bei Jugendlichen nach dem 12. Lebensjahr zu erwarten. Dann können Atemnot, eine chronische Bronchitis oder ein unproduktiver Husten auftreten. Weitere Symptome des A1-AT-Mangels sind bronchiale Hyperreaktivität und rezidivierende Pneumonien.

D Cave

Bei einem Icterus gravis bzw. prolongatus oder einer unklaren pulmonalen Symptomatik sollte ein A1-AT-Serumspiegel bestimmt werden.

Diagnose. Diagnoseweisend ist die Bestimmung von A1-AT im Serum. Bei Serumspiegeln unter $120 \mathrm{mg} / \mathrm{dl}$ sollte eine PI-Typisierung veranlasst werden. Mit Hilfe der Lungenfunktionsprüfung können Veränderungen, die durch einen Verlust der elastischen Rückstellkraft bedingt sind, erfasst werden. Hier fallen initial eine Erhöhung des Residualvolumens und reduzierte Flussraten auf.

Therapie. Für Erwachsene ist die i.v. Behandlung mit A1-AT zugelassen. Auch bei Kindern ist wohl eine Substitution sinnvoll, auch wenn keine Daten über Langzeitverläufe vorliegen. Bei einem fortgeschrittenen Stadium ist eine Transplantation von Lunge und Leber indiziert.

Tabakrauch hemmt die Aktivität von Antiproteasen wie A1AT. Bei einem bestehenden Mangel an A1-AT kommt es daher zu einer Agravierung der Symptome. Raucher mit einem homozygoten A1-AT-Mangel weisen einen schnelleren Abfall der Lungenfunktion auf und haben eine deutlich geringere Lebenserwartung als betroffene Nichtraucher. 


\subsection{Akute und chronische Entzündung der oberen Luftwege}

\author{
M. Kopp
}

\subsubsection{Akute Rhinitis}

Die akute Rhinitis ( Kap. 16) ist eine virale (u. a. durch Rhino-, Parainfluenza-, Influenza-, RS-, oder Adenoviren verursachte) Entzündung der oberen Atemwege, die mit wässriger Rhinorrhö, nasaler Obstruktion und gelegentlich weiteren Allgemeinsymptomen (Abgeschlagenheit, Gliederschmerzen) einhergeht. Die Diagnose wird klinisch gestellt. Eine Virusanzüchtung aus dem Nasensekret ist i. d. R. überflüssig, serologische Untersuchungen sind unzuverlässig.

\subsubsection{Chronische Rhinitis}

Definition. Die chronische Rhinitis ist eine chronische Entzündung der Nasenschleimhaut, die oft mit purulenter Rhinorrhö und/oder nasaler Obstruktion einhergeht.

Ätiologie und Pathogenese. Im Kindesalter kann eine chronischen Entzündung der Nasenschleimhaut u. a. durch große adenoide Vegetationen (Rachenmandelhyperplasie), durch eine anatomische Fehlanlage (Choanalatresie, Lippen-Kiefer-Gaumenspalte) durch Polypen, Nasennebenhöhleninfektionen, durch Aeroallergene oder durch einen Fremdkörper hervorgerufen werden. Sie kann auch im Rahmen von Systemerkrankungen (PCD, zystische Fibrose, Sarkoidose, Wegenersche Granulomatose) auftreten. Schließlich kann der chronische Abusus von toxischen Substanzen (wie z. B. abschwellende Nasentropfen) zu einer chronischen Rhinitis führen (Privinismus).

$>$ Bei einer chronischen Rhinitis wird eine diagnostische Abklärung empfohlen. Dabei sind insbesondere auf eine Rachenmandelhyperplasie oder eine anatomische Fehlanlage zu achten. Bei einer einseitigen Symptomatik muss immer an einen nasalen Fremdkörper gedacht werden.

Diagnose. Die Diagnose wird klinisch gestellt.

D Cave

Im Säuglings- und Kleinkindesalter führt eine dauerhafte Behinderung der Nasenatmung zu einer chronischen Mundatmung. In der Folge davon verändert sich die Position der Zunge, es kommt zu einer maxillären und mandibulären Fehlstellung mit Ausbildung der sog. adenoiden Fazies.

Therapie. Die Therapie ist zunächst symptomatisch und besteht aus abschwellenden Nasentropfen (3-5 Tage). Ggf. kommen topische Steroide zum Einsatz. Das weitere therapeutische Vorgehen richtet sich nach der Ursache der chronischen Rhinitis. Die Besonderheiten der Therapie der allergischen Rhinitis sind in - Kap. 14.6.1. dargestellt.

\subsection{Akute und chronische Entzündung der mittleren Atemwege}

\author{
W. Leupold, M. Kopp
}

\subsubsection{Stenosierende Laryngotracheitis (Pseudokrupp)}

Definition. Die stenosierende Laryngotracheitis (Synonyme: viraler Krupp, Pseudokrupp) ist ein akutes Krankheitsbild mit neu auftretendem inspiratorischen Stridor, bellendem Husten, Heiserkeit und je nach Schweregrad Dyspnoe.

Ätiologie und Pathogenese.Pathophysiologisch liegt eine Schleimhautschwellung vor, die von den Stimmbändern aus bis weit in die Trachea reichen kann. Die häufigsten Erreger sind Parainfluenza-Viren Typ I-III (66\%), RS (Respiratory Syncytial)-Viren (10\%) sowie gelegentlich Influenza A und B.

Klinik. Die Symptome beginnen meistens nachts oder in den frühen Morgenstunden. Oft geht für 1-3 Tage ein Infekt der oberen Atemwege voraus. Häufig besteht ein charakteristischer, bellender Husten, ein inspiratorischer Stridor und Heiserkeit. Der Allgemeinzustand ist in der Regel wenig beeinträchtigt. Bei schweren Verläufen werden Dyspnoe mit subkostalen, interkostalen und jugulären Einziehungen, Zyanose oder Blässe beobachtet. Betroffen sind vor allem Kleinkinder, im Schulkindesalter ist die stenosierende Laryngotracheitis selten.

Im Gegensatz zur Epiglottitis ist beim Pseudokrupp der Allgemeinzustand oft nur wenig beeinträchtigt das begleitende Fieber nur mäßig hoch, es bestehen keine Schluckbeschwerden und kein Speichelfluss.

Diagnose. Neben der Anamnese, zu der insbesondere auch die Erhebung des Impfstatus gehört (insbesondere Diphtherie, HiB) ist die klinische Untersuchung entscheidend. Hier werden die Vitalparameter inklusive der transkutanen Sauerstoffsättigung und Temperatur erhoben. Wenn es der klinische Zustand erlaubt, sollte man sich mit invasiven Maßnahmen wie z. B. Blutabnahme oder Infusionsanlage zurückhalten, da dies die Dyspnoe verstärken kann. Eine Erregerdiagnostik ist beim unkomplizierten Infektkrupp nicht notwendig.

Differenzialdiagnose. Hierzu zählen die Epiglottitis, Diphtherie, EBV-Tonsillitis mit »kissing tonsils«, Fremdkörper, tonsilläre oder retropharyngeale Schwellung durch Abszedierung, Hämangiom, Laryngomalazie, allergisches Glottisödem, Hypokalzämie, bakterielle Tracheitis und eine mediastinale Raumforderung.

Therapie. Die Therapie richtet sich nach der Ausprägung der Symptomatik (- Tab. 22.3). Der positive Effekt einer Steroidgabe bei stenosierender Laryngotracheitis ist klar belegt. Folgende Punkte sind dabei zu beachten: Bei rektaler Anwendung ist die Resorption mit $20-80 \%$ sehr variabel. Es wird daher auch bei Säuglingen die hohe Dosis von 100 mg Prednisolon oder Prednison empfohlen. Maximale Blutspiegel werden nach 2-5 h erreicht. Bei einem Stadium IV ist die frühzeitige und ggf. wiederholte Gabe von systemischen Steroiden die am besten abgesicherte Therapieform. Auch die topische Applikation von Budesonid ( $2 \mathrm{mg}$ über Düsenvernebler) führt zu einer Verbesserung der klinischen Symptome bei leichteren Formen. Die Inhalation 
- Tabelle 22.3. Symptomatik der stenosierenden Laryngotracheitis

\begin{tabular}{|c|c|c|}
\hline Stadium & Symptomatik & Therapie \\
\hline I & $\begin{array}{l}\text { Bellender Husten, } \\
\text { Heiserkeit, leiser Stridor bei } \\
\text { Erregung }\end{array}$ & 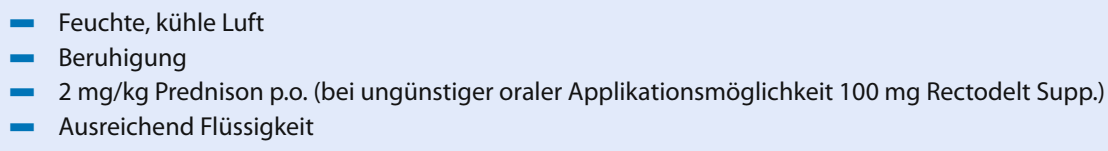 \\
\hline ॥ & $\begin{array}{l}\text { Stridor in Ruhe, } \\
\text { beginnende Dyspnoe, } \\
\text { leichte juguläre } \\
\text { Einziehungen }\end{array}$ & $\begin{array}{l}\text { - Inhalation mit Adrenalin (z. B. Infectokrupp } 1 \mathrm{ml} \text { der gebrauchsfertigen Lösung, bei HF > 180/min } \\
\text { beenden). } \\
\text { - } 2 \mathrm{mg} / \mathrm{kg} \text { Prednison p.o. (bei ungünstiger oraler Applikationsmöglichkeit } 100 \mathrm{mg} \text { Rectodelt Supp.) } \\
\text { - } \text { Ab diesem Stadium in der Regel stationäre Aufnahme }\end{array}$ \\
\hline III & $\begin{array}{l}\text { Ruhe-Dyspnoe, deutliche } \\
\text { Thorakale Einziehungen, } \\
\text { Blässe, } \\
\text { Tachykardie }>160 / \text { min }\end{array}$ & $\begin{array}{l}\text { - Stets stationäre Aufnahme } \\
\text { - Inhalation mit Adrenalin (z. B. Infectokrupp } 1 \mathrm{ml} \text { der gebrauchsfertigen Lösung, bei HF > 180/min } \\
\text { beenden), ggf. Inhalation wiederholen } \\
\text { - } 2 \mathrm{mg} / \mathrm{kg} \text { Prednison p.o. oder i.v./i.m., ggf. Steroidgabe wiederholen } \\
\text { - } \text { BGA und Überwachung des Blutdruckes }\end{array}$ \\
\hline IV & $\begin{array}{l}\text { Hochgradige Dyspnoe } \\
\text { mit zunehmender } \\
\text { Ateminsuffizienz, Zyanose, } \\
\text { Erstickungsgefahr, } \\
\text { Bradykardie, Somnolenz }\end{array}$ & $\begin{array}{l}\text { - Intensivmedizinische Überwachung } \\
\text { - Venöser Zugang, } \mathrm{O}_{2} \text {-Gabe, evtl. Sedierung } \\
\text { - Ggf. Intubation, Tracheotomiebereitschaft } \\
\text { - Inhalation mit Adrenalin (z. B. Infectokrupp } 1 \mathrm{ml} \text { der gebrauchsfertigen Lösung), ggf. Inhalation } \\
\text { wiederholen } \\
\text { - } 0,6 \mathrm{mg} / \mathrm{kg} \text { Dexamethason oder } 2-5 \mathrm{mg} / \mathrm{kg} \text { Prednison i.v., ggf. Steroidgabe wiederholen }\end{array}$ \\
\hline
\end{tabular}

von Adrenalin wirkt über eine $a$-sympathomimetisch bedingte Schleimhautabschwellung innerhalb von wenigen Minuten für die Dauer von etwa $2 \mathrm{~h}$. Der mittelfristige Verlauf wird durch die Adrenalin-Inhalation nicht beeinflusst, so dass die gleichzeitige Steroidgabe sinnvoll ist.

Wiederholte Inhalationen maximal 1- bis 2-stündlich sind möglich, wichtig ist die Überwachung der Nebenwirkungen (Tachykardie > 180/min in Ruhe, Übelkeit, Blässe, Unruhe). Bei einem viralen Krupp besteht keine Indikation zu einer antibiotischen Therapie.

Prognose. In der Regel ist die Prognose sehr gut.

\subsubsection{Epiglottitis}

Definition. Bei der Epiglottitis handelt es sich um eine Entzündung der Epiglottis meist durch Haemophilus influenzae Typ b, selten durch andere Bakterien. Aufgrund der einsetzenden Bakteriämie kommt es zu einer generalisierten Erkrankung, die immer ein medizinischer Notfall ist.

Pathogenese. Die Entzündung und damit das Anschwellen der Epiglottis nach bakterieller Infektion ist die Hauptursache dieses sehr akuten Krankheitsbildes. Die entzündlich vergrößerte Epiglottis verlagert sich nach hinten und verlegt so den Larynxeingang und die Atemwege. Der akute Atemwegsverschluss kann zur Erstickungen führen.

Klinik. Meist binnen Stunden entwickeln sich hohes Fieber, Schluckschmerzen, deutlich reduzierter Allgemeinzustand, heisere Stimme mit inspiratorischem Stridor, Speichelfluss, kloßige Sprache (»hot potatoe voice»), karchelnde Atmung. Das Kind wird dann ruhig, will vor alles Sitzen mit Abstützen der Arme nach vorne (»tripode position«) als Ausdruck des Einsatzes der Atemhilfsmuskulatur, und verhindert jegliches Sprechen (Schmer- zen). Die Untersuchung ergibt sofortige Druckdolenz über dem Kehlkopf bei leichter Berührung, hohes Fieber und blaß-graues Hautkolorit.

Diagnose. Anamnese und Klinik mit hohem Fieber, Schluckschmerzen, inspiratorischem Stridor, Speichelfluss, »hot potatoe voice«, sitzende Körperhaltung sind wegweisend.

\section{Cave}

Jede Manipulation oder Inspektion ohne Intubations- und Narkosebereitschaft ist strikt zu unterlassen! Das Kind muss mit ärztlicher Begleitung unter dauernder $\mathrm{O}_{2}$-Gabe in die Klinik eingewiesen werden.

Differenzialdiagnose. In • Tab. 22.4 sind verschiedene Differenzialdiagnosen und die dazu gehörigen Leitsymptome aufgeführt.

8 Die Epiglottitis ist viel seltener als die stenosierende Laryngotracheitis. Die Diagnose darf aufgrund der Bedrohlichkeit jedoch nicht verpasst werden. Betroffen sind eher ältere ( $>2$ Jahre) Kinder, die mit hohem Fieber, Speicheln, kloßiger Sprache und Schluckstörung und deutlich reduziertem Allgemeinzustand auffallen.

Therapie. Die Inspektion des Rachens darf nur von einem erfahrenen Intensivmediziner in Intubationsbereitschaft erfolgen. Eine unkontrollierte Racheninspektion kann zu einer kritischen Atemwegsobstruktion führen.

Neben der Sicherung der Atemwege ist eine intravenöse antibiotische Therapie i. d. R. mit einem Cephalosporin über 4-7 Tage indiziert.

Prognose. Bei rechtzeitiger Therapie ist die Prognose sehr gut. Die Immunisierung gegen Haemophilus influenzae Typ b im Rahmen des Grundimmunisierungsprogrammes ist die beste Prophylaxe. Rezidive sind selten. Die Krankheit kann auch im Erwachsenenalter (sehr viel seltener) auftreten. 


\begin{tabular}{l|l|l|l|l|}
\hline $\begin{array}{l}\text { - Tabelle 22.4. Differenzialdiagnosen der Epiglottitis mit zugehö- } \\
\text { rigen Symptomen }\end{array}$ & Mögliche Ursache \\
\hline $\begin{array}{l}\text { Symptomkomplex } \\
\text { Mundgeruch, Halslymphknoten, } \\
\text { Angina-Anamnese }\end{array}$ & Retropharyngealer Abszess \\
\hline $\begin{array}{l}\text { Schluckbeschwerden, reduzierter } \\
\text { Allgemeinzustand, hohes Fieber, } \\
\text { kloßige Sprache, Speicheln }\end{array}$ & Epiglottitis (HiB-Impfung?) \\
\hline Süßlicher Mundgeruch & Diphtherie (Diphtherie-Impfung?) \\
\hline Allergie-Anamnese & Glottisödem \\
\hline $\begin{array}{l}\text { Älteres Kind, Epiglottitis-Symp- } \\
\text { tome, grobblasige Rasselge- } \\
\text { räusche }\end{array}$ & Tracheitis mit Pus \\
\hline Chronisch rezidivierender Verlauf & Fremdkörper im Larynx, Reflux \\
\hline Bellender Husten & Pseudokrupp \\
\hline
\end{tabular}

\subsubsection{Akute Bronchitis}

Epidemiologie. Die Epidemiologie der akuten Bronchitis ist vor allem für die Abschätzung des Ansteckungsrisikos innerhalb von bestimmten Gruppen, wie z. B. Kindergärten, Schulen und bestimmten Berufsgruppen von Bedeutung. Saisonale Schwankungen des Auftretens von verschiedenen Viren können so abgeschätzt und evtl. Immunisationsprogramme geplant werden (z.B. Grippeimpfung).

Pathogenese. Diese ist durch die Infektion mit Viren (primär $>90 \%$ ), Bakterien und Pilzen gegeben. Die allergische akute Bronchitis ist eher unter das Krankheitsbild des Asthmas einzuordnen. Toxische akute Bronchitis, z. B. nach Exposition von Rauch in Brandherden, ist anamnestisch einfach zu erfassen.

Pathophysiologie. Die Grundlage bildet eine Entzündung mit Schwellung der Mukosa, Abschilferung und Zerstörung des Bronchialepithels, Hypersekretion der Becherzellen, interstitiellem Ödem sowie leukozytäre und lymphozytäre Infiltration des Stromas. Bei Infiltration in die weitere Umgebung und Einbezug des ganzen Lungengewebes spricht man von Bronchopneumonie, bei Beteiligung der Pleura von Pleuropneumonie.

Klinik. Eine akute banale Bronchitis sieht man meist im Zusammenhang mit einem viralen Infekt der oberen und mittleren Atemwege während eines grippalen Infektes. Damit ist diese meist virusbedingt durch RSV, Adeno-, Rhino-, Influenza- und Parainfluenzaviren. Husten ist das vorherrschende Symptom, meist in Kombination mit seröser Rhinitis und leichtem Fieber. Der Husten ist vorerst eher trocken und löst sich dann in einer Phase von Hypersekretion (feuchter Husten). Das Allgemeinbefinden ist nur wenig beeinträchtigt, die Dauer der Erkrankung beträgt 7-14 Tage.

Diagnose. Diese ist anhand der Klinik und Anamnese einfach. Der Rachenraum kann etwas gerötet sein, über den Lungenfeldern hört man mittel- bis grobblasige Rasselgeräusche. Weitergehende Untersuchungen erübrigen sich.
Differenzialdiagnose. In der Differenzialdiagnose muss an die beginnende, protrahiert chronisch verlaufende Bronchitis, das Asthma, die toxische akute Bronchitis nach Inhalation von Gasen oder Flüssigkeit (Aspiration) eine Fremdkörperaspiration oder auch an eine Pertussiserkrankung gedacht werden.

Therapie und Prognose. Diese ist meist symptomatisch und besteht aus fiebersenkenden Maßnahmen, genügender Flüssigkeitszufuhr, evtl. Gabe von Antitussiva und Inhalation von $\beta_{2^{-}}$ Agonisten. Die häufig verordneten Mukolytika und Antihistaminika sind in ihrer Wirkung umstritten. Bei Verdacht auf bakterielle Superinfektion ist eine antibiotische Therapie gerechtfertigt.

In der Regel ist die Prognose bei unkompliziertem Verlauf sehr gut. Ein Übergang in eine chronisch verlaufende Bronchitis ist möglich (z. B. bei weiterbestehender Irritation und Rauchen). Die Entstehung von Bronchiektasien nach akuter unkomplizierter Bronchitis wird kaum beobachtet.

\subsubsection{Chronische Bronchitis}

Grundlagen. Der bakterielle Superinfekt als Komplikation bei akuter viraler Bronchitis kann Ursache einer prolongierten Bronchitis mit Übergang in ein chronisches Stadium sein.

Von chronischer Bronchitis spricht man dann, wenn die Symptome der Bronchitis, vor allem Husten und Auswurf, über mehr als 3 Monate anhalten.

Epidemiologie. Chronische Bronchitis sehen wir im Kindesalter vor allem bei ständiger Exposition von Luftschadstoffen (vor allem Zigarettenrauch). Eine chronische Bronchitis kann aber Zeichen einer anderen zugrunde liegenden Krankheit sein und bedarf daher der erweiterten diagnostischen Abklärung.

Pathogenese. Der Startpunkt kann eine bakterielle Superinfektion nach akuter viraler Bronchitis sein. Dabei kommen vor allem Staphylokokken, Pneumokokken, Haemophilus influenzae und Moraxella catharralis infrage. Seltener sind eine primäre bakterielle Infektion oder prädisponierende Grundkrankheiten (z.B. zystische Fibrose) als Ursache zu finden.

Pathophysiologie. Das durch die Wegbereiter (Viren, toxische Substanzen, Allergene) verletzte Bronchialepithel kann die lokalen Abwehrmechanismen wie Zilienschlag und Immunabwehr (z. B. sekretorisches IgA) nicht aufrecht erhalten. Es erfolgt eine bakterielle Invasion mit leukozytärem Infiltrat, Ödem und Hypersekretion und Bildung von fibrinösen Ablagerungen. Die Reparation erfolgt über Fibroblasten, was zu einer signifikanten Narbenbildung führen kann. Der Aufbau des Bronchialepithels mit zilienschlagenden Zellen ist damit beeinträchtigt, ein Circulus vitiosus beginnt.

Klinik. Der chronische, meist gegen Morgen akzentuierte Husten mit Schleimproduktion ist das vorherrschende Symptom. Das vorerst noch bestehende Fieber verschwindet nach einigen Tagen, der Auswurf wird gelb, gelb-grün oder grün-bräunlich, leichte Blutbeimischungen (Hämoptoe) kommen vor. Der Husten kann dauernd oder in Konvulsionen vorhanden sein. Meist besteht wenig Atemnot. Über den Lungenfeldern auskultiert man grob- bis mittelblasige Rasselgeräusche, Giemen und Pfeifen. 
Akute Komplikationen. Diese sind vor allem als Pneumonie oder Pleuraerguss in Folge der Ausdehnung eines Infektes zu sehen. Je nach Grundkrankheit ist mit anderen Komplikationen wie Hämoptoe größeren Ausmaßes, Atelektasen, Pneumothorax oder akuter Ateminsuffizienz zu rechnen.

Diagnose. Diese beruht vor allem auf der Anamnese und der auffallenden Klinik des lange andauernden Hustens. Die radiologische Untersuchung ergibt meist Transparenzminderungen im Hilusbereich mit Doppelkonturen entlang der mittleren und größeren Bronchien. Dieses als Peribronchitis benanntes visuelles Phänomen kommt durch Verdichtung der Bronchialwände durch Infiltration und reparative Fibrose zustande.

Da bei chronischem Husten die Differenzialdiagnose weiter gefasst werden muss, empfiehlt sich eine weitergehende Diagnostik mit Blutbild, Blutsenkungsreaktion, CRP, Tuberkulinprobe, Serumimmunglobulinbestimmung evtl. mit Subklassenbestimmung, Bestimmung von $\alpha_{1}$-Antitrypsin, Schweißtest, Lungenröntgenbild in 2 Ebenen, Nasennebenhöhlenaufnahme, Lungenfunktion mit Bestimmung der statischen und dynamischen Lungenvolumina und evtl. der Diffusionskapazität, kapilläre oder arterielle Blutgasanalyse, Bronchoskopie, Lungenszintigraphie und Computertomographie. Diese Analysen sind entsprechend der klinisch-anamnestischen Wahrscheinlichkeit in einem zeitlichen Stufenverfahren vorzunehmen. Eine Pertussis-Infektion ist auszuschließen, eine HNO-ärztliche Untersuchung zu veranlassen.

Differenzialdiagnose. In der Differenzialdiagnose des chronischen Hustens und Auswurfs muss im Kindesalter an Aspiration (Reflux!), Rauchexposition, beginnendes allergisches Asthma, zystische Fibrose, Bronchiektasen (z.B. im Rahmen eines Kartagener-Syndroms), Immundefekt, $\alpha_{1}$-Antitrypsin-Mangel (sehr selten), Sarkoidose, allergische Alveolitis, Immotile-Cilia-Syndrom, idiopathische Lungenfibrose und pulmonale Hypertension gedacht werden. Ein chronischer Infekt, wie z. B. Tuberkulose, Pseudomonas-aeruginosa-Infektion, Pilzinfektion (Immundefekte) muss ausgeschlossen werden.

Therapie. Diese richtet sich nach der Grundkrankheit.

$>$ Das Entfernen von toxischen Quellen (Zigarettenrauch) oder Allergenen ist von entscheidender Bedeutung.

Bei fehlender Grundkrankheit ist meist eine 10-14 Tage dauernde Antibiotikatherapie, am besten entsprechend einem bakteriellen Antibiogramm aus dem Bronchialsekret (Auswurf, angehusteter Rachenabstrich) durchzuführen. Eine Inhalationstherapie mit $\beta_{2}$-Agonisten oder Ipatropiumbromid in $\mathrm{NaCl}$ hilft meist die Symptomatik zu lindern. Ohne klare Indikation ist die Verabreichung von inhalativen Steroiden sinnlos. Mukolytika sind von fraglicher Wirksamkeit.

Prognose. Diese hängt weitgehend von der zugrunde liegenden Krankheit ab. Bei protrahiertem Verlauf nach akuter Bronchitis und entsprechender antibiotischer Behandlung des bakteriellen Superinfektes ist eine restitutio ad integrum zu erwarten. Die Entfernung der Reizquellen der Bronchialschleimhaut bestimmt die Prognose entscheidend.

\subsubsection{Bronchiolitis}

Definition. Die obstruktive Bronchitis ist eine entzündliche Erkrankung der Schleimhäute der Bronchien mit zum Teil erheblicher Schleimhautschwellung, Hypersekretion und mit unterschiedlich ausgeprägtem Bronchospasmus, der besonders in den ersten drei Lebensjahren bedeutsam ist.

Die Ursache ist in über $90 \%$ der Erkrankungen eine Virusinfektion. In den ersten 2-9 Monaten liegt der obstruktiven Bronchitis sehr häufig eine Infektion mit RS-Viren zu Grunde. Bei 2-3 \% dieser Säuglinge kommt es zu einer besonders schweren Entzündung vor allem der kleinen Bronchien und Bronchiolen mit erheblicher Schleimhautschwellung und intraluminaler Zelldesquamation (Bronchiolitis im eigentlichen Sinn).

Die Übergänge zwischen obstruktiver Bronchitis und Bronchiolitis sind fließend. Eine Unterscheidung wird im deutschen Sprachraum (nicht im angloamerikanischen) aufgrund des klinischen Hauptbefundes getroffen:

- Bronchiolitis: erhebliche Lungenüberblähung mit endexspiratorischen feinblasigen Rasselgeräuschen (stille Obstruktion)

- Obstruktive Bronchitis: Überblähung und deutliches Giemen

Epidemiologie. Da bei einer Bronchiolitis fast immer RS-Viren die Ursache sind und diese in wiederkehrendem, meist 2-Jahresrhythmus während der Wintermonate auftreten, können kleinere lokale Epidemien ( $>5 \%$ aller Hospitalisationen) vorkommen. Diese Tatsache ist vor allem im Hinblick auf die heute möglichen Immunisierungsprogramme von Bedeutung.

Pathogenese. Wie der Terminus beschreibt, werden vor allem die Bronchioli terminales betroffen. Auslöser ist fast ausschließlich (80\%) das RS-Virus. Weshalb eine solche spezifische Tropie im frühen Kindesalter für dieses Virus für diese spezielle bronchiale Region besteht, ist nicht bekannt. In den restlichen 20\% der Bronchiolitiden sind Parainfluenza Typ III, Adenoviren und selten Mykoplasmen für die Infektion verantwortlich. Immerhin können viral bedingte histologische Veränderungen auch in den größeren Bronchien und in der Trachea und nicht nur in den Bronchioli gesehen werden. Meist handelt es sich um lymphoplasmazelluläre Infiltrationen mit Bronchialnekrose, Zelldesquamation und Ödembildung.

( )

Kinder aus atopischen Familien scheinen für Bronchiolitis anfälliger zu sein. Man nimmt auch an, dass Bronchiolitis für späteres Asthma prädisponiert.

Klinik. Das Krankheitsbild beginnt meist langsam als banaler Schnupfen über 2-3 Tage. Dann beherrschen zunehmende Atemnot, Dyspnoe, Tachypnoe, Husten, in- und exspiratorisches Stöhnen, inspiratorisch beobachtbare interkostale, subkostale und suprasternale Einziehungen, Nasenflügeln und wechselnde Zyanose das klinische Ausdrucksbild. Aufgrund der vermehrten Atemarbeit kommt es auch zu einem abdominellen Meteorismus mit Beeinträchtigung der Zwerchfellbeweglichkeit. Fieber kann, muss aber nicht vorhanden sein. Die Säuglinge können sich sehr rasch pulmonal erschöpfen und brauchen unter Umständen Atemhilfe inkl. Intubation. Durch die Anoxie des Gehirns kommt es unter Umständen zu einer Bewusstseinstrübung.

Akute Komplikationen. Diese sind vor allem durch die sich entwickelnde Ateminsuffizienz programmiert: Intubation, Beatmung, Pneumothorax, Herzinsuffizienz. 
Diagnose. Das klinische Bild, das Alter, der Zeitpunkt der Präsentation (Wintermonate) und die Anamnese sind wegweisend für die Diagnose. Es besteht eine deutliche Atemnot, auskultatorisch imponierten Wheezing und verlängertes Exspirium zum Teil mit Knisterrasseln. Durch die vorherrschende Überblähung der Lungen durch bronchiale Obstruktion und Verdrängung des Zwerchfelles nach kaudal wird meist die Leber palpabel. Das Blutbild ist meist normal oder »viral«. Im Röntgenbild finden sich die auffallenden Zeichen der Lungenüberblähung mit tief liegendem, horizontal abgrenzbarem Zwerchfell, horizontal gestellten Rippen und interkostalen Vorwölbungen nach außen. Multiple kleinere subsegmentale Dys- oder Atelektasen und eine peribronchiale Strukturvermehrung sind oft vorhanden. Die kompromittierte Sauerstoffaufnahme wird durch Tachypnoe kompensiert und führt damit zu einem Absinken des kapillären $\mathrm{pCO}_{2}$. Steigt dieser an, muss an die beginnende globale Ateminsuffizienz gedacht werden.

Differenzialdiagnose. Alle zu einer akuten Atemsymptomatik im Säuglingsalter führenden Ursachen können eine Bronchiolitis vortäuschen: erster Asthmaanfall, beginnende virale oder bakterielle Pneumonie, zystische Fibrose, Aspiration, Keuchhusten, Fremdkörperaspiration etc.

Therapie. Säuglinge mit Zyanose, Tachydyspnoe ( $>60 / \mathrm{min})$, arteriellem (kapillärem) $\mathrm{pCO}_{2}>45$ mmHg oder $\mathrm{pO}_{2}<60 \mathrm{mmHg}$ unter Zimmerluft müssen dringend überwacht werden und brauchen vorerst angefeuchteten Sauerstoff. Dabei kann die perkutan gemessene $\mathrm{O}_{2}$-Sättigung (Pulsoxymetrie) als Orientierungshilfe (92\% als Grenze) gelten. Auf eine genügende Flüssigkeitszufuhr (Magensonde oder i.v.) ist zu achten, evtl. können Inhalationen mit Bronchodilatatoren (Cave: paradoxe Reaktion) etwas Linderung verschaffen. Die Inhalation mit Steroiden ist sehr wahrscheinlich nicht entscheidend für den Verlauf. Die systemische Gabe von Steroiden (0,6-6 mg/kg/Tag Prednisolon-Äquivalent) hingegen lässt positive Effekte erwarten. Eine antivirale Therapie mit Ribavirin, Anti-RSV-Antikörpern etc. ist bedingt wirksam. Bei schweren Verlaufsformen (Bronchiolitis) kann die Anwendung einer Atemhilfe (z.B. CPAD) hilfreich sein.

Besonders gefährdete Säuglinge (z.B. Frühgeborene $<28$. SSW mit bronchoputmonaler Depglasie) sollten in den Wintermonaten durch die passive Immunisierung mit einem RSV-AK (Palirizumab) geschützt werden.

Prognose. Die meist selbstlimitierende Erkrankung dauert in der Regel 4-7 Tage; komplizieren können den Verlauf eine bakterielle Superinfektion oder die schwere Ateminsuffizienz mit der Notwendigkeit der Intubation und Beatmung.

\subsubsection{Rezidivierende Infekte der Atemwege - Infektanfälligkeit}

Wiederholte Atemwegserkrankungen sind im Kleinkindesalter sehr häufig. Im Praxisalltag stellt sich daher oft die Frage, ob bei einem Kind Häufigkeit und Schweregrad der Erkrankungen im Rahmen der "physiologischen Infektanfälligkeit» liegen. Als »normal « wird in den einzelnen Altersgruppen die in • Tab. 22.5 aufgeführte Infekthäufigkeit gesehen.

Berücksichtigt man zusätzlich, dass die meisten Virusinfektionen zu Schleimhautschäden führen, deren Ausheilung 4-6 Wochen dauert, so ergeben sich hieraus in der kalten Jahreszeit

\begin{tabular}{l|l|l|l}
\hline \multicolumn{4}{|l}{ - Tabelle 22.5. Physiologische Infekthäufigkeit } \\
\hline $\begin{array}{l}\text { Alter } \\
\text { (Jahre) }\end{array}$ & $\begin{array}{l}\text { Respiratorische } \\
\text { Infekte pro Jahr }\end{array}$ & $\begin{array}{l}\text { Standard- } \\
\text { abweichung }\end{array}$ & Maximum \\
\hline$<1$ & 6,1 & $\pm 2,6$ & 11,3 \\
\hline $1-2$ & 5,7 & $\pm 3,0$ & 11,7 \\
\hline $3-4$ & 4,7 & $\pm 2,9$ & 10,5 \\
\hline $5-9$ & 5,5 & $\pm 2,6$ & 8,7 \\
\hline $10-14$ & 2,7 & $\pm 2,2$ & 7,2 \\
\hline
\end{tabular}

lange Krankheitsepisoden. Bei Kindern mit intensiven sozialen Kontakten (Gemeinschaftseinrichtung) ist zusätzlich die Reinfektionsgefahr groß. Mit diesen Informationen kann man die oft sehr besorgten und auch belasteten Eltern etwas beruhigen.

Umgekehrt sollten folgende Faktoren Anlass sein, über die Differenzialdiagnose eines Immundefektes nachzudenken: rezidivierende tiefe Haut- oder Organabszesse, eine persistierende Candidainfektion nach dem 1. Lebensjahr, eine Gedeihstörung oder eine positive Familienanamnese mit einem primären Immundefekt (unklare Todesfälle im Kleinkindesalter eingeschlossen). Weitere Verdachtsmomente sind

$-\geq 8$ Otitiden/Jahr

- $\geq 2$ Sinusitiden/Jahr

- $\geq 2$ Major-Infektionen (Sepsis, Osteomyelitis, Meningitis, septische Arthritis, Empyem, Organabszesse)

- $\geq 2$ Pneumonien/Jahr

- eine lange antibiotische Therapie (> 2 Monate) ohne Effekt $(\triangleright$ Kap. 13)

$>$ Der wichtigste Rat an die Eltern ist, einem Kind mit rezidivierenden Atemwegsinfektionen genügend Zeit zur Erholung zu lassen. Antibiotika sind nur in Ausnahmefällen indiziert.

\subsection{Akute und chronische Entzündung der Lunge}

$$
\text { M. Kopp, W. Leupold }
$$

\subsubsection{Pneumonie}

Definition. Die Pneumonie ist definiert als eine Entzündung des Lungengewebes, die auf eine Infektion mit Krankheitserregern zurückgeht. Sie kann akut oder chronisch verlaufen.

Die meisten Pneumonien im Kindesalter, insbesondere in der Altergruppe von 6 Monaten bis 3 Jahre, werden durch Viren (RSV, Parainfluenza-, Adeno-, und Influenza-Viren) verursacht. Bei den bakteriellen Pneumonien gibt es für die unterschiedlichen Altergruppen ein charakteristisches Erregerspektrum (• Tab. 22.6).

Einteilung. Neben den in • Tab. 22.6 aufgeführten Einteilungen nach Verlauf (akut/chronisch) oder Erreger (viral/bakteriell) berücksichtigt die pathologisch-anatomische Einteilung die Lokalisation. In - Abb. 22.3 sind klassische Befunde einer Bronchopneumonie, einer interstitiellen Pneumonie und einer Lobäroder Segmentpneumonie dargestellt. Für das Säuglings- und 
- Tabelle 22.6. Häufigste Erreger der Pneumonie im Kindesalter in den einzelnen Altersgruppen. (Mod. nach DGPI-Handbuch, 4. Auflage)

\begin{tabular}{|l|l|l|l|}
\hline & Viren & Bakterien & Pilze \\
\hline $\begin{array}{l}\text { Neuge- } \\
\text { borenen- } \\
\text { pneumonie }\end{array}$ & $\begin{array}{l}\text { RSV } \\
\text { Parainfluenzavi- } \\
\text { ren Adenoviren } \\
\text { CMV, HSV, VZV }\end{array}$ & $\begin{array}{l}\text { B-Streptokokken } \\
\text { Klebsiellen } \\
\text { L. monocytogenes } \\
\text { S. aureus } \\
\text { Chlamydia tra- } \\
\text { chomatis }\end{array}$ \\
\hline
\end{tabular}

\begin{tabular}{l|l|l|l}
\hline $\begin{array}{l}\text { Ambulant } \\
\text { erworbene } \\
\text { Pneumonie }\end{array}$ & $\begin{array}{l}\text { RSV } \\
\text { Parainfluenza-, } \\
\text { Influenzaviren } \\
\text { Adenoviren }\end{array}$ & $\begin{array}{l}\text { S. pneumoniae } \\
\text { H. influenzae } \\
\text { M. pneumoniae } \\
\text { B. pertussis }\end{array}$ & \\
\hline $\begin{array}{l}\text { nosokomial } \\
\text { erworbene } \\
\text { Pneumonie }\end{array}$ & $\begin{array}{l}\text { RSV } \\
\text { Parainfluenza-, } \\
\text { Influenzaviren } \\
\text { Adenoviren } \\
\text { CMV, HSV, VZV }\end{array}$ & $\begin{array}{l}\text { E. coli, } \\
\text { Klebsiellen } \\
\text { S. aureus } \\
\text { H. influenzae }\end{array}$ & $\begin{array}{l}\text { Candida } \\
\text { albicans } \\
\text { Aspergillus }\end{array}$ \\
\hline $\begin{array}{l}\text { Aspirati- } \\
\text { onspneu- } \\
\text { monie }\end{array}$ & $\begin{array}{l}\text { Gram-negative } \\
\text { Bakterien und } \\
\text { Anaerobier (z. B. } \\
\text { Bacteroides, Pepto- } \\
\text { streptococcus) }\end{array}$ & \\
\hline $\begin{array}{l}\text { Pneumonie } \\
\text { bei Immun- } \\
\text { defizienz }\end{array}$ & $\begin{array}{l}\text { CMV, VZV, HSV, } \\
\text { HHV-6 }\end{array}$ & $\begin{array}{l}\text { S. aureus } \\
\text { P. aeruginosa } \\
\text { "Opportunisten« }\end{array}$ & $\begin{array}{l}\text { Candida } \\
\text { albicans } \\
\text { Aspergillus }\end{array}$ \\
\hline
\end{tabular}

Kleinkindesalter ist die Bronchopneumonie typisch, während ältere Kinder häufiger an einer meist durch Pneumokokken verursachten Lobär- oder Segmentpneumonie erkranken. Primär abszedierene Pneumonien werden oft durch S. aureus verursacht.

Schließlich wird eine primäre Pneumonie, bei der ein gesundes Individuum erkrankt, von einer sekundären Pneumonie aufgrund eines Immundefektes oder einer Grundkrankheit (CF, PCD) unterschieden. Je nach Art der Grundkrankheit findet sich ein charakteristisches Keimmuster, z. B. bekapselte Erreger bei humoralen Immundefekten, und Pilze, Viren oder Parasiten (Pneumocystis jirovecii) bei T-Zelldefekten.

In - Abb. 22.4 sind die wichtigsten Dimensionen zur Beurteilung bzw. Einteilung von Pneumonien im Kindesalter aufgeführt.

Epidemiologie. Im Kindes- und Vorschulalter beträgt die Inzidenz etwa 40 Pneumonien/1000 Kinder pro Jahr, im Schulkindesalter etwa 10-15 Pneumonien/1000 Kinder pro Jahr.

Ätiologie und Pathogenese. Die meisten relevanten Erreger der Pneumonie kolonisieren auch bei gesunden Kindern den Nasopharyngealtrakt, ohne dass es zu einer Erkrankung kommt. Durch Aspiration oder Inhalation gelangen die pathogenen Keime in die tieferen Atemwege. Bei besonderer Virulenz des Erregers oder durch Überwindung der Schutzbarriere der Atemwegsschleimhaut kommt es schließlich zur Pneumonie. Zu den vielfältigen Schutzmechanismen zählen u. a. die ziliäre Clearance, sekretorisches IgA, Surfactant, Alveolarmakrophagen oder vasoaktive Mediatoren. Hieraus wird deutlich, dass bestimmte Bedingungen zur Pneumonieentstehung prädisponieren, wie
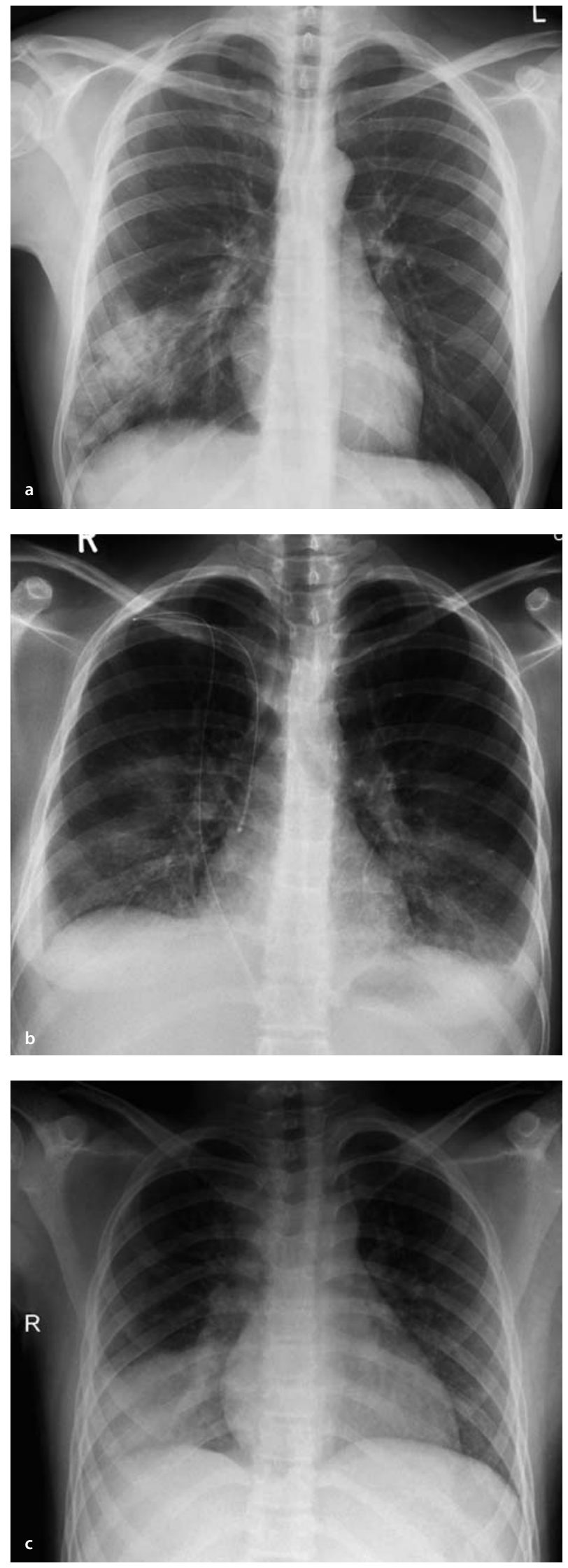

- Abb. 22.3a-c. Radiologische Beispiele für Pneumonien. a Bronchopneumonie, b interstitielle Pneumonie, c Lobärpneumonie 
- Abb. 22.4. Vier Dimensionen, nach denen Pneumonien eingeteilt bzw. beurteilt werden können

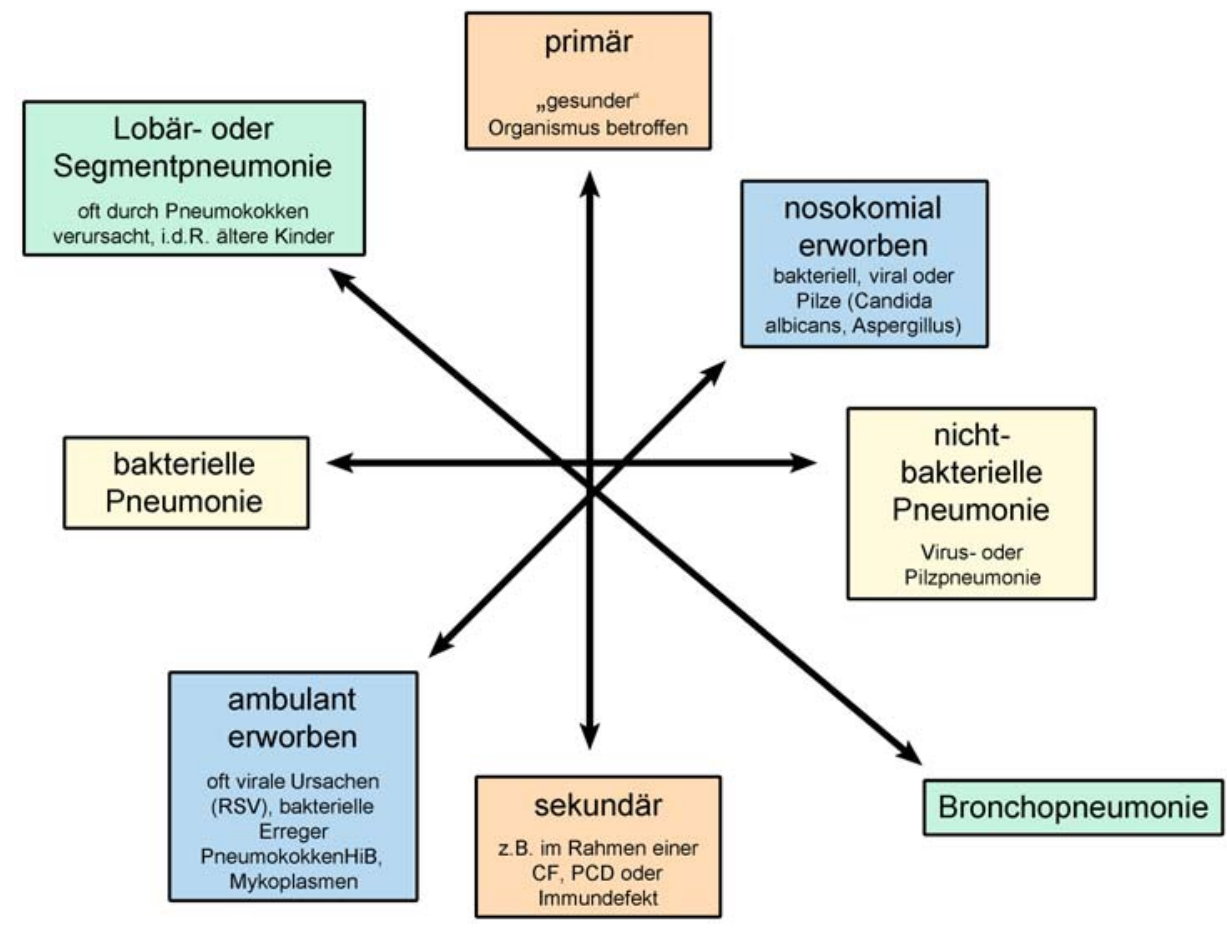

etwa schlechter Ernährungszustand, Aspirationen z. B. im Rahmen eines gastro-ösophagealen Refluxes, einer anatomischen Fehlbildung oder eine verminderte Immunabwehr. Bei bestimmten Grundkrankheiten fallen diese Abwehrmechanismen ganz oder teilweise aus, wie z. B. bei der zystischen Fibrose oder der primären ziliären Dyskinesie.

Prädisponierende Erkrankungen für bakterielle Pneumonien sind auch neuromuskuläre Erkrankungen sowie Herzfehler, bei denen ein Links-rechts-Shunt mit vermehrter Lungendurchblutung besteht. Schließlich können virale Infektionen (Influenza, Masern) eine bakterielle Pneumonie bahnen.

Klinik. Bei Neugeborenen und jungen Säuglingen stehen unspezifische Allgemeinsymptome im Vordergrund: Trinkunlust oder Trinkverweigerung, Erbrechen, Apathie, Temperaturinstabilität mit Hypothermie oder Fieber, kühle Akren oder ein geblähtes Abdomen.

Im Kleinkind- und Schulkindesalter ist die klinische Präsentation anders: $\mathrm{Zu}$ den Allgemeinsymptomen zählen in dieser Altergruppe Fieber, z. T. mit Schüttelfrost, allgemeines Krankheitsgefühl, Unruhe, Brust- und/oder Bauchschmerzen. So kann z. B. eine basale Pneumonie mit Erguss von der Symptomatik wie eine akute Appendizitis imponieren.

Bei den organspezifischen Symptomen besteht in beiden Altersgruppen fast immer eine Tachypnoe, Dyspnoe (Nasenflügeln, juguläre und/oder interkostale Einziehungen), eine Tachykardie, Husten und ggf. eine Zyanose.

$>$

Der Auskultationsbefund kann bei zentralen Pneumonien unauffällig sein. Die klinischen Beschwerden gehen den radiologischen Veränderungen einige Tage voran.

Körperliche Untersuchung. Der Verdacht einer Pneumonie ergibt sich aus dem klinischen Befund. Neben den oben dargestellten Symptomen treten bei der körperlichen Untersuchung klassi- scherweise feinblasige, ohrnahe, hochfrequente Rasselgeräusche, ein abgeschwächtes Atemgeräusch und bei lobärem Befall eine Klopfschalldämpfung auf. Bei der Auskultation können aber auch zahlreiche andere Befunde erhoben werden, z. B. mittel- bis grobblasige Rasselgeräusche als Ausdruck der intrabronchialen Sekretstase.

(7) An eine Mykoplasmen-Infektion muss bei begleitendem Exanthem, Krämpfen oder Bewusstseinstrübung sowie einer milder Begleithepatitis oder Arthritis gedacht werden. Umgekehrt ist bei Kindern unter 3 Jahren und einer Fieberdauer von $\leq 2$ Tagen eine Mykoplasmen-Infektion sehr unwahrscheinlich.

Röntgen-Thorax. Die Röntgen-Thoraxaufnahme im sagittalen Strahlengang ist nach wie vor der Goldstandard in der Diagnostik der Pneumonie. Eine Seitaufnahme ist nur dann notwendig, wenn die Übersichtsaufnahme nicht ausreichende beurteilbar ist. Die radiologischen Veränderungen hinken der Klinik um einige Tage hinterher. Umgekehrt bilden sich die radiologischen Veränderungen erheblich langsamer zurück als die Beschwerden. Ist eine abschließende Röntgenkontrolle indiziert, so sollte diese daher nach unkompliziertem Verlauf erst nach 4-6 Wochen erfolgen.

Die verschiedenen radiologischen Charakteristika der Pneumonie sind in - Abb. 22.3 dargestellt.

Labor. Im Blutbild findet sich je nach Ätiologie eine Leukozytose mit Linksverschiebung oder eine Lymphozytose. Die Blutsenkungsgeschwindigkeit und CRP sind in der Regel erhöht. Weiterhin sind eine Blutkultur und eine Blutgasanalyse abzunehmen.

Erregerdiagnostik. Zum Nachweis einer bakteriellen Pneumonie kann neben der Blutkultur, die nur bei einem kleinen Teil der Patienten positiv ist, ein Rachenabstrich, ein Nasopharyngealsekret 
oder bei älteren Kindern auch ein induziertes Sputum gewonnen werden. Die Bronchoskopie kann zur Gewinnung von Sekret aus den tiefen Atemwegen bei nosokomialen Pneumonien mit schwerem Verlauf oder bei immundefizienten Patienten indiziert sein. Zum Erregernachweis bei viralen Pneumonien ist für RS-, Adeno- oder Influenzaviren der Antigennachweis aus dem Nasopharyngealsekret hilfreich. Der Polymerasekettenreaktion (PCR) als Genamplifikationsverfahren gewinnt in der molekularbiologischen Diagnostik vor allem für die Mikroorganismen große Bedeutung, die nur schwer oder gar nicht anzüchtbar sind, wie beispielsweise Mykoplasmen oder Aspergillen. Eine serologische Diagnostik ist in der Regel wenig aussagekräftig.

Weitere Diagnostik. Bei allen persistierenden Verschattungen, bei Patienten mit zusätzlichen Symptomen (Gewichtsverlust, Nachtschweiß) muss eine Tuberkulose ausgeschlossen werden.

D Cave

Trockener, quälender Reizhusten und septisches Fieber müssen bei immunsupprimierten Kindern an eine Pneumocystis-jirovecii-Pneumonie denken lassen.

Differenzialdiagnose. Differenzialdiagnosen der bakteriellen Pneumonie sind zunächst virale bzw. durch Pilze verursachte Pneumonien. Nichtinfektiöse Ursachen, die radiologisch wie eine Pneumonie imponieren, lassen sich in der Regel durch die Anamnese und Laborparameter von einer Pneumonie abgrenzen. Ursachen hierfür können u. a. sein:

- Fremdkörperaspiration,

- Atelektase,

- Asthma bronchiale,

- Inhalation toxischer Substanzen (»Pneumonitis«),

- Raumforderungen (Thymus, Tumoren),

- interstitielle Lungenerkrankungen.

Stationäre versus ambulante Therapie. Zunächst muss über die Notwendigkeit einer stationären Therapie entschieden werden.
Leichte Pneumonien können ambulant zu Hause behandelt werden. Die Indikation zu einer stationären Aufnahme ist in der Regel gegeben, wenn eines der folgenden Kriterien erfüllt ist:

- Säugling < 6 Monate,

- unzureichende orale Aufnahme des Antibiotikums,

- deutliche Allgemeinbeeinträchtigung,

- Notwendigkeit von intravenöser Rehydratation oder Sauerstoffzufuhr.

Indikation einer antibiotischen Therapie. Die zweite Entscheidung betrifft die Indikation zu einer antibiotischen Therapie. Diese ergibt sich nicht allein aus dem Röntgenbild oder aufgrund von Entzündungswerten (z. B. CRP). In der Bewertung der vorliegenden Befunde spielt der klinische Gesamtzustand die entscheidende Rolle. So sprechen z. B. Giemen beim Kleinkind, eine begleitende seröse Rhinitis und/oder Konjunktivitis sowie ein unspezifisches Exantheme eher für virale Infektionen. Hochfieberhafte Erkrankungen mit allgemeinem Krankheitsgefühl, Einziehungen und Tachypnoe sprechen eher für eine bakterielle Infektion.

Auch der Nachweis von bakteriellen Erregern im Nasopharyngealsekret (Pneumokokken, Haemophilus influenzae, Moraxella catarrhalis) repräsentiert zunächst lediglich die vermehrte Kolonisation auf einem - möglicherweise durch die Virusinfektion vorgeschädigten - respiratorischen Epithel und ist nicht per se als Hinweis auf eine bakterielle Genese zu bewerten.

Anhaltspunkte für eine kalkulierte antibiotische Therapie finden sich in - Tab. 22.7. Die Dauer der antibiotischen Therapie beträgt in der Regel 7-10 Tage bzw. 5 Tage über Entfieberung hinaus, bei Mykoplasmen-Pneumonie 14 Tage.

Supportive Therapie. Hierzu zählen folgende Maßnahmen:

- Gabe von angefeuchtetem Sauerstoff bei einer transkutanen Sättigung < $95 \%$,

- Antipyrese bei Fieber $>39^{\circ} \mathrm{C}$,

- reichlich Flüssigkeitszufuhr (1,5× Tagesbedarf),

- Tabelle 22.7. Initialtherapie bei bakterieller Pneumonie

\begin{tabular}{|c|c|c|c|}
\hline Altersstufe & & Antibiotikum & Dosierung \\
\hline Neugeborene $0-4$ Wochen & 1. Wahl & Piperacillin/Netilmicin & Nach Sepsisschema \\
\hline \multirow[t]{2}{*}{ Säuglinge 1-6 Monate } & 1. Wahl & Cefotiam & $100 \mathrm{mg} / \mathrm{kg} / \mathrm{Tag}$ i.v. in $3 \mathrm{ED}$ \\
\hline & 2. Wahl & Ampicillin/Sulbactam & $125 \mathrm{mg} / \mathrm{kg} / \mathrm{Tag}$ i.v. in $3 \mathrm{ED}$ \\
\hline \multirow{2}{*}{$\begin{array}{l}\text { Säuglinge } 6 \text { Monate bis } \\
\text { Kinder } 9 \text { Jahre }\end{array}$} & 1. Wahl & Ampicillin & $100 \mathrm{mg} / \mathrm{kg} / \mathrm{Tag}$ i.v. in $3 \mathrm{ED}$ \\
\hline & 2. Wahl & Cefotiam & $100 \mathrm{mg} / \mathrm{kg} / \mathrm{dTag}$ i.v. in $3 \mathrm{ED}$ \\
\hline \multirow[t]{2}{*}{ Kinder $>9$ Jahre } & 1. Wahl & Ampicillin & $100 \mathrm{mg} / \mathrm{kg} / \mathrm{Tag}$ i.v. in $3 \mathrm{ED}$ \\
\hline & 2. Wahl & Doxycyclin & Initial $4 \mathrm{mg} / \mathrm{kg} / \mathrm{Tag}$ i.v. in $1 \mathrm{ED}$, dann $2 \mathrm{mg} / \mathrm{kg} / \mathrm{Tag}$ i.v. in $1 \mathrm{ED}$ \\
\hline \multicolumn{4}{|c|}{ Bei Verdacht auf atypische Pneumonie } \\
\hline Kinder $\leq$ Jahre & 1. Wahl & Erythromycin & $50 \mathrm{mg} / \mathrm{kg} / \mathrm{Tag}$ p.o. in $3 \mathrm{ED}$ \\
\hline \multirow[t]{2}{*}{ Kinder $>9$ Jahre } & 1. Wahl & Doxycyclin & Initial $4 \mathrm{mg} / \mathrm{kg} / \mathrm{Tag}$ i.v. in $1 \mathrm{ED}$, dann $2 \mathrm{mg} / \mathrm{kg} / \mathrm{Tag}$ i.v. in $1 \mathrm{ED}$ \\
\hline & 2. Wahl & Erythromycin & $50 \mathrm{mg} / \mathrm{kg} / \mathrm{Tag}$ p.o. in $3 \mathrm{ED}$ \\
\hline \multicolumn{4}{|c|}{ Bei Pleuraempyem oder abszedierender Pneumonie } \\
\hline Altersunabhängig & 1. Wahl & Cefotiam & 100(-150)mg/kg/Tag i.v. in 3 ED \\
\hline
\end{tabular}


- rasche Mobilisierung, ggf. Physiotherapie,

- Inhalation mit $0,9 \% \mathrm{NaCl}$, oder bei Indikation mit $\beta 2$-Sympathomimetikum.

Komplikationen. Der parapneumonische Erguss und das parapneumonische Empyem haben eine Inzidenz, die etwa zwischen 0,5-5 pro 100.000 Kinder liegt und gehäuft während der Wintermonate beobachtet wird. Die meisten parapneumonischen Ergüsse sind durch S. pneumoniae und S. aureus bedingt. Etwa ein Drittel der Kinder klagen über Thoraxschmerzen und/oder Bauchschmerzen. Kleine Ergüsse können mit einer symptomatischen Therapie und durch Gabe von Antiphlogistika rein konservativ therapiert werden. Größere Ergüsse erfordern in der Regel ein interdisziplinäres Vorgehen mit Punktion des Ergusses und ggf. thoraxchirurgischer Intervention. Die Prognose ist im Kindesalter gut, in der Regel haben die Kinder keine funktionellen Beeinträchtigungen.

Prognose. In der Regel heilen ambulant erworbene Pneumonien bei einer adäquaten Therapie ohne Residuen aus. Während in Entwicklungsländern Pneumonien unter den Haupttodesursachen sind, liegt die Letalität in Deutschland weit unter $1 \%$. Hier haben vor allem nosokomial erworbene Pneumonien bei Patienten mit primärem oder sekundärem Immundefekt eine höhere Komplikationsrate. Als Möglichkeiten der Prophylaxe sind vor allem die Impfungen gegen Haemophilus influenzae Typ B, Pneumokokken und Influenza zu nennen. Die Impfung gegen $\mathrm{H}$. influenzae schützt allerdings nicht gegen nichtbekapselte Stämme.

\subsubsection{Asthma bronchiale}

Definition. Asthma bronchiale ist definiert als eine chronisch entzündliche Erkrankung der Atemwege mit reversibler Obstruktion wechselnder Intensität ausgelöst durch unterschiedliche Stimuli auf dem Boden einer bronchialen Hyperreagibilität. Diese Definition beinhaltet wesentliche Aspekte für das pathophysiologische Verständnis, die Diagnostik und die Therapie dieser Erkrankung.

Zentral für das Verständnis des Asthmas ist die chronische Entzündungsreaktion der Atemwege. Dies impliziert für die Therapie die herausragende Bedeutung einer langfristigen antiinflammatorischen Therapie, bei der heute die topische Applikation von inhalativen Steroiden an erster Stelle steht. Diagnostisch kann die Inflammation der Atemwege u. a. durch die Bestimmung von exhaliertem NO quantifiziert werden.

Die reversible Obstruktion wechselnder Intensität bedeutet, dass ein Asthmatiker in Ruhe oder im symptomfreien Intervall in der Lungenfunktion völlig unauffällig sein kann. Erst eine Provokationstestung führt bei diesen Patienten zu einer messbaren Verengung der Atemwege mit Abfall der Fluss-Volumen-Parameter. Mit diesen Untersuchungen gelingt es, die als bronchiale Hyperreaktivität bezeichnete Überempfindlichkeit der Atemwegsschleimhaut zu quantifizieren. Hierbei wird mit Hilfe der Lungenfunktionsprüfung erfasst, in wie weit körperliche Anstrengung oder eine Inhalation (z. B. mit Histamin) zu einer schnelleren und ausgeprägteren Obstruktion der Atemwege führt als bei Gesunden.

Von einer Reversibilität der Obstruktion spricht man, wenn es nach Inhalation mit einem Bronchodilatator zu einer Verbesserung eines Obstruktionsparameters, z. B. der Ein-SekundenKapazität FEV1 kommt. Mit dem Definitionsmerkmal »reversible Obstruktion « ist das Asthma bronchiale von anderen Atemwegserkrankungen differenzialdiagnostisch abzugrenzen, bei denen eine fixierte Verengung der Atemwege vorliegt (COPD, Bronchiolitis obliterans).

Bei Kindern liegt bei etwa $85 \%$ eine allergische Mitbeteiligung vor. Die anamnestische Erfassung »exogener Stimuli« beinhalten daher Fragen nach dem tageszeitlichen Höhepunkt der Beschwerden, saisonalen Schwankungen und der Haustierhaltung. Neben den Allergien spielen überwiegend virale Atemwegsinfektionen als Auslöser eine Rolle.

Epidemiologie. Die Häufigkeit von Asthma bronchiale schwankt weltweit ganz erheblich zwischen $2 \%$ und $20 \%$. Sie ist besonders gering in Ländern mit niedrigem sozioökonomischem Lebensstandard. Es zeigt sich eine deutliche Abhängigkeit von Faktoren des »westlichen Lebensstils«, sodass mit dessen Verbreitung in den letzten 40 Jahren auch eine Zunahme der Erkrankung zu verzeichnen ist.

Die punktuelle (zum Zeitpunkt der Untersuchung) und kumulative Prävalenz (alle Probanden, die irgendwann in ihrem Leben einmal unter Asthmasymptomen gelitten haben) geht aus - Tabelle 22.8 hervor.

$>$ Mit diesen Zahlen ist das Asthma in Mitteleuropa die häufigste chronische Erkrankung im Kindesalter.

Dabei sind bis zum Ende der Pubertät doppelt so viel Knaben wie Mädchen betroffen. Im späteren Leben sind beide Geschlechter annähernd gleich betroffen.

Mehr als die Hälfte aller Ersterkrankungen an Asthma fällt in das Kindesalter. Bei 80\% der kindlichen Asthmatiker manifestiert sich die Erkrankung bereits bis zum 1. Schuljahr, bei $45 \%$ bereits im 1. Lebensjahr. Andererseits ist nicht jede obstruktive Bronchitis in den ersten 3 Lebensjahren bereits ein Bronchialasthma. Wir können davon ausgehen, dass sich bei etwa 15-30\%

- Tabelle 22.8. Häufigkeit (\%) von Asthmasymptomen und -diagnosen in Deutschland bei Kindern verschiedener Alters-gruppen (1995/96)

\begin{tabular}{|c|c|c|c|c|}
\hline \multirow{2}{*}{$\begin{array}{l}\text { Symptome in den letzten } \\
12 \text { Monaten }\end{array}$} & \multicolumn{2}{|l|}{ München } & \multicolumn{2}{|l|}{ Dresden } \\
\hline & 5-7 Jahre & 9-11 Jahre & 5-7 Jahre & 9-11 Jahre \\
\hline - Giemen & 9,0 & 8,6 & 6,9 & 7,9 \\
\hline - Morgendliches Husten & 15,5 & 12,4 & 10,0 & 11,8 \\
\hline \multicolumn{5}{|l|}{ Arztdiagnose } \\
\hline - Jemals & 10,0 & 10,3 & 5,8 & 7,9 \\
\hline - Gegenwärtig & 4,7 & 5,1 & 3,1 & 4,0 \\
\hline
\end{tabular}


der Säuglinge mit »giemender« Bronchitis auch später ein Asthma nachweisen lässt.

Ätiologie. Eine genetische Steuerung für das Auftreten des Asthma bronchiale ist wahrscheinlich. Dabei können 2 zumindest primär voneinander unabhängige Faktoren zur Erkrankung führen, die sich sekundär jedoch gegenseitig verstärken. Ein Faktor ist die bronchiale Hyperreaktivität, der andere die allergische Disposition (Atopie). Bis zu 16\% aller Menschen (je nach Alter und Nachweismethode) lassen Hinweise für eine bronchiale Überempfindlichkeit erkennen. Allerdings nur die Hälfte dieser Personen erkrankt manifest. Im Rahmen einer chronischen Entzündung der Bronchialschleimhaut kann die Hyperreaktivität auch neu erworben werden.

Die allergische Disposition in Form einer überschießenden Immunantwort des IgE-Systems (Typ-I-Allergie) ist ebenfalls genetisch verankert. Aber auch hier gilt, dass nur ein Teil der sensibilisierten, d. h. spezifisches IgE bildenden Individuen manifest erkrankt. Dieser wird allerdings umso größer sein, je stärker die Belastung ist (z.B. Zahl und Erkrankungsart bei Verwandten 1. Grades). Die familiäre und eigene Atopiebelastung scheint auch der entscheidende Faktor zu sein, ob aus einer obstruktiven Bronchitis im frühen Kindesalter (»wheezy babys «) ein Asthma bronchiale wird.

Nach ätiologischen Gesichtspunkten lassen sich folgende, am häufigsten anzutreffende Asthmaformen herausstellen:

- Extrinsic Asthma: Exogen-allergisches Asthma bronchiale, bei dem IgE-Antikörper die alleinige Ursache der Symptome sind (ca. 20\%).

- Intrinsic Asthma: Endogenes Asthma ohne Hinweis für allergische Ursache. Auslösung meist durch Virusinfekte oder andere Triggermechanismen (5-10\%).

- Mischformen: Häufigste Asthmaform im Kindesalter, bei der allergische Mechanismen, aber auch andere Faktoren zur Anfallsauslösung führen (ca. 65\%).

Da körperliche Belastungen - insbesondere Rennen, schnelle Ballspiele, Skilanglauf - bei der Mehrzahl der asthmatischen Kinder als Ausdruck der bronchialen Hyperreaktivität zu einer belastungsinduzierten Bronchialobstruktion führen, ist es nicht sinnvoll, noch ein eigenständiges Anstrengungsasthma (»exercise-induced asthma «) abzugrenzen.

Pathogenese und Pathophysiologie. Die Atemnot eines Asthmapatienten kommt über eine Strömungsbehinderung durch Obstruktion in den Atemwegen zustande. Diese wird verursacht durch (• Abb. 22.5):

- Kontraktion der glatten Bronchialmuskulatur,

- Hyperämie, Ödem und entzündliche Infiltration der Schleimhaut,

- Verstopfung der Atemwegslichtung durch Schleim (Hyperkrinie) und abgelöste Bronchialepithelzellen.

Basis der Obstruktion ist die bronchiale Hyperreaktivität, über die verschiedene Auslösungsfaktoren zur Wirkung kommen (- Abb. 22.6). Für den kindlichen Asthmatiker sind dabei von besonderer Bedeutung:

- Allergenkontakt (z. B. Pollen, Hausstaubmilben, Tierhaare),

- Infekte der Atemwege,

- körperliche Belastungen.

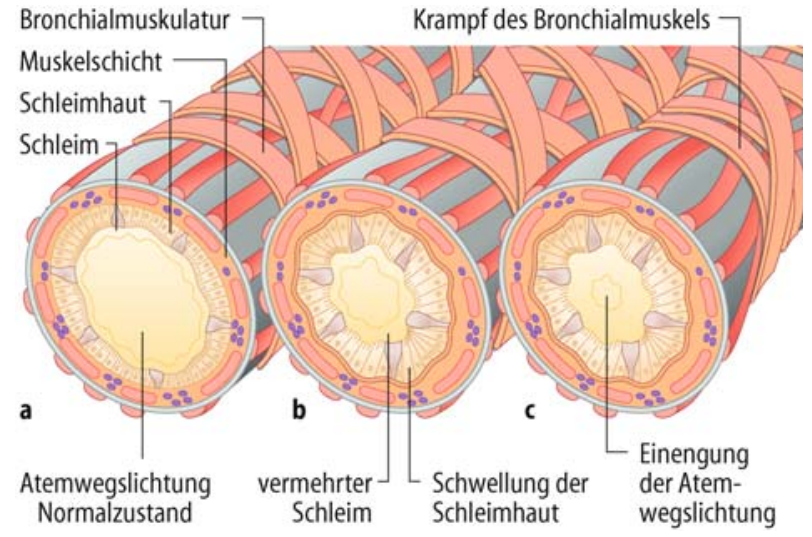

- Abb. 22.5. Pathogenese der Atemwegsobstruktion bei Asthma bronchiale

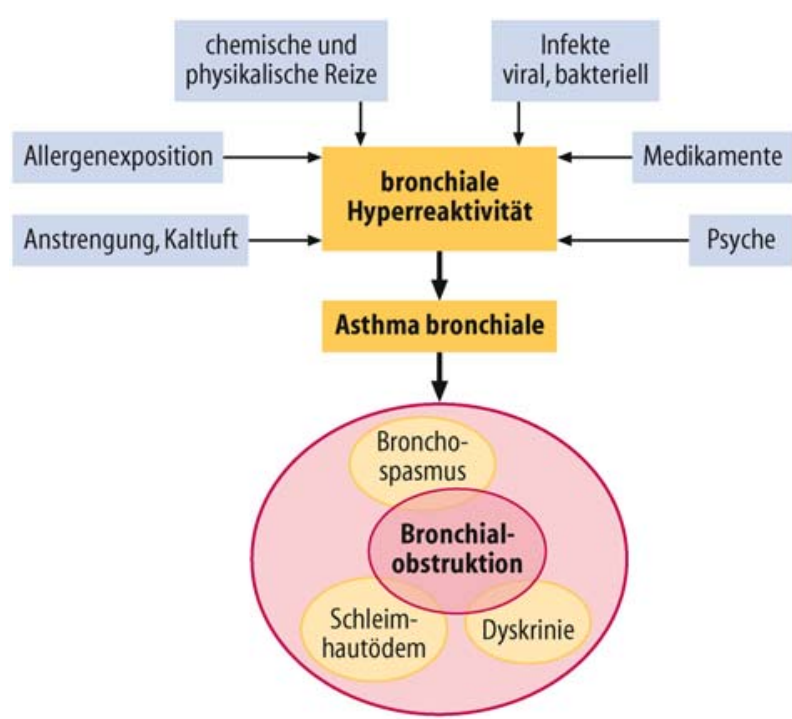

Veränderungen der Lungenfunktion

- Erhöhung des Atemwegswiderstandes

- ventilatorische Verteilungsstörungen

- exspiratorische Flussbehinderung

- Abb. 22.6. Auslösung und Pathophysiologie eines Asthmaanfalls

Durch diese Triggermechanismen kommt es zu einer Stimulation von intraepithelial gelegenen Mastzellen, Basophilen und alveolären Makrophagen, die über immunologische Prozesse (Brückenbildung zwischen 2 IgE-Antikörpern auf einer Mastzelle) oder rezeptorgesteuerte Mechanismen (adrenerg, cholinerg) Mediatoren freisetzen. Bereits vorhandene, präformierte Mediatoren (z.B. Histamin) führen nach einem Allergenkontakt innerhalb von wenigen Minuten zu einer bronchialen Sofortreaktion unter dem Bild einer akuten Bronchialobstruktion (• Abb. 22.7).

Parallel zum Degranulationsvorgang der Mastzellen kommt es aber auch zur Neugenerierung von Lipidmediatoren, die in ihrer biologischen Wirkung die des Histamins um ein Vielfaches übertreffen und zu einer länger anhaltenden Bronchokonstriktion führen. Es sind das insbesondere die Leukotriene $\mathrm{C}_{4}, \mathrm{D}_{4}, \mathrm{E}_{4}(=$ "slow reacting substance of anaphylaxis «) sowie Prostaglandin $\mathrm{D}_{2}$ und der plättchenaktivierende Faktor (PAF). Gleichzeitig setzen Mastzellen und auch andere Zellen, wie Eosinophile, Makropha- 

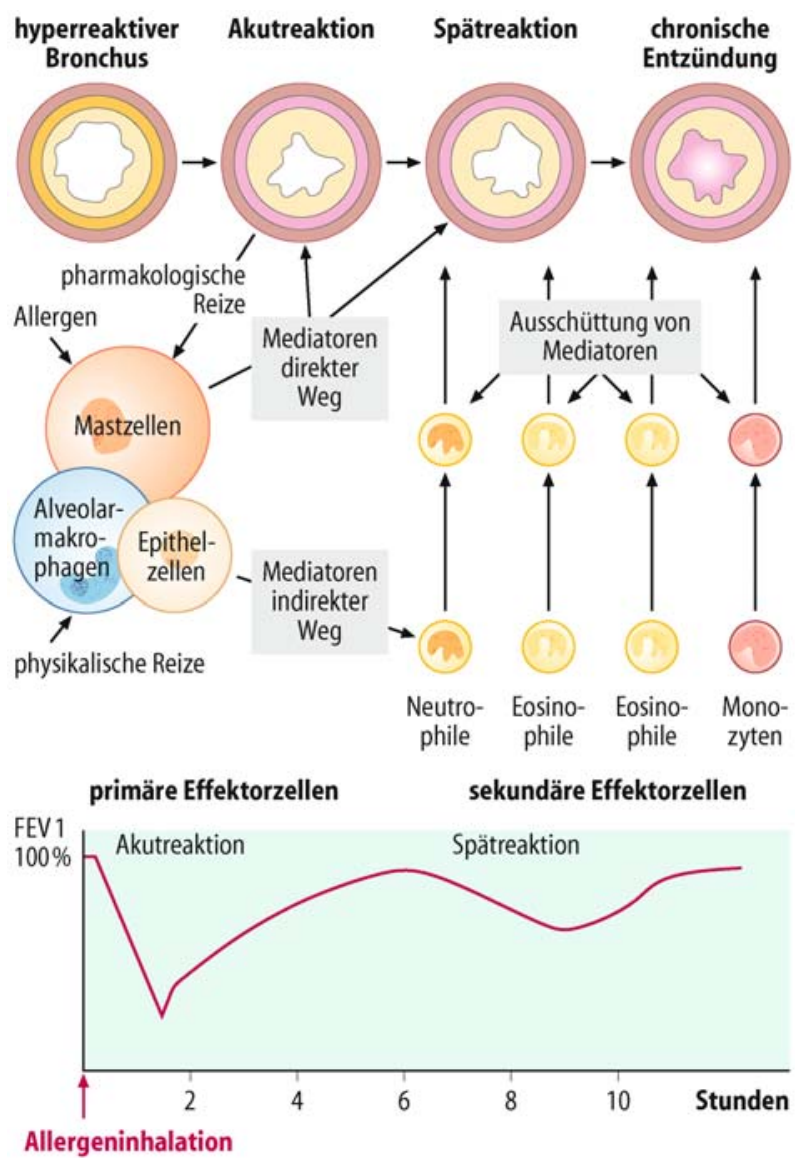

- Abb. 22.7. Schematische Darstellung des Reaktionsablaufs einer asthmatischen Reaktion am Bronchus mit Akut- und Spätreaktion

gen und Thrombozyten, chemotaktisch wirkende Mediatoren frei, die eine 2. Phase, nämlich die Spätreaktion einleiten.

Durch die chemotaktisch wirkenden Mediatoren - in erster Linie Leukotrien $\mathrm{B}_{4}$, neutrophiler-chemotaktischer Faktor (NCF), eosinophiler-chemotaktischer Faktor (ECF) und plättchenaktivierender Faktor (PAF) - werden Entzündungszellen, wie Neutrophile, Eosinophile und Makrophagen, angelockt. Sie wandern in die Bronchialschleimhaut ein, setzen eigene Mediatoren frei und halten dadurch den Entzündungsprozess aufrecht. Die chronische asthmatische Entzündung wird zu einem weiteren Anstieg der bronchialen Hyperreaktivität führen.

Klinik. Die Leitsymptome sind anfallsartige, vorwiegend exspiratorische Atemnot mit Husten, Kurzatmigkeit und Giemen. Gelegentlich können anstrengungsinduzierte Beschwerden oder ein persistierender, oft nächtlicher Husten das einzige Symptom sein. Im klinischen Alltag begegnen uns dabei unterschiedliche Erscheinungsformen:

- Chronische Bronchitis

- Chronischer Husten

- Asthmaanfall und Status asthmaticus

Chronische Bronchitis. Die chronische Bronchitis ist eine besondere Verlaufsform und häufig die erste klinische Asthmamanifestation bei jungen Kindern. Allerdings wird nicht aus jeder chronischen (obstruktiven) Bronchitis in den 3 ersten Lebensjahren ein Bronchialasthma. Die relative Neigung zu Atemwegsobstruktion bei Infekten ist in dieser Altersgruppe vorwiegend durch anatomische und funktionelle Besonderheiten bedingt und verliert sich bei einem Großteil der Kinder wieder. Der Übergang in ein Asthma - bei 15-30\% zu beobachten - ist besonders zu erwarten bei familiärer Atopiebelastung, eigener Disposition (atopische Dermatitis, erhöhtes IgE und positive Allergietests in den ersten Lebensjahren) und über das 3./4. Lebensjahr hinaus anhaltenden Beschwerden.

Das klinische Erscheinungsbild ist gekennzeichnet durch eine Verlängerung des Exspiriums meist im Verein mit exspiratorischen Atemnebengeräuschen (Giemen, Brummen), die teilweise schon auf Distanz, auf jeden Fall aber bei der Auskultation des meist überblähten Thorax zu hören sind. Die Beeinträchtigung des Allgemeinbefindens kann sehr unterschiedlich sein und reicht vom »fröhlichen Giemer« bis zum schwer kranken Kind.

Chronische Huster.

( An die Möglichkeit, dass ein anfallsweise auftretender, schwer stillbarer Reizhusten die alleinige klinische Erscheinungsform des Asthma bronchiale darstellen kann, wird nicht immer gedacht.

Typischerweise tritt er dann in besonderen Situationen auf: nachts im Schlaf, bei körperlichen Belastungen, bei Wetter- oder Temperaturwechsel sowie bei Nebel und hoher Luftverschmutzung.

Asthmaanfall. Der Asthmaanfall beginnt in der Regel ebenfalls mit Husten (die Kinder "husten sich in die Atemnot hinein") und ist vor allem durch eine plötzlich einsetzende und sich vielfach bis zur bedrohlichen Atemnot steigernde exspiratorische Dyspnoe gekennzeichnet. Die Patienten reduzieren ihre körperliche Aktivität und stützen oft zur Fixierung des Schultergürtels die Arme auf, um damit den Einsatz der Atemhilfsmuskulatur zu ermöglichen (Orthopnoe). Der Thorax ist überbläht und die heftigen Atemanstrengungen führen zu Einziehungen (intercostal, jugulär, epigastrisch) bei der Einatmung. Die Kinder haben einen ängstlichen Gesichtsausdruck, sehen blass, im fortgeschrittenen Stadium zyanotisch aus. Auskultatorisch hört man ein raues, oft aber auch ein sehr leises und von Giemen überdecktes Vesikuläratmen. Zeitweise ist über einzelnen Lungenabschnitten das Atemgeräusch völlig aufgehoben, bedingt durch die regional unterschiedliche Ausprägung der bronchialen Obstruktion (ventilatorische Verteilungsstörung). Die Exspirationsphase ist verlängert. Pfeifende, giemende und brummende Geräusche können zu hören sein, manchmal auch klingende Rasselgeräusche. Eindrucksvoll ist infolge der starken Blähung der hypersonore bis tympanitische Klopfschall.

Status asthmaticus. Der Status asthmaticus ist definiert als schwerer Anfall, der über mehr als $24 \mathrm{~h}$ anhält und in dieser Zeit nicht auf adäquate Therapiemaßnahmen anspricht. Der Status asthmaticus ist ein intensivmedizinischer Notfall.

(C) Cave

Das Leiserwerden von Atem- und Nebengeräuschen im Rahmen eines schweren Asthmaanfalls ist ein Alarmsignal für die weitere Verschlechterung.

Abzugrenzen vom Status asthmaticus sind die malignen Asthmakrisen im Jugendalter. Dabei kommt es ohne Vorboten zu akuten, schwersten peripheren Obstruktionen mit ausgeprägter 
Hypoxie bis zum Bewusstseinsverlust mit hypoxisch bedingten zerebralen Krampfanfällen. Ursache ist meistens eine unzureichende antiinflammatorische Dauertherapie. Die Mortalität der malignen Asthmakrise ist hoch. Betroffen sind davon fast ausschließlich Patienten mit einem intrinsischen Asthma.

Komplikationen. Durch den Einriss überblähter Alveolen kann es zum Pneumomediastinum und/oder Pneumothorax kommen. Gelegentlich bilden sich bei starker Schleimhautschwellung und Sekretverlegung auch Atelektasen aus. Bei einem chronischen Asthmaverlauf - insbesondere durch nicht ausreichende Therapie - besteht meist über längere Zeit eine Flussbehinderung für den Atemstrom, sodass die erhöhte Zwerchfellaktivität einen verstärkten Zug auf das Thoraxskelett ausübt. Folge davon ist eine Verformung im Sinne des Glocken- oder Fassthorax bzw. verstärkter seitlicher Furchen.

Diagnose. Zur Einschätzung eines akuten Asthmaanfalles sind erforderlich:

- kurze Anamnese (Asthmatyp, Auslöser, bisherige Therapie, Einsatz von Betamimetika),

- klinische Untersuchung (Tachy-/Dyspnoe? seitengleiches Atemgeräusch? endexspiratorisches Giemen? transkutane Sättigung?),

- Bestimmung der Blutgase, des Blutbildes und CrP,

- Röntgen-Thorax (Überblähung? Pneumothorax? Pneumonie? Fremdkörper?).

Die Basisdiagnostik bei Verdacht auf Asthma bronchiale sollte folgende Schritte enthalten:

- Differenzierte Anamnese: Bei der Anamnese sind drei Themenkomplexe zu erfragen:

- »Beeinträchtigung im Alltag«: Besteht nächtlicher Husten? Besteht morgendlicher Husten? Kann das Kind durchschlafen? Schnarcht das Kind nachts?

- »Beeinträchtigung bei körperlicher Anstrengung«: Besteht Husten bei Anstrengung? Muss das Kind beim Sport pausieren? Wie belastet sich das Kind beim Sport?

- »Umgebungsanamnese«: Wer ist in der Familie von atopischen Erkrankungen betroffen? Gibt es zu Hause Tiere? Besteht eine Passivrauchexposition? Wie oft werden Medikamente genommen ( $\beta 2$-Mimetika)? Gibt es Hinweise für das Vorliegen einer atopischen Dermatitis oder einer allergischen Rhinitis?

- Bei der körperlichen Untersuchung sollten auch die oberen Atemwege mit im Fokus sein. Hier ist z. B. auf die Behinderung der Nasenatmung bei Kindern mit allergischer Sensibilisierung gegen Hausstaubmilben, Tierhaare und Pollen zu achten.

- Lungenfunktionsprüfung zur Einschätzung der Obstruktion und Überblähung der Atemwege. Die Lungenfunktion bietet sich zur Überprüfung des Therapieerfolges im Verlauf an. Die Reversibilität einer vorhandenen Obstruktion kann mit dem Bronchospasmolysetest (Inhalation eines schnell wirkenden $\beta$-Sympathomimetikums) geprüft werden (z. B. 2 Hübe Sultanol Dosieraerosol). Ist die Lungenfunktion in Ruhe normal, kann das Verhalten der Werte, z. B. nach 6 min freiem Rennen Aufschluss über die Gefahr eines Belastungsasthmas geben. Bestehen Zweifel an der Diagnose Asthma, lässt sich durch eine inhalative Provokation mit Histamin oder Metacholin direkt die bronchiale Reaktivität bestimmen.
- Allergologische Laboruntersuchungen: Sie umfasst Hauttestungen (Prick-, selten Intrakutantest), Serumuntersuchungen (spezifische IgE-Antikörper) sowie u. U. Provokationstests an bestimmten Organen (Auge, Nase, Bronchien). Dabei sollte möglichst klar werden, ob erkannte Sensibilisierungen auch klinisch bedeutsam sind.

- Röntgenuntersuchung: Röntgenaufnahmen von Thorax und Nasennebenhöhlen sind nur bei der initialen Untersuchung bzw. ganz konkreten Fragestellungen (z. B. Pneumothorax?) indiziert.

- Differenzialdiagnostische Untersuchungen: Schweißtest, a1Antitrypsin, bei spezieller Fragestellung ggf. Immunglobuline mit Subklassen und Impfantikörper (Immundefekt).

\section{Differenzialdiagnosen}

- chronische Bronchitis, Bronchiolitis obliterans,

- exogen allergische Alveolitis,

- zystische Fibrose,

- Primäre ziliäre Dyskinesie,

- Fremdkörperaspiration,

- rezidivierende Entzündungen bei Immundefekt,

- exogene Kompression der Atemwege (Lymphome, Lymphknoten, Gefäße),

- strukturelle Atemwegsdefekte (z. B. Bronchomalazie).

Therapie. Um langfristig ein therapeutisches Bündnis mit den Patienten und den Eltern einzugehen, ist es wichtig, dass Asthma bronchiale als eine chronische Erkrankung der Atemwege verstanden wird. Eine kurzzeitige, rein symptomatische Therapie ist daher auf lange Sicht unwirksam. Oft ist es dabei hilfreich, sich über die Ziele der Asthmatherapie zu verständigen. Wichtig ist dabei auch die Information, dass mit den unten dargestellten Maßnahmen bei ca. 90 \% der Asthmatiker diese Ziele auch zu erreichen sind.

Ziele der Asthmatherapie sind:

- Symptomfreiheit,

- altersentsprechende Belastbarkeit,

- normale Lungenfunktion,

- keine notfallmäßigen Arztvorstellungen,

- keine Medikamentennebenwirkungen,

- normale psychische und psychosoziale Entwicklung

Die Grundsätze der Therapie umfassen drei Säulen:

- Meidung von Triggerfaktoren,

- medikamentöse Therapie, bestehend aus

- antiobstruktiver Bedarfsmedikamentation für den Notfall und

- antiinflammatorischer Basismedikamentation,

- spezifische Immuntherapie (SIT).

Meidung von Triggerfaktoren. Bei Kindern mit einem exogen-allergischen Asthma ist die Allergenmeidung eine wichtige Therapiesäule. Dies betrifft vor allem Patienten, die eine klinisch relevante Sensibilisierung auf Innenraumallergene haben. Bei einer Sensibilisierung gegen Katzen- oder Hundeepithelien muss der Kontakt mit den entsprechenden Tieren vermieden werden. Bei einer Sensibilisierung gegen Hausstaubmilben sind Veränderungen im Wohnbereich erforderlich. Hierzu zählen: Umhüllung der Matratze mit einem milbendichten Überzug, Waschen von Kuscheltieren, Kissen und Decken alle 3-4 Monate, wö- 
chentliches Wechseln der Bettwäsche. Sind Nahrungsmittel (Nüsse) als Auslöser von Atemwegsobstruktionen bekannt, ist eine strikte Allergenkarenz obligat. Unspezifische Triggerfaktoren wie Tabakrauch sind ebenfalls zu meiden.

Medikamentöse Therapie. Mit der medikamentösen Therapie werden 2 grundlegende Strategien verfolgt. Unabhängig vom Schweregrad der Erkrankung soll bei akut auftretenden Beschwerden eine schnelle und sichere Beseitigung der Bronchialobstruktion erzielt werden. Geeignet und empfohlen sind dafür kurz wirksame $\beta$-Mimetika, die in der Regel inhalativ verabfolgt werden (Bedarfsmedikation).

Die Dauermedikation (Basistherapie) besteht in der regelmäßigen Anwendung von Medikamenten mit dem Ziel, die asthmatische Entzündungsreaktion zu unterdrücken und dadurch langfristig eine Kontrolle der Symptome und einen günstigen Krankheitsverlauf zu erreichen. Beginn und Umfang der Basistherapie hängen vom Schweregrad der Erkrankung ab, sodass ein entsprechender Stufenplan (• Tabelle 22.9) entwickelt worden ist. Steuerungselement zur Intensivierung (step up) oder Reduzierung (step down) der Therapie ist dabei die erreichte Asthmakontrolle.

Die Behandlung sollte auf der Stufe einsetzen, die dem augenblicklichen Schweregrad des Krankheitsbildes entspricht. Der entscheidende Schritt im Schema ist, ab Stufe 2 konsequent Entzündungshemmer einzusetzen. Dafür eignen sich in erster Linie niedrig dosierte inhalative Kortikosteroide. Deren Einsatz hat eine völlig neue Qualität der Asthmatherapie eingeleitet. Um jedoch mögliche Nebenwirkungen (vor allem bei Dosierungen $>400 \mu \mathrm{g} / \mathrm{Tag}$ ) zu vermeiden bzw. frühzeitig zu erkennen, ist es erforderlich, folgende Grundsätze zu beachten:

- Anwendung 1-2-mal pro Tag,

- Benutzung einer Vorschaltkammer (Spacer) bei Verwendung eines Dosieraerosols (• Abb. 22.8),

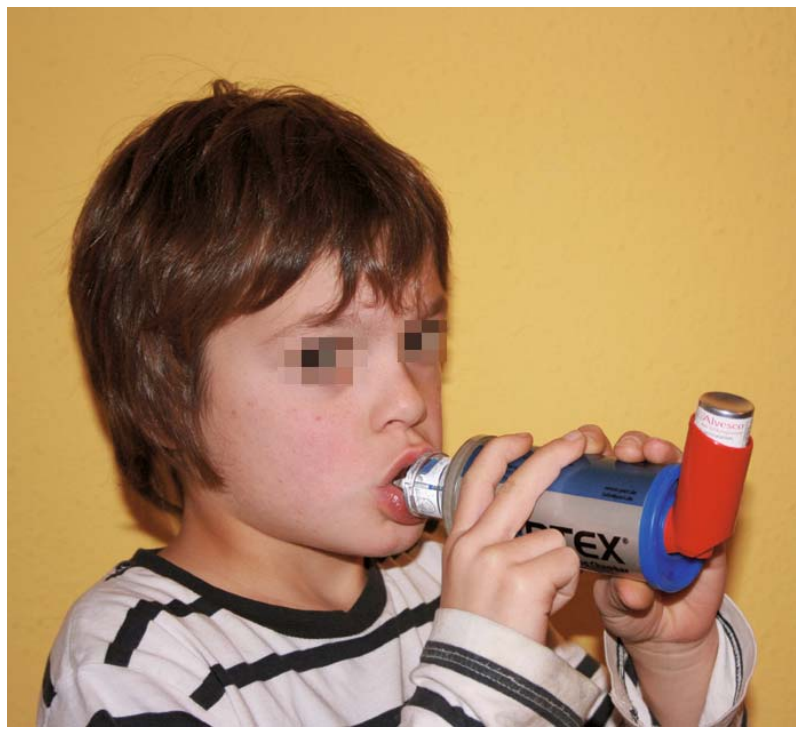

- Abb. 22.8. Inhalation mittels Dosieraerosol und großvolumiger Vorratskammer (Spacer) zur Überbrückung der Koordinationsschwierigkeiten bei der Inhalation. Das in die Vorratskammer versprühte Medikament wird mit einigen tiefen Atemzügen von dort aus inhaliert

- Ausspülen des Mundes (oder Zähneputzen) nach der Inhalation,

- Kontrolle der jährlichen Wachstumsrate,

- Einhaltung der niedrigsten, noch wirksamen Dosis (• Tabelle 22.10).

Auch ein primärer Therapieversuch mit dem Leukotrienantagonisten Montelukast ist vor allem bei Kindern möglich, sollte aber nach 4-8 Wochen hinsichtlich seiner Effektivität kri-

- Tabelle 22.9. Stufenplan der Therapie des Asthma bronchiale bei Kindern

\begin{tabular}{|c|c|c|c|}
\hline Schweregrade & Merkmale & Therapie bei Bedarf & Dauertherapie \\
\hline $\begin{array}{l}\text { Stufe 1: } \\
\text { Intermittierend }\end{array}$ & $\begin{array}{l}\text { Intermittierend Husten, leichte Atemnot } \\
\text { Symptomfreies Intervall > } 2 \text { Monate } \\
\text { Lungenfunktion: Nur intermittierend obstruk- } \\
\text { tiv, Lungenfunktion dann oft noch normal. Im } \\
\text { Intervall ohne pathologischen Befund }\end{array}$ & $\begin{array}{l}\text { Inhalatives kurz } \\
\text { wirksames } \beta_{2} \text {-Sympa- } \\
\text { thomimetikum }\end{array}$ & Keine \\
\hline $\begin{array}{l}\text { Stufe 2: } \\
\text { Persistierend } \\
\text { geringgradig }\end{array}$ & $\begin{array}{l}\text { Intervall zwischen Episoden }<2 \text { Monate } \\
\text { Lungenfunktion nur episodisch obstruktiv, } \\
\text { dann pathologisch: } \mathrm{FEV}_{1}<80 \% \\
\text { Lungenfunktion im Intervall meist noch ohne } \\
\text { pathologischen Befund: } \mathrm{FEV}_{1}>80 \%\end{array}$ & $\begin{array}{l}\text { Inhalatives kurz } \\
\text { wirksames } \beta_{2} \text {-Sympa- } \\
\text { thomimetikum }\end{array}$ & $\begin{array}{l}\text { Therapie der } 1 . \text { Wahl: niedrig dosierte inhalative } \\
\text { Kortikosteroide } \\
\text { oder } \\
\text { Montelukast (Wirksamkeit nach 4-8 Wochen } \\
\text { endgültig beurteilen) }\end{array}$ \\
\hline $\begin{array}{l}\text { Stufe 3: } \\
\text { Persistierend } \\
\text { mittelgradig }\end{array}$ & $\begin{array}{l}\text { An mehreren Tagen/Woche und auch nächt- } \\
\text { liche Symptome } \\
\text { Lungenfunktion: auch im Intervall obstruktiv: } \\
\text { FEV }_{1}<80 \%\end{array}$ & $\begin{array}{l}\text { Inhalatives kurz } \\
\text { wirksames } \beta_{2} \text {-Sympa- } \\
\text { thomimetikum }\end{array}$ & $\begin{array}{l}\text { Mittlere Dosis der inhalativen Kortikosteroide, } \\
\text { oder add on lang wirksames } \beta_{2} \text {-Sympathomime- } \\
\text { tikum (LABA) } \\
\text { und/oder Montelukast }\end{array}$ \\
\hline $\begin{array}{l}\text { Stufe 4: } \\
\text { Persistierend } \\
\text { schwergradig }\end{array}$ & $\begin{array}{l}\text { Anhaltende tägliche Symptome, häufig auch } \\
\text { nachts } \\
\text { Lungenfunktion: } \mathrm{FEV}_{1}<60 \% \\
\text { Variabilität }>30 \%\end{array}$ & $\begin{array}{l}\text { Inhalatives kurz } \\
\text { wirksames } \beta_{2} \text {-Sympa- } \\
\text { thomimetikum }\end{array}$ & $\begin{array}{l}\text { Hohe Dosis inhalativer Steroide plus LABA und } \\
\text { Montelukast } \\
\text { Bei ungenügender Wirkung andere Thera- } \\
\text { pieformen: } \\
\text { - systemische Steroide } \\
\text { - Omalizumab (Anti-IgE-AK) } \\
\text { - Retard-Theohyllin }\end{array}$ \\
\hline
\end{tabular}


- Tabelle 22.10. Dosisbereich inhalativer Kortikoide für Kinder (Tagesdosis in $\mu \mathrm{g}$ )

\begin{tabular}{l|l|l|l} 
Wirkstoff & Niedrige Dosis & Mittlere Dosis & Hohe Dosis \\
\hline $\begin{array}{l}\text { Beclometason } \\
\text { Pulver }\end{array}$ & $<400$ & 400 (Pulver) & $>400$ \\
\hline $\begin{array}{l}\text { Beclometa- } \\
\text { son-HFA }\end{array}$ & $<200$ & 200 (löslich) & $>200$ \\
\hline Budesonid & $<400$ & 400 & $>400$ \\
\hline Fluticason & $<200$ & 200 & $>200$
\end{tabular}

tisch beurteilt werden. Bei ungenügendem Therapieerfolg muss dann auf ein inhalierbares Kortikosteroid umgestellt werden.

Wurde dieses primär eingesetzt und wird darunter keine adäquate Kontrolle erreicht bzw. lag gleich ein höherer Schweregrad vor, können zusätzlich lang wirkende $\beta_{2}$-Sympathomimetika (LABA) und/oder Antileukotriene (Moutelukast) gegeben werden, bevor die Dosis des topischen Steroids weiter angehoben und über den Einsatz von Retard-Theophyllin nachgedacht wird. Orale Steroide als Dauertherapie (Stufe 4) sind als letzte Option zu betrachten und beim kindlichen Asthma glücklicherweise nur noch extrem selten erforderlich. Seit einigen Jahren ist ein monoklonaler Anti-IgE-Antikörper (Omalizumab) für die Therapie des schweren allergischen Asthma bronchiale (Stufe 4) ab 12 Jahren zugelassen. Dieses hochwirksame Therapieprinzip reduziert die Anzahl der Asthmaexazerbationen und den Bedarf von Steroiden.

Bei der zu bevorzugenden inhalativen Applikation der Asthmamedikamente müssen in Abhängigkeit von Alter und Kooperationsbereitschaft der einzelnen Patienten geeignete Inhalationssysteme ausgesucht werden. - Tabelle 22.11 gibt dazu einen Überblick.

$>$ Die Inhalationstechnik des Patienten muss kontinuierlich überprüft werden.

Kausale Therapieoption. Die spezifische Immuntherapie (Hyposensibilisierung, »Allergie-Impfung «) ist die einzige kausale Behandlungsmöglichkeit bei einem allergischen Bronchialasthma. In Anbetracht der möglichen Nebenwirkungen ist ihre Indikation jedoch besonders zu prüfen. Diese ist dann gegeben, wenn ein als krankheitsauslösend erkanntes Allergen nicht gemieden werden kann und die übliche Therapie einen ungenügenden Therapieerfolg zeigt. Sie kann auch erwogen werden, wenn ein »Etagenwechsel« (Entwicklung eines Asthmas aus einer allergischen Rhinitis) oder mögliche Sensibilisierungen durch weitere Allergene vermieden werden sollen. Geeignete Allergene sind in erster Linie Pollen (Gräser, Roggen Birke etc.) und Hausstaubmilben. Die Behandlung erfolgt in der Regel durch anfangs wöchentliche, später 4-wöchentliche subkutane Injektionen (ab 5. Lebensjahr), wobei die Dosis stufenweise gesteigert wird. Andere Applikationsformen (oral, sublingual, inhalativ) können nicht empfohlen werden.

\section{(D) Patientenschulung}

Ein wesentlicher Bestandteil der Behandlung ist die Asthmaschulung, bei der Patienten und Eltern handlungsrelevantes Wissen über die Krankheit und die zum Einsatz kommenden Medikamente vermittelt bekommen. Sie wird als Gruppenschulung unter ärztlicher Anleitung möglichst interdisziplinär durchgeführt.

Wesentliche Schulungsinhalte sind:

- Aufklärung über Krankheitsmechanismen, auslösende Stimuli und Beschwerden,

- Körperselbstwahrnehmung,

- richtige Inhalationstechnik,

- Verhaltenstraining, Asthmasport und Atemübungen,

- Unterscheidung zwischen Dauer- und Bedarfsmedikation,

- Erkennen einer Asthmaexazerbation und möglichst auch der Auslöser,

- Peak-flow-Messung, Dokumentation von Symptomen und Medikamentenverbrauch,

- Selbsthilfemaßnahmen und Selbstmedikation,

- Umgang mit emotionalen Auswirkungen,

- Asthma und sozialer Bereich (z. B. Familie, Schule, Freunde).

Therapie des akuten Asthmaanfalles. - Tab. 22.12.

Prognose. Die Prognose des Asthma bronchiale im Kindesalter gilt heute im Allgemeinen als gut. Todesfälle kommen sehr selten vor. Ein Teil der Kinder verliert seine Beschwerden spontan bis zur Pubertät (40-50\%), andere sind aufgrund einer adäquaten Therapie praktisch beschwerdefrei. Trotzdem lässt sich bei vielen von ihnen mit entsprechenden Methoden noch eine - gegenüber dem primären Ausmaß vielleicht etwas reduzierte - bronchiale Hyperreaktivität nachweisen. Langzeitstudien zeigen, dass bei einem bedeutsamen Teil dieser Patienten jedoch nach dem 22. Lebensjahr erneut Beschwerden auftreten. Bis zu 76\% der asthmatischen Kinder waren danach auch im Erwachsenenalter noch oder wieder symptomatisch.

- Tabelle 22.11. Altersentsprechende Auswahl der Inhalationssysteme

\begin{tabular}{|l|l|l|l}
\hline Alter [Jahre] & Inhalationssystem & Akutbehandlung & Dauerbehandlung \\
\hline$<2$ & $\begin{array}{l}\text { Düsenvernebler mit Kompressor } \\
\text { Dosieraerosol (DA) mit Spacer und Maske }\end{array}$ & $\begin{array}{l}\text { Fenoterol } \\
\text { Salbutamol }\end{array}$ & Inhalierbare Steroide \\
\hline $2-4$ & $\begin{array}{l}\text { DA mit Spacer } \\
\text { Düsenvernebler mit Kompressor }\end{array}$ & $\begin{array}{l}\text { Terbutalin } \\
\text { Ipratropiumbromid }\end{array}$ & \\
\hline$>4$ & $\begin{array}{l}\text { DA mit Spacer } \\
\text { Pulverinhalatoren (i.d.R. ab Schulalter) } \\
\text { Düsenvernebler mit Kompressor (bestimmte } \\
\text { Indikationen, z. B. Exazerbation) }\end{array}$ & & $\begin{array}{l}\text { Inhalierbare Steroide und langwirkende } \beta_{2} \text {-Sympa- } \\
\text { thomimetika }\end{array}$ \\
\hline
\end{tabular}


- Tabelle 22.12. Therapie des akuten Asthmaanfalls

Symptome

Therapie

Mittelschwerer Anfall

Unvermögen einen längeren Satz während eines Atemzuges zu vollenden, Gebrauch der akzessorischen Atemmuskulatur, Atemfrequenz unter 30/min, Herzfrequenz unter 120/min

2-4 Hübe eines kurzwirksamen $\beta 2$-Sympatominetikums (z. B. Salbutamol), ggf. alle $10 \mathrm{~min}$, evtl. 2-3 I/min Sauerstoff über Maske oder Nasensonde (Ziel $\mathrm{SaO}_{2}>$ $92 \%)$, evtl. 1-2 mg/kg KG Prednisolon oral

Schwerer Anfall

Unvermögen zu sprechen oder Nahrung aufzunehmen, sitzende Haltung, Arme seitlich abgestützt

Atemfrequenz über 5 Jahre: $>30 / \mathrm{min}, 2-5$ Jahre $>40 / \mathrm{min}$

Herzfrequenz über 5 Jahre $>120 / \mathrm{min}, 2-5$ Jahre $>130 / \mathrm{min}$

$\mathrm{SaO}_{2}<90 \%$ unter Raumluft

2-4 Hübe eines kurzwirksamen $\beta 2$-Sympatominetikums (Salbutamol), ggf. alle $10 \mathrm{~min} \mathrm{1-3} \mathrm{I/min} \mathrm{Sauerstoff} \mathrm{über} \mathrm{Maske} \mathrm{oder} \mathrm{Nasensonde,} \mathrm{1-2} \mathrm{mg/kg} \mathrm{KG} \mathrm{Pred-}$ nisolon oral oder i.v. (evtl. mit höherer Dosis rektal)

Ggf. muss diese Therapie eskaliert werden und schließt dann eine parenterale Flüssigkeits- und Elektrolytzufuhr sowie die i.v. Gabe von Theophyllin und/oder eines $\beta 2$-Sympatominetikums mit ein

Bei mangelndem Ansprechen auf die $\beta 2$-Sympatominetika-Therapie kann wiederholt zusätzlich Ipratropiumbromid inhaliert werden
Die Spätprognose ist schlechter bei Beginn der Beschwerden $<2$ Jahre und bei Mädchen. Weitere die Prognose verschlechternde Faktoren sind ein schweres Krankheitsbild, ausgesprägte Lungenfunktionsstörung, eine begleitende atopische Dermatitis und eine familiäre Belastung.

\subsubsection{Exogen-allergische Alveolitis}

\section{W. Leupold}

Synonyme. Synonym wird dieses Krankheitsbild auch als allergische Alveolitis, Hypersensitivitätspneumonitis oder unter Bezug auf die Herkunft der verantwortlichen Allergene z. B. als Vogelhalterlunge oder Farmerlunge bezeichnet.

Definition. Es handelt sich um eine allergische Reaktion gegenüber organischen Stäuben, die zu einer nichtinfektiösen, immunologischen Entzündungsreaktion im Interstitium, an den terminalen Bronchioli und den Alveolen führt. In Abhängigkeit von Art und Ausmaß der Allergenexposition verläuft die Erkrankung in akuten Schüben (z. B. jeweils nach dem Säubern eines Taubenschlages) oder chronisch (z. B. bei Dauereinwirkung von Schimmel im Haus). In beiden Fällen kommt es zu einer fortschreitenden Verschlechterung der Lungenfunktion, und der Übergang in eine Lungenfibrose ist möglich.

Epidemiologie. Die exogen-allergische Alveolitis (EAA) ist im Kindesalter eine seltene Erkrankung. Für Kinder wurde in Deutschland eine Prävalenz von 0,05\% errechnet, wobei aber noch eine hohe Dunkelziffer angenommen wird. Man kann davon ausgehen, dass $15 \%$ aller Patienten Kinder sind.

Ätiologie und Pathogenese. Die wichtigsten Antigene sind Schimmelpilze, tierische Eiweiße (z. B. Vogelkot), Bakterien (Thermoaktinomyzeten) und Arzneimittel (Nitrofurantoin, Carbamazepin). Die Erkrankung beruht auf einer hyperergischen Reaktion, an der die Immunreaktionen des Typs III und IV beteiligt sind. Zum Typ III - verzögerte Immunreaktion mit neutrophiler Alveolitis - gehört die Bildung von Antikörpern vorwiegend der Klasse IgG, die mit den Antigenen unter Anlagerung von Komplementfaktoren Immunkomplexe bilden.
Klinik. Die bei Erwachsenen bekannten, akuten Krankheitsformen, die oft im Rahmen einer beruflichen Allergenexposition auftreten, stellen im Kindesalter eher die Ausnahme dar. Es kommt dabei etwa 4-6 h nach Exposition (z. B. Spielen in feuchtem Heu) zu Husten, Atemnot und Fieberanstieg. Bei deutlicher Beeinträchtigung des Allgemeinbefindens ähnelt das Krankheitsbild dem einer bakteriellen Pneumonie, zumal auch feinblasige Rasselgeräusche bei der Auskultation zu hören sind.

Bei Kindern verläuft die Erkrankung überwiegend schleichend mit zunehmender Leistungsminderung, Gewichtsverlust und anderen, uncharakteristischen Symptomen. In der Anamnese berichten diese Patienten häufig über Belastungsdyspnoe und Husten. Klinisch bestehen Tachypnoe, eventuell Hinweise für eine Zyanose, und man hört meist diskrete, feinblasige Rasselgeräusche über den Unterfeldern.

Diagnose. Bei der akuten Verlaufsform kommt es zu einer Leukozytose mit Linksverschiebung und einem Anstieg des CRP sowie der BSG. Die chronischen Formen gehen meist mit normalen Leukozytenzahlen einher. Von den Immunglobulinen ist insbesondere das IgG erhöht. Charakteristisch für die Krankheit ist die Bildung spezifischer Antikörper der Klassen IgG und teilweise IgA gegen das jeweilige Antigen.

Diagnostisch wertvoll sind sowohl die präzipitierenden Antikörper (Doppeldiffusionstest nach Ouchterlony) wie auch die nicht präzipitierenden (ELISA). Zu beachten sind aber 2 Besonderheiten:

$>$ Bei entsprechend Exponierten können Antikörper ohne jegliche Krankheitserscheinungen vorhanden sein. Je höher der Antikörpertiter, desto wahrscheinlicher ist jedoch die allergische Alveolitis.

Wiederholt wurde das Fehlen von Antikörpern bei klinisch sicheren Fällen beschrieben. Trotz fehlender Antikörper kann also eine EAA vorliegen.

Unter Antigenkarenz kommt es zum Abfall der Antikörperkonzentration, der in den ersten 2 Monaten rasch, später verlangsamt verläuft.

Inhalative Provokationsproben sind im Kindesalter in der Regel entbehrlich, da keine arbeitsmedizinische Fragestellung vorliegt. 

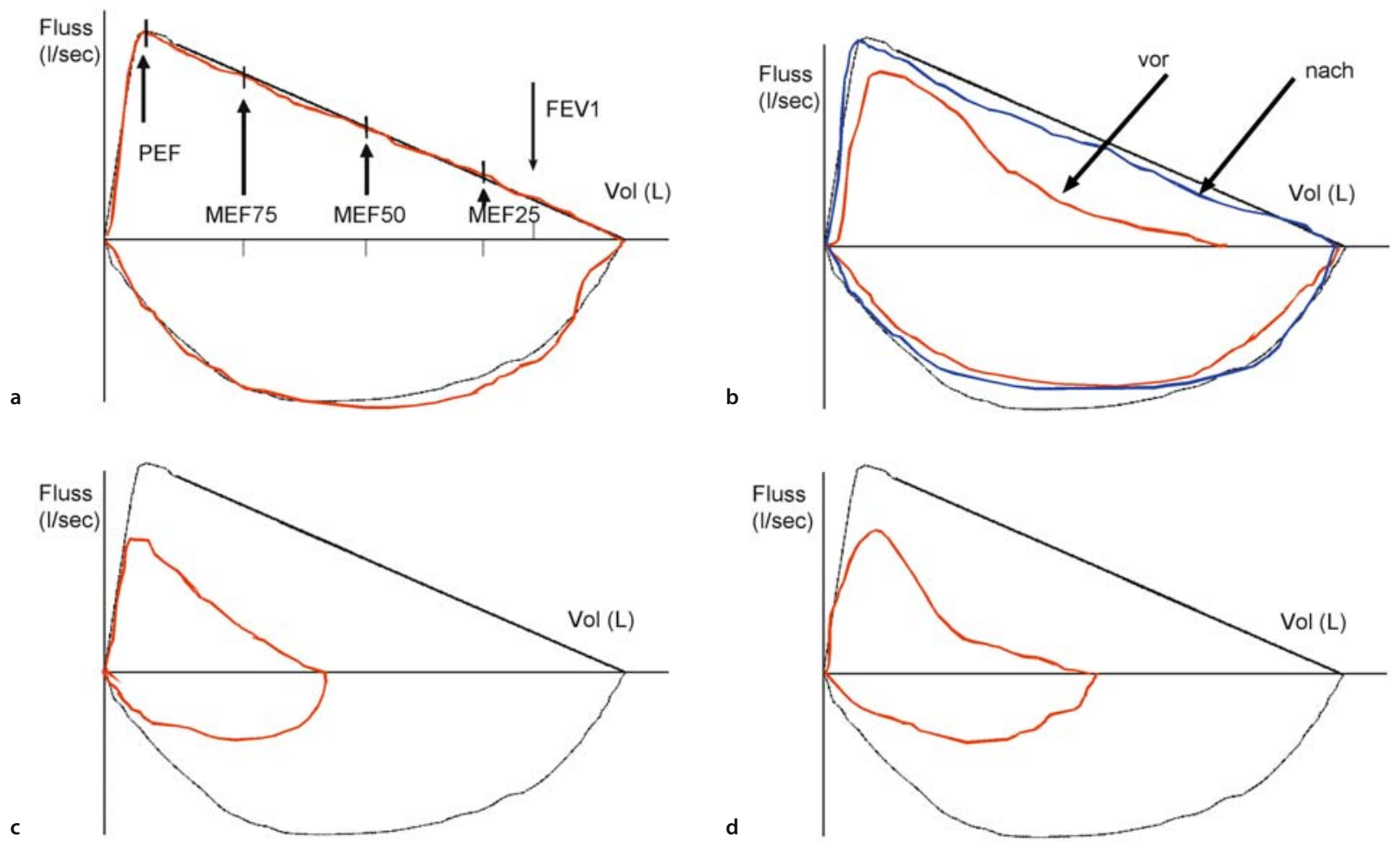

- Abb. 22.9a-d. Lungenfunktionsprüfung. Die schwarze Kurve stellt den Sollwert dar. a Normale Flussvolumenkurve. Hier wird der Atemfluss in I/sec gegenüber dem Volumen aufgetragen. PEF: exspiratorischer Spitzenfluss. MEF: maximaler exspiratorischer Fluss, d. h. Atemwegsfluss, wenn noch $75 \%$ (bzw. $50 \%, 25 \%$ ) des Volumens auszuatmen sind. Der Parameter MEF $50 \%$ wird in der Pädiatrie als Maß für die Obstruktion der kleinen Atemwege verwendet. FEV1: forciert ausgeatmetes Volumen in der ersten Sekunde: Maß für die globale Obstruktion der Atemwege.

Die Vermehrung von Zellen in der bronchoalveolären Lavageflüssigkeit ist neben der Alveolarwandverdickung im histologischen Bild das zuverlässigste diagnostische Kriterium. Besonders betroffen sind davon die T-Lymphozyten.

Die Lungenfunktionsprüfung ergibt bei der Mehrzahl der Kinder eine restriktive Ventilationsstörung mit Verminderung aller statischen Lungenvolumina (• Abb. 22.9). Die Steifheit der Lunge führt zur Verminderung der Compliance. Die Diffusionsleistung ist eingeschränkt, erkennbar an einem erniedrigten Transferfaktor und dem (weiteren) Absinken des $\mathrm{pO}_{2}$ unter körperlicher Belastung.

Im Rahmen der Quellensuche ist es bei Verdacht auf Auslösung der Erkrankung durch Kontakt mit Schimmelsporen sinnvoll, entsprechende Platten in der Wohnung des Patienten aufzustellen. Diese Messung sollte auch nach Sanierungsmaßnahmen wiederholt werden.

Konventionelle Röntgenaufnahmen (Thoraxübersicht) können das gesamte Spektrum interstitieller Muster zeigen, aber auch unauffällig sein. Am häufigsten werden gefunden:

- noduläre Schatten,

- milchglasartige Trübungen,

- retikuläre Zeichnung.

Das hochauflösende CT (HR-CT) ist exogen-allergischen Alveolitis konventionellen Thoraxaufnahmen deutlich überlegen.

Differenzialdiagnose. Interstitielle, atypische Pneumonien bei Infektionen mit Viren, Mykoplasmen, Chlamydien und Rickettsien können in ihrem Verlauf dem akuten Bild der EAA entsprechen. Die chronische Verlaufsform wird anfangs oft als rezidivierende Bronchitis oder grippale Infektion mit allgemeiner Leistungsminderung fehlgedeutet.

Differenzialdiagnostisch beachtet werden müssen interstitielle Prozesse, die durch toxische Schädigung (Medikamente), im Rahmen systemischer Erkrankungen (z.B. Lupus erythematodes) oder aus bisher unbekannter Ursache (z. B. idiopathische Lungenfibrose) auftreten.

Therapie. Die wichtigste therapeutische Maßnahme ist die Meidung des Allergenkontaktes. Das kann schwieriger als erwartet sein, wenn die Allergenzufuhr indirekt und manchmal unbeeinflussbar weiter anhält. Tauben und Hühner in der Nachbarschaft, Vogelantigen im Teppichfußboden oder Schimmelpilze im Haus sind nicht immer im gewünschten Ausmaß zu entfernen. Gelegentlich ist auch bei Kindern das Tragen einer Atemschutzmaske unter besonderen Bedingungen erforderlich. Die Karenz sollte sich auch auf potenzielle Antigene erstrecken, da bei diesen Patienten eine erhöhte Sensibilisierungsbereitschaft besteht.

Bei chronischen Verlaufsformen genügt meistens nicht nur die Karenz. Hier muss durch eine systemische Therapie mit Kortikosteroiden (anfangs z.B. 2 mg Prednisolon/kgKG/Tag) eine 
Abschwächung und Verkürzung der Symptomatik erreicht werden. Dosis und Dauer der Gesamtbehandlung müssen anhand von Entzündungsparametern, Werten der Lungenfunktionsprüfung und Titerverlauf der Antikörper entschieden werden.

\section{Prognose}

$>$ Die Prognose hängt entscheidend davon ab, ob die Diagnose rechtzeitig (vor einer möglichen Fibrosierung) gestellt wird und ob es gelingt, das Antigen konsequent auszuschalten. Anderenfalls kann der mögliche Übergang in eine Fibrose zur pulmonalen Insuffizienz führen.

\subsection{Bronchiolitis obliterans}

\section{Kopp}

Definition. Unter einer Bronchiolitis obliterans versteht man die gemeinsame Endstrecke unterschiedlicher Krankheitsprozesse, die mit einem irreversiblen Umbau der kleinen Atemwege einhergehen. Im Kindesalter sind folgende Auslöser beschrieben:

- parainfektiös (u. a. nach RSV, Influenza-, Parainfluenza oder Adenoviren, Mykoplasmen-Infektionen),

- chronische Abstoßungsreaktion nach Lungentransplantation,

- graft-versus-host-disease (GvHD) nach Knochenmarkstransplantation,

- Toxische oder irritative Auslöser: inhalative Noxen, Medikamente, Bestrahlung,

- Zustand nach Autoimmunreaktionen,

- in Assoziation mit interstitiellen Lungenerkrankungen,

- rezidivierende Aspirationen z. B. im Rahmen eines Refluxes.

Pathogenese und Pathophysiologie. Für das Krankheitsbild ist hauptsächlich eine Einschränkung der Sauerstoffaustauschfläche durch fibröse Umwandlung und Vernarbung der bronchioalveolären Einheit verantwortlich. Die Ursache dieser Defektheilung ist unklar. Möglicherweise spielen lokal wirksame Faktoren (Chemokine, Zytokine, Interleukine) eine entscheidende Rolle. Dies zeigt sich auch durch die bekannte Beeinflussung diser Gewebsreaktion durch Steroide, wie man sie bi der akuten Abstoßungsreaktion kennt.

8 Der Verdacht auf eine Bronchiolitis obliterans muss gestellt werden, wenn sich nach einer akuten Bronchitis/Bronchiolitis eine auf Bronchodilatatoren resistente fixierte Obstruktion mit Sauerstoffabhängigkeit entwickelt.

Klinik. Eine »nicht ausheilende obstruktive Bronchitis« mit Beschwerden wie einem überwiegend expiratorisches Giemen (»wheezing«), rascher Erschöpfbarkeit mit Anstrengungsdyspnoe und ggf. begleitender Zyanose oder einem Sauerstoffbedarf können Ausdruck einer Bronchiolitis obliterans sein. Initial sind die Symptome oft unspezifisch. Der Verlauf der Erkrankung kann schleichend oder rasch progredient sein.

Diagnose. Neben der klinischen Symptomatik können bei der klinischen Untersuchung folgende Befunde auffallen: leises Atemgeräusch, obstruktiver Auskultationsbefund, Tachypnoe, Dyspnoe, verminderte transkutane Sauerstoffsättigung. In der Lungenfunktionsprüfung zeigt sich eine Reduktion der exspiratorischen Flussraten, in der Blutgasanalyse sieht man eine Hypoxie und ggf. Hyperkapnie. In der konventionellen Röntgen-Thoraxaufnahme können Dys- oder Atelektasen oder eine Überblähung auffallen. Wegweisend ist die CT-Thoraxuntersuchung: Hier zeigt sich ein charakteristisches mosaikartiges Verteilungsmuster mit z. T. konsolidierten und z. T. überblähten Lungenarealen. Die definitive Diagnose kann mit Hilfe einer Lungenbiopsie erfolgen. Oft ist hierbei jedoch die Sensitivität einer transbronchialen Biopsie nur sehr niedrig, die offene Lungenbiopsie geht mit einer nicht unerheblichen Morbidität einher.

Differenzialdiagnostisch kommen eine protrahierte bakterielle Superinfektion nach akuter Bronchiolitis sowie andere seltene chronische Lungenerkrankungen wie z. B. die idiopathische Lungenfibrose in Betracht.

Therapie. Initial muss versucht werden, den Auslöser der Erkrankung zu identifizieren und ggf. zu beseitigen. Hierunter fallen vor allem die exogen ausgelösten Formen der Erkrankung (Medikamente, Noxen, Aspirationen). In der Regel wird nach Sicherung der Diagnose ein initialer Therapieversuch mit systemischen Steroiden (Prednison 2-4 mg/kg KG/Tag) über 4-6 Wochen vorgenommen. Therapeutische Alternativen stellen z. B. der Einsatz von Cyclophosphamid oder Ciclosporin dar. Im Management der Bronchiolitis obliterans nach Lungentransplantation wird dem Makrolid Azithromycin eine therapeutische Wirkung zugeschrieben.

Prognose. Die Prognose einer Bronchiolitis obliterans als Ausdruck einer chronischen Abstoßungsreaktion nach Lungentransplantation ist ernst. Günstiger sind Verläufe nach viral bedingter akuter Bronchiolitis. Allerdings erstrecken sich die Reparationsprozesse über Monate bis Jahre.

\subsection{Bronchiektasen}

\section{W. Leupold}

Definition. Bronchiektasen sind irreversible Erweiterungen der Bronchien, die entsprechend ihrer Morphologie als zylindrisch, sackförmig oder varikös beschrieben werden.

Sie sind von Bronchialdilatationen und der deformierenden Bronchitis (Wandunregelmäßigkeiten der Bronchien) abzugrenzen, da diese reversibel sein können. Ursache der Erweiterung ist eine angeborene (selten!) oder erworbene Destruktion der Bronchialwand, die mit einer chronischen Bronchitis und dem Verlust der bronchoziliären Clearance verbunden ist. Bronchiektasen können lokalisiert oder generalisiert auftreten.

Epidemiologie. Genaue Angaben zur Häufigkeit von Bronchiektasen sind schwer zu machen, da asymptomatische und Patienten mit milden Beschwerden oft gar nicht untersucht werden sowie gelegentlich auch unterschiedliche Definitionen in Gebrauch sind. Die Inzidenz ist sehr niedrig, sie soll in Industrieländern gegenwärtig bei 0,1 pro 100.000 Kinder liegen. In bronchopneumologischen Spezialambulanzen leiden 1-2\% der betreuten Kinder an Bronchiektasen.

Die Erkrankungshäufigkeit ist in den letzten Jahrzehnten deutlich rückläufig. Das wird überwiegend auf den Rückgang von Tuberkulose, Masern und Keuchhusten sowie die bessere Behandlung der Infektionen der tiefen Atemwege zurückgeführt (Breitbandantibiotika).

Pathogenese. Der wesentliche Grundmechanismus scheint das Wechselspiel zwischen Infektion und Obstruktion zu sein, wobei 
deren Ausgangspunkt auf unterschiedlichen Ebenen liegen kann (• Tabelle 22.13). Beide Faktoren beeinflussen sich gegenseitig und münden schließlich in einen Circulus vitiosus mit chronischer Entzündung und Destruktion der Bronchialwand, exspiratorischem Kollaps, erhöhtem mechanischen Zug des Lungenparenchyms, Ausbildung von Atelektasen und Pneumonien. Im weiteren Verlauf kommt es zum peribronchialen fibrotischen Umbau mit Schrumpfung und Funktionsverlust der befallenen Lungenareale.

Angeborene Bronchiektasen sind sehr selten und scheinen im Rahmen einer Entwicklungsabnormalität mit zystischer Deformierung der Atemwege zu entstehen.

Klinik. Bis auf einzelne Patienten mit symptomlosen Bronchiektasen sind folgende Symptome typisch:

- Husten (besonders morgens),

- Auswurf,

- giemende/pfeifende Atmung,

- Thoraxschmerz,

- Hämoptysis,

- Dyspnoe.

Diagnose. Bei der klinischen Untersuchung findet man in der Regel konstant Rasselgeräusche über der betroffenen Region, die auch nach Hustenmanövern nicht verschwinden. Bei ausgeprägten Bronchiektasen leiden auch Gewichts- und Größenentwicklung, und es sind Zeichen der Hypoxämie (Zyanose, Uhrglasnägel, Trommelschlegelfinger) zu beobachten.

Die Thoraxübersichtsaufnahme trägt meist nur wenig zur Aufklärung bei. Eine vermehrte Streifenzeichnung und so genannte Doppelkonturierungen (Darstellung der verdickten Bronchialwände) sind indirekte Hinweise. Der Nachweis von Bronchiektasen gelingt in der Regel mit der HR-Computertomographie. Eine Bronchographie ist im Einzelfall zu erwägen, wenn es - besonders vor geplanter Operation - um die Darstellung von Ausmaß, Form und anatomischen Beziehungen der Veränderungen geht.

Differenzialdiagnose. Das Leitsymptom »chronisch produktiver Husten« wird häufig als chronische Bronchitis gedeutet. Diese beruht im Kindesalter in der Regel auf einer Grunderkrankung (- Tabelle 22.14), nach der mit entsprechenden Methoden gefahndet werden muss.

Therapie. Bei lokalisierten, poststenotischen Prozessen (z. B. nach Fremdkörperaspiration) wird man sich schneller zu einer Segment- oder Lappenresektion entschließen, da die übrige Lunge in der Regel gesund ist (muss nachgewiesen werden), die Kinder danach geheilt sind und ihnen eine Langzeittherapie erspart werden kann.

Bei generalisierten Bronchiektasen ist eine konservative Therapie angezeigt mit dem Ziel, die Bronchien möglichst frei von Sekret und bakteriellen Infektionen zu halten. Der Sekretentfernung dienen Sekretolytika oral und inhalativ, Inhalationen mit $\mathrm{NaCl}$ (auch hyperton) und $\beta$-Sympathomimetika. Ebenso bedeutsam ist die kontinuierliche Durchführung einer Physiotherapie (autogene Drainage, Flutter, Vibrationsmassage).

Antibiotika sollten gezielt - nach Antibiogramm - oder kalkuliert bei akuten Exazerbationen eingesetzt werden. Vorliegende Grunderkrankungen müssen zusätzlich behandelt werden (z. B. Immundefekte).
- Tabelle 22.13. Ursachen für Sekretstau und Entzündung bei der Entstehung von Bronchiektasen

\begin{tabular}{|c|c|c|}
\hline $\begin{array}{l}\text { Angeborene } \\
\text { Erkrankungen der } \\
\text { Bronchialwand }\end{array}$ & $\begin{array}{l}- \\
-\end{array}$ & $\begin{array}{l}\text { Bronchusstenosen /-malazien } \\
\text { Mukoviszidose } \\
\text { Kartagener-Syndrom/Syndrom der im- } \\
\text { motilen Zilien }\end{array}$ \\
\hline $\begin{array}{l}\text { Erworbene } \\
\text { Störungen der } \\
\text { Bronchialwand }\end{array}$ & $=$ & $\begin{array}{l}\text { Pertussis, Masern } \\
\text { Infektion mit Adenoviren, Herpesviren, } \\
\text { Mykoplasmen, Aspergillus fumigatus }\end{array}$ \\
\hline $\begin{array}{l}\text { Erworbene } \\
\text { Bronchusstenosen }\end{array}$ & $\begin{array}{l}- \\
-\end{array}$ & $\begin{array}{l}\text { Tuberkulose } \\
\text { Fremdkörper } \\
\text { Tumoren }\end{array}$ \\
\hline $\begin{array}{l}\text { Andere Grunder- } \\
\text { krankungen }\end{array}$ & $\begin{array}{l}= \\
=\end{array}$ & $\begin{array}{l}\text { Asthma bronchiale (intrinsic) } \\
\text { Immundefekte } \\
\text { Persistierende Atelektasen } \\
\text { Intoxikationen (Lampenöl, Heroin) }\end{array}$ \\
\hline
\end{tabular}

- Tabelle 22.14. Erkrankungen mit dem Symptom »chronischer, produktiver Husten« bei Kindern

\begin{tabular}{|l|l|}
\hline Entzündliche Lungenerkrankungen & $\begin{array}{l}\text { Angeborene } \\
\text { Lungenerkrankungen }\end{array}$ \\
\hline - Bronchiektasen & - Mukoviszidose \\
- Tuberkulose & - Ziliendyskinesie \\
- Lungenabszess & - Bronchiektasen \\
- Bronchopulmonale Aspergillose & - Lungenzysten \\
- Chronischer Fremdkörper &
\end{tabular}

Prognose. Die Prognose ist vom Ausmaß der Erkrankung abhängig. Unilokuläre Bronchiektasen beeinträchtigen die Lebenserwartung praktisch nicht mehr bzw. können durch eine Resektion völlig beseitigt werden. Bei multilokulärem Befall ist die Prognose mit der heute möglichen antibiotischen und intensiven Physiotherapie ebenfalls sehr gut, wenn nicht eine besondere Grundkrankheit (z. B. Mukoviszidose) vorliegt.

\subsection{Interstitielle Lungenerkrankungen}

$$
\text { M. Kopp }
$$

Grundlagen. Interstitielle Lungenerkrankungen fassen eine heterogene Gruppe von Lungenerkrankungen unterschiedlicher Ursachen zusammen, die im Kindesalter insgesamt jedoch selten sind. Gemeinsam ist diesen Erkrankungen eine Lungenfibrose im Endstadium. In - Tab. 22.15 sind die Erkrankungen mit interstitieller Lungenbeteiligung aufgeführt. Epidemiologische Daten über die exakte Prävalenz im Kindesalter fehlen.

Pathogenese. Diese ist in den meisten Fällen nicht geklärt. Ein Nebeneinander von akuten und chronischen Entzündungszeichen mit fokaler oder diffuser Infiltration der Lunge und Fibrosebildung im Interstitium und in den Alveolarsepten charakterisieren das histologische Bild.

Pathophysiologie. Die Entzündung und Fibrose des Interstitiums führen zu dem charakteristischen interstitiellen Muster, das vor allem radiologisch auffällt und zur Verdachtsdiagnose führt. Ein fein- oder grobretikuläres Muster dominiert das Lungenröntgen- 
- Tabelle 22.15. Interstitielle Lungenerkrankungen (Erkrankungen mit interstitieller Beteiligung der Lunge)

Idiopathische Formen

- Idiopathische, diffuse Lungenfibrose (Hamman-Rich-Syndrom)

- Idiopathische Lungenhämosiderose mit Lungenfibrose inkl. Herz- oder Nierenbeteiligung (Goodpasture-Syndrom)

- Interstitielle lymphoplasmazelluläre Pneumonie Liebow

Begleitformen bei

- Allergischer Alveolitis (exogen allergische Alveolitis)

- Zystischer Fibrose

- Nach Lipidaspiration (Ölaspirationspneumonie)

- Sarkoidose

- Phakomatosen (tuberöse Hirnsklerose, Sturge-Weber)

- Xanthomatosen (Hand-Schüller-Christian, Gaucher, NiemannPick, Abt-Letterer-Siwe, Amyloidose)

- Kollagenosen/rheumatische Erkrankungen: Sklerodermien, LE, Periarteriitis nodosa, Dermatomyositis, rheumathoide Arthritis

- Pneumonien mit interstitieller Beteiligung: Viren (Masern, Varizellen, Zytomegalie, kong. Röteln), Mykoplasmen, Chlamydien, Toxoplasmose, Treponemen, Listerien

bild, wobei aber auch granuläre oder mikro- und makronoduläre Bilder gesehen werden. Unter desquamativer interstitieller Pneumonie versteht man histologisch die Abschilferung von Zellen und deren Proliferation ins Alveolarlumen. Ist diese Abschilferung von einer deutlichen Infiltration und Proliferation von Lymphozyten mit Lymphfollikelbildung in den Alveolarsepten begleitet, spricht man von interstitieller lymphatischer Pneumonie (LIP), z. B. bei HIV-Infektion.

Klinik. Akuter oder langsamer Beginn mit Dyspnoe, die vor allem bei Anstrengung zuerst auffällt, Husten, Schwächezustände, evtl. Fieber und Thoraxschmerzen herrschen vor. Dies sind zwar unspezifische Symptome, müssen aber in der Differenzialdiagnose an eine interstitielle Lungenerkrankung denken lassen, insbesondere bei länger andauernder und progredienter Symptomatik. In späteren Stadien besteht dann auch Sauerstoffbedarf, zuerst bei Belastung, dann auch in Ruhe.

Diagnose. Die Diagnose wird gestellt durch Ausschluss häufigerer pulmonaler Erkrankungen wie u. a. der zystischen Fibrose, a1-Antitrypsinmangel oder einer primären ziliären Dyskinesie. Wegweisend können neben der protrahierten Beschwerdesymptomatik Veränderungen im Thorax-Röntgenbild sein. Charakteristisch sind hier eine interstitielle Zeichnungsvermehrung und später das Auftreten der »Wabenlunge« (»honey comb lung«). Initial kann das Thorax-Röntgenbild jedoch keine oder nur minimale Veränderungen aufweisen. Spezifischer ist das Lungen$\mathrm{CT}$, das retikuläre Verdichtungen und zystische Aufhellungen zeigt.

In der Lungenfunktionsprüfung sind die Vital- und Totalkapazität sowie die Compliance deutlich vermindert.

Die Blutgasanalyse zeigt insbesondere nach Anstrengung einen verminderten $\mathrm{pO}_{2}$ mit metabolisch kompensierter respiratorischer Alkalose und initial tiefem $\mathrm{pCO}_{2}$. Im terminalen Krankheitsstadium kommt es zur Hyperkapnie.

Die definitive Diagnose wird an Hand des charakteristischen histologischen Befundes nach offener Lungenbiopsie gestellt. Die Differenzialdiagnosen gehen aus - Tab. 22.15 hervor.
Therapie. Nach histologischer Sicherung der Diagnose ist die Möglichkeit der Ausschaltung eines identifizierten auslösenden Agens von entscheidender Bedeutung. Ansonsten ist die Behandlung mit systemischen Steroiden die Therapie der Wahl. Allgemein gültige Therapieschemata gibt es nicht. Als Ausweichpräparate werde Immunsuppresiva und Zytostatika eingesetzt.

Prognose. Diese ist meist als ernst zu beurteilen, besonders bei den idiopathischen Formen. Nach Pneumonien ist die Prognose deutlich besser. In der Regel wird die Prognose durch das Grundleiden bestimmt.

\subsection{Systemkrankheiten mit Beteiligung der Lunge}

$$
\text { M. Kopp, W. Leupold }
$$

\subsubsection{Sarkoidose}

Definition. Bei der Sarkoidose handelt es sich um eine chronische, mehrere Organsysteme betreffende, granulomatöse Systemerkrankung unbekannter Ätiologie. Im Kleinkindalter sind vor allem Haut, Gelenke und Augen befallen, selten findet sich eine Lungenbeteiligung. Bei Adoleszenten und Erwachsene sind Lunge, Lymphknoten und Augen involviert. Eine kardiale Beteiligung ist wegen möglicher Reizleitungsstörungen besonders ernst zu nehmen. Die Inzidenz beträgt etwa 0,29/100.000 Personenjahre.

\section{Cave}

Im Kleinkindesalter ist bei der Sarkoidose selten die Lunge betroffen. Wichtig ist es, frühzeitig eine mögliche kardiale Beteiligung zu erkennen (Rhythmusstörungen!).

Ätiologie und Pathogenese. Die Ursache der Sarkoidose ist unbekannt. Die typische Läsion besteht in einem nicht-verkäsenden Granulom, die in nahezu allen Organen des Körpers vorkommen können. Die Granulombildung wird als immunologische Reaktion auf die Präsentation eines Antigens durch Makrophagen an T-Lymphozyten angesehen.

Klinik. Neben Allgemeinbeschwerden wie Müdigkeit, Abgeschlagenheit, Gewichtsverlust (45\%) und Fieber (35\%) sind organspezifische Beschwerden charakteristisch, die in • Tab. 22.16 aufgeführt sind:

Diagnose. Zu den empfohlenen diagnostischen Maßnahmen gehören:

- Anamnese und körperliche Untersuchung mit Fokus auf die Organsysteme Haut, Auge, Lymphknotenstatus, Lunge, Herz, Leber und Gelenkstatus,

- Augenärztliche Untersuchung,

- Blutbild und klinische Chemie. Charakteristisch sind eine erhöhte Blutsenkung, Hyperkalzämie, Hypergammaglobulinämie, Hyperkaliämie, erhöhte alkalische Phosphatase. So genannte Aktivitätsmarker wie die Bestimmung von ACE (»angiotensin converting enzyme«) sind unspezifisch, die Wertigkeit im Kindesalter ist unklar.

- Röntgen-Thorax und Lungenfunktion. Hier findet sich überwiegend eine restriktive Ventilationsstörung (50\%), seltener eine Obstruktion (15\%), 


\begin{tabular}{|c|c|}
\hline Organ & Symptome \\
\hline Augen & $\begin{array}{l}\text { Granulomatöse Uveitis mit Rötung, tränenden } \\
\text { Augen und Lichtscheu (etwa } 25 \% \text { ) } \\
\text { Konjunktivaler Befall mit blassgelben Knötchen }\end{array}$ \\
\hline Parotis & $\begin{array}{l}\text { Parotitis (gemeinsam mit Uveitis auch als Heer- } \\
\text { fordt-Syndrom bekannt) }\end{array}$ \\
\hline Lymphknoten & Periphere Lymphadenopathie (40 \%) \\
\hline Haut & $\begin{array}{l}\text { Erythema nodosum (etwa } 30 \text { \%) } \\
\text { Papulöse, nodöse z. T. plaqueförmige Hautver- } \\
\text { änderungen, oft im Gesicht } \\
\text { Makulopapuläre Hautrötung (Kleinkinder) }\end{array}$ \\
\hline Lunge & $\begin{array}{l}\text { Husten } \\
\text { Restriktive Ventilationsstörung, selten begleiten- } \\
\text { de obstruktive Ventilationsstörung } \\
\text { Charakteristisches Thorax-Röntgenbild mit bila- } \\
\text { teraler hilärer Lymphknotenvergrößerung }\end{array}$ \\
\hline Herz & Rhythmusstörungen (30 \% der Erwachsenen) \\
\hline Leber, Milz & $\begin{array}{l}\text { Hepatosplenomegalie } \\
\text { Transaminasenerhöhung }\end{array}$ \\
\hline Muskel/Skelett & $\begin{array}{l}\text { (Monoartikuläre) Arthritis } \\
\text { Gelenkschmerzen, Erguss }\end{array}$ \\
\hline $\begin{array}{l}\text { Neurologische } \\
\text { Symptome }\end{array}$ & $\begin{array}{l}\text { Kopfschmerzen ( } 20 \% \text { ) } \\
\text { Periphere Neuropathie, Hydrozephalus }\end{array}$ \\
\hline Labor & Hyperkalzämie und Hyperkalziurie \\
\hline
\end{tabular}

- EKG und Echokardiographie,

- Biopsie.

$>$ Die Diagnose muss mittels Biopsie gesichert werden. Diese kann an Lymphknoten, an der Haut, in der Lunge oder der Leber erfolgen.

Differenzialdiagnose. Diese ist aufgrund des Mutliorgangeschehens äußerst groß. Alle möglichen Erkrankungen, die mit einer hilären Adenopathie (• Abb. 22.10) mit oder ohne pulmonale Infiltrate einhergehen, sind in Betracht zu ziehen. Ein malignes Geschehen ist primär bioptisch auszuschließen. Nicht verkäsende Granulome können bei sehr vielen Erkrankungen vorkommen: bei Mykobakteriosen, Lymphomen, allergischer Alveolitis, Toxoplasmose, Pilzinfektionen, Katzenkratzkrankheit, chronischer Granulomatose, Histiozytosis X, Polyarthritis, Morbus Crohn, Wegener-Granulomatose, um nur einige zu erwähnen.

Therapie. Die Behandlung richtet sich nach dem Befall der Lunge, des Herzens und der Augen. Steroide sind Therapie der Wahl. Man beginnt i. d. R. mit einer Prednisontherapie mit $1 \mathrm{mg} / \mathrm{kg}$ KG/Tag und reduziert die Dosis über mehrere Monate, sobald die klinischen Beschwerden zurückgehen. Weitere Optionen sind die Therapie mit Methotrexat oder Azathioprim. Im Kindesalter fehlen jedoch kontrollierte Studien über entsprechende therapeutische Effekte.

Prognose. In einer Gruppe von knapp 50 dänischen Kindern mit Sarkoidose kam es bei 78 \% nach 6 Monaten bis etwa 6 Jahren zu einer kompletten Remission. $11 \%$ hatten weiterhin eine chro-

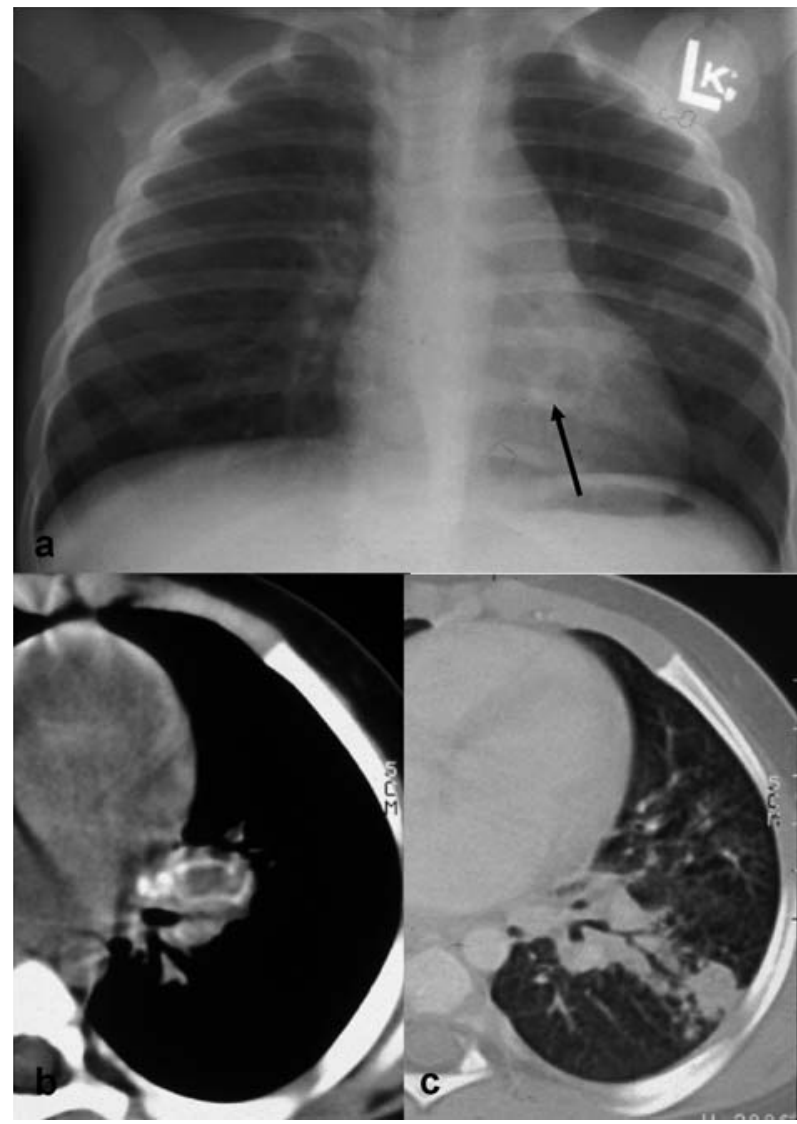

- Abb. 22.10. Hiläre Adenopathie mit Verkalkungen links bei Primärkomplex einer pulmonalen Tuberkulose. Im Röntgenbild (a) kaum sichtbar links retrokardial. Im CT Nachweis von verkalkten Lymphknoten (b) und Primärherd (c) in linken Unterlappen

nisch-aktive Sarkoidose. In dieser Population ging das Erythema nodosum mit einer günstigen Prognose einher.

\subsubsection{Neuromuskuläre Erkrankungen und Ateminsuffizienz}

\section{Grundlagen}

Von respiratorischer Globalinsuffizienz spricht man, wenn paO2 erniedrigt und paCO2 erhöht ist. Bei einer Partialinsuffizienz findet sich eine Hypoxämie aber noch keine Hyperkapnie.

Ätiologie. Eine Ateminsuffizienz kann bei fast allen krankhaften Zuständen vorkommen; sie kann auftreten wegen:

- des Versagens der respiratorischen Kontrolle (Atemantrieb und Ventilation),

- der Insuffizienz der Mechanik (Ventilation),

- der Beeinträchtigung der Lunge selbst (Oxygenation).

Die häufigen Ursachen einer Ateminsuffizienz sind in • Tabelle 22.17 aufgeführt.

Pathogenese und Pathophysiologie. Allen Formen der Ateminsuffizienz ist terminal eine schwere alveoläre Hypoventilation gemeinsam. Diese entsteht entweder auf direktem Weg durch eine Lähmung der Atemmuskulatur oder durch eine zentrale Störung 


\begin{tabular}{l|l|l}
\hline \multicolumn{2}{l}{ - Tabelle 22.17. Ursachen der Ateminsuffizienz } \\
\hline $\begin{array}{l}\text { Respiratorische } \\
\text { Kontrolle }\end{array}$ & Mechanik & Lunge \\
$\begin{array}{l}\text { (Atemantrieb, } \\
\text { Ventilation) }\end{array}$ & (Ventilation) & (Oxygenation) \\
\hline $\begin{array}{l}\text { Intoxikationen } \\
\text { (Medikamente) }\end{array}$ & Kyphoskoliose & Asthma \\
\hline ZNS-Läsion (Medulla) & Rippenserienfraktur & Pneumonie \\
\hline Adipositas (Apnoe) & Adipositas & Zystische Fibrose \\
\hline $\begin{array}{l}\text { Metabolische } \\
\text { Störungen }\end{array}$ & Poliomyelitis & Interstitielle Fibrose \\
\hline Schädel-Hirn-Trauma & Muskeldystrophien & Lungenödem \\
\hline Hirndruck (Tumoren) & $\begin{array}{l}\text { Guillain-Barré- } \\
\text { Syndrom }\end{array}$ & Aspiration \\
\hline Tetanus & Para-Tetraplegie & $\begin{array}{l}\text { Hyaline Membranen, } \\
\text { ARDS }\end{array}$ \\
\hline
\end{tabular}

des Atemantriebes oder auf indirektem Weg über eine konsumierende Grundkrankheit mit progredienter Einschränkung der Funktion der Atemhilfsmuskulatur (z. B. bei schwerer Kyphoskoliose mit Atelektase und Belüftungsstörung).

Damit unterscheiden wir als Ursache für die Hypoventilation eine Form mit mechanischer Behinderung oder eine Form mit neuromuskulärer Behinderung. Da die alveoläre Hypoventilation nicht schlagartig auftritt, sondern sich über Jahre entwickelt (z.B.. bei Muskeldystrophie, Polio, Skoliosen etc.), kann sich der Körper an die sich langsam entwickelnde Hypoxämie und Hyperkapnie gewöhnen. Das Zusammenspiel von Atemkontrolle über die Chemorezeptoren und das Atemzentrum, die Aufrechterhaltung der Thoraxbeweglichkeit über die mechanische Pumpe (Muskeln, Zwerchfell, Skelett) und die Funktionstüchtigkeit des Gasaustauschapparates (Ventilation, Diffusion, Perfusion) sind komplexer Natur und von entscheidender Bedeutung zum Überleben. Auf jeder Stufe dieses Steuerungsapparats kann ein Defekt oder Teilausfall vorkommen und in der Kette der ineinander greifenden Prozesse zu einer Ateminsuffizienz führen. Nicht zu vergessen ist, dass sich fast immer auch eine Herzinsuffizienz einstellt, die mit der Ateminsuffizienz parallel entsteht.

Klinik. Bei langsam sich einstellender Insuffizienz der Atmung sind zuerst vor allem bei Anstrengung Symptome zu erwarten, die sich in einem Leistungsabfall oder -knick, in Müdigkeit, vermehrtem Schlafbedürfnis am Tag, Unruhe, Schwitzen, Zittern, Angstgefühl und Depression, Tachy- und Dyspnoe äußern. Später kommen Ruhedyspnoe, Gewichtsverlust, rezidivierende (Stress-) Ulzera des Magen-Darm-Kanals, Zyanose, Ödeme, Kopfschmerzen, Schwindelanfälle und Bewusstlosigkeit dazu.

D Cave

Jede Art einer akuten Komplikation, sei diese infektiöser, pulmonaler, kardialer oder neurogener Ursache, können für den Patienten lebensbedrohlich werden.

Diagnose. Die Werte der Blutgase, evtl. tags und nachts, geben Auskunft über den Schweregrad der Hypoventilation. Bei einer Hyperkapnie $\left(\mathrm{p}_{\mathrm{a}} \mathrm{CO}_{2}>45 \mathrm{mmHg}\right.$ ) ist immer eine Mangelbelüf- tung der Alveolen vorhanden. Als Verlaufsparameter kann die in Abständen gemessene transkutane $\mathrm{O}_{2}$-Sättigung verwendet werden.

Die Lungenfunktion kann Auskunft geben über die Restkapazität der Lunge, wobei vor allem die statischen Lungenvolumina interessieren: so findet man eine Verminderung der Vitalkapazität (VC), eine restriktive Ventilationsstörung (FVC, TLC, FRC vermindert) als Ausdruck der verminderten muskulären Dehnung des Thorax. In Zeiten von zusätzlich komplizierenden Infekten kommt dann eine Obstruktion dazu, die auf die vermehrte Sekretstase als Folge der verminderten Exspirationskraft (Husten) zurückzuführen ist.

Im EKG zeigen sich die Zeichen des Cor pulmonale, das Röntgenbild gibt z. B. Auskunft über das Ausmaß einer Minder- oder Unterbelüftung (Atelektasen, Infiltration). Terminal wird meist ein pulmonaler Infekt das Schicksal des Patienten bestimmen.

Differenzialdiagnose. Diese ist sehr breit und in • Tabelle 22.17 in reduzierter Form dargestellt. Nicht eingeschlossen sind Formen der neonatalen Fehlbildungen, die schon sehr früh zur Ateminsuffizienz und zum Tod führen können. Nicht aufgeführt sind auch alle Formen der angeborenen Fehlbildungen der Lunge, wie z. B. Hypoplasien, Aplasien, Sequester etc., die auch mit Ateminsuffizienz verbunden sein können.

Therapie. Von Bedeutung sind der Entstehungsmechanismus und die Geschwindigkeit des Auftretens der Ateminsuffizienz. Generell ist die Sicherstellung der Atmung »per se« mit Gabe von Sauerstoff, Atemhilfe mit Ventilation (Maskenbeatmung, Intubation) und Sicherstellung genügender $\mathrm{O}_{2}$-Träger (Erythrozyten) zu garantieren. Das Ziel ist, die alveoläre Hypoventilation zu beheben. Das weitere Vorgehen richtet sich aber immer nach den Ursachen der Ateminsuffizienz: die Therapiebedürftigkeit bei langsam sich entwickelnder Ateminsuffizienz, z. B. als Folge einer Muskeldystrophie, richtet sich dann nach den Blutgasanalysewerten, der verbleibenden Vitalkapazität und dem subjektiven Befinden des Patienten und erstreckt sich über die Verabreichung von $\mathrm{O}_{2}$ mittels Nasenkatheter bis zur mechanischen Beatmung. Heute kommen verschiedene Methoden der Atemhilfe wie z. B. nasaler CPAP (»continuous positive airway pressure») bis zur Heimbeatmung infrage.

Prognose. Diese richtet sich nach der Grundkrankheit und deren Progression. Die akute Ateminsuffizienz z. B. als Folge eines Unfallgeschehens ist anders zu beurteilen als diejenige bei progressiver Muskeldystrophie, bei hoher Querschnittslähmung oder bei zystischer Fibrose.

\subsection{Aspiration}

$$
\text { M. Kopp }
$$

Aspiriert werden können Flüssigkeiten und Fremdkörper. Die Schwere der Beeinträchtigung der Lungenfunktion und damit auch des klinischen Zustandsbildes wird entscheidend geprägt durch:

- die Art des aspirierten Materials (z. B. Mageninhalt, infiziertes Fruchtwasser, Nahrung),

- die Menge, Größe und Beschaffenheit des aspirierten Materials (z.B. fest, flüssig, obstruierend),

- das Alter und eine eventuelle Vorschädigung des Kindes. 


\subsubsection{Fremdkörperaspiration}

Definition. Als Fremdkörperaspiration wird jede unbeabsichtigte Inhalation fester Gegenstände in den Tracheobronchialbaum bezeichnet.

Epidemiologie. Die Aspiration von Fremdkörpern ist bei Kindern im Alter von 6 Monaten bis zu 4 Jahren kein allzu seltenes Ereignis. Bevorzugtes Alter ist das 2. und 3. Lebensjahr (ca. 50\% der Ereignisse).

Epidemiologie. Bevorzugtes Alter für die Fremdkörperaspiration ist das 2. und 3. Lebensjahr (ca. 50\% der Ereignisse im Kindesalter). Etwa 85 \% der Ereignisse treten bis zum 5. Lebensjahr auf.

Pathogenese. Die Art der aspirierten Fremdkörper ist sehr vielfältig. Am häufigsten sind vegetabile Fremdkörper (Erdnüsse), danach folgen Gegenstände aus Kunststoff (Spielzeugteile), Gummi oder metallische Fremdkörper (Schrauben) (• Abb. 22.11).

Ältere Säuglinge und Kleinkinder stecken die verschiedensten kleinen Gegenstände gerne in den Mund. Eine Aspiration kann ohne äußeren Anlass erfolgen. Häufig sind aber plötzliche Gemütsreaktionen (Schreck, Freude) der Auslöser für das Ereignis. Statt zu schlucken, setzt das Kind zum Schreien an: Mit dem ersten, tiefen Atemzug gelangt der Fremdkörper dabei in die tiefen Atemwege.

Pathophysiologie. Obwohl kleinere Partikel bis in die Subsegmentbronchien gelangen können, liegen die allermeisten Gegenstände doch in den Haupt- und Zwischenbronchien, wobei die rechte Seite etwas häufiger betroffen ist (Abgang steiler!). In der Regel kommt es durch den Fremdkörper zu einer Obstruktion der Atemwege, wobei unterschiedliche Mechanismen zu beobachten sind. Wird das Lumen nicht vollständig verschlossen, bildet sich meist eine Ventilstenose aus, die zu einer distalen Überblähung führt. Bei vollständigem Verschluss (primär oder allmählich durch entzündliche Anschwellung der Schleimhaut) kommt es zu einer distalen Minderbelüftung bzw. Atelektase.

$>$ Bei einer akuten Hustensymptomatik muss immer auch an die Möglichkeit einer Fremdkörperaspiration gedacht werden! Meistens haben die Eltern dabei ein Aspirationsereignis nicht selbst beobachtet.

Klinik. Oft tritt unmittelbar nach der Aspiration ein akuter, anfallsartiger Reizhusten auf. Daneben können Stridor, Dyspnoe

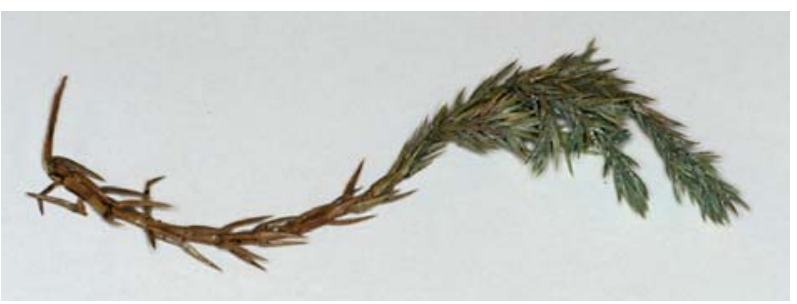

- Abb. 22.11. Die Aspiration eines Tannenzweiges in den rechten Unterlappenbronchus hat bei einer 4-jährigen Patientin zu einer protrahierten Symptomatik mit Husten und rezidivierenden, hochfieberhaften Pneumonien geführt. Bronchoskopisch konnte dieser organische Fremdkörper aufgrund seiner Mazeration nur partiell entfernt werden, so dass in diesem Fall schließlich eine Operation mit Lobektomie notwendig wurde
- Tabelle 22.18. Die häufigsten Symptome und radiologischen Befunde bei Kindern mit einer gesicherten Fremdkörperaspiration

\begin{tabular}{l|l|l|l}
\hline $\begin{array}{l}\text { Klinische } \\
\text { Symptome }\end{array}$ & Häufigkeit & $\begin{array}{l}\text { Radiologische } \\
\text { Befunde }\end{array}$ & Häufigkeit \\
\hline Husten & $50 \%$ & Atelektase & $14 \%$ \\
\hline Fieber & $30 \%$ & Air trapping & $64 \%$ \\
\hline Kurzatmigkeit & $26 \%$ & Pneumonie & $13 \%$ \\
\hline »Wheezing« & $26 \%$ & $\begin{array}{l}\text { Sichtbarer } \\
\text { Fremdkörper }\end{array}$ & $4 \%$ \\
\hline $\begin{array}{l}\text { Ohne initiale } \\
\text { Beschwerden }\end{array}$ & $2 \%$ & $\begin{array}{l}\text { Unauffälliger } \\
\text { Befund }\end{array}$ & $12 \%$ \\
\hline
\end{tabular}

und ggf. auch eine Zyanose beobachtet werden (•Tab. 22.18). Akut kann es durch eine Verlegung von Larynx oder Trachea zu einer zum Tode führenden Asphyxie kommen. Diese oft dramatische Initialsymptomatik kann von einem symptomarmen oder sogar symptomfreien Intervall gefolgt sein. Wird der Fremdkörper nicht unmittelbar entfernt, bilden sich Symptome einer chronischen Fremdkörperaspiration aus: durch Granulombildung und Infektion kommt es zu rezidivierenden Pneumonien mit Fieber und letztendlich zu einer Destruktion des betroffenen Lungensegmentes.

Diagnose. Bei der klinischen Untersuchung kann ein abgeschwächtes Atemgeräusch, ein hypersonorer Klopfschall bei bestehendem Ventilmechanismus bzw. ein gedämpfter Klopfschall bei einer Atelektase auffallen. Ggf. kann ein i. d. R. einseitiges Giemen auskultierbar sein.

Bei Verdacht auf Fremdkörperaspiration muss eine Röntgenaufnahme von der Zahnleiste bis zum Abdomen veranlasst werden. Bei laryngealer oder trachealer Lage ist ein Seitbild hilfreich, um eine Lage im Ösophagus auszuschließen. Da nur die wenigsten aspirierten Fremdkörper schattengebend sind, muss man auf indirekte radiologische Veränderungen achten wie einseitige Überblähung, Dys- oder Atelektase (- Tab. 22.18).

Differenzialdiagnose. Anamnese und Krankheitsbild der akuten Fremdkörperaspiration sind meist so typisch, dass kaum andere Ursachen infrage kommen. In seltenen Fällen kommen differenzialdiagnostisch infrage:

- Epiglottitis,

- Krupp,

- Asthma bronchiale,

- allergische Ödeme im Larynx,

- Pertussis,

- Nahrungsmittelallergie (Nüsse!).

Mehr differenzialdiagnostische Probleme bereitet hingegen die chronische Fremdkörperaspiration, die unter folgenden Bildern auftreten kann:

- chronische Bronchitis,

- Asthma bronchiale,

- rezidivierende Pneumonien (besonders im selben Gebiet),

- endobronchiale Tuberkulose. 
(C) Cave

Ein unauffälliger klinischer Befund und ein normales Röntgenbild schließen eine Fremdkörperaspiration nicht aus. Daher muss bei jedem begründeten Verdacht auf ein Aspirationsereignis eine Bronchoskopie durchgeführt werden!

Therapie. Jeder Verdacht auf eine Fremdkörperaspiration sollte zur sofortigen Bronchoskopie Anlass geben. Bei Kindern verwendet man dazu in der Regel ein starres Bronchoskop, mit dem die gesamten Atemwege sorgfältig abgesucht werden. Größere und feste Fremdkörper werden meist unter Sicht mit der Zange gefasst und extrahiert. Kleine Partikel können nach Spülung abgesaugt werden. Sehr selten sind chirurgische Maßnahmen zur Fremdkörperentfernung nötig.

Die Notwendigkeit einer Nachbehandlung hängt von der konkreten Situation ab. Fremdkörper, die innerhalb der ersten $24 \mathrm{~h}$ entfernt werden, hinterlassen kaum Schleimhautschäden, sodass weitere Maßnahmen nicht erforderlich sind. Ist es zu Reaktionen am Bronchialsystem gekommen, sind Inhalationen und eine Therapie mit Antibiotika zu empfehlen. Beim geringsten Verdacht auf verbliebene Fremdkörperreste bzw. bei chronischer Aspiration sind Kontrollbronchoskopien erforderlich.

Prognose. Bei zeitgerechter Extraktion des Fremdkörpers ist die Prognose gut. Bei chronischer Fremdkörperaspiration kann es zu pulmonalen Spätkomplikationen kommen, die eine regelmäßige Verlaufskontrolle (ggf. mit Kontrollbronchoskopie und/oder CT) notwendig machen.

\subsubsection{Aspiration von Flüssigkeiten}

Pathogenese. Aspirationen von Flüssigkeit treten am häufigsten in der Neugeborenenperiode auf. Bereits unter der Geburt kann es zur Fruchtwasseraspiration kommen, die besonders folgenreich ist, wenn dieses infiziert oder mekoniumhaltig ist. Neugeborene und Säuglinge neigen in stärkerem Maße zum Spucken und Erbrechen, sodass die Aspiration von Mageninhalt möglich ist. In Abhängigkeit vom pH-Wert (besonders $<3,0$ ) entwickelt sich dabei eine chemische Pneumonie (Mendelson-Syndrom). Zum gleichen Befund führt oft auch die akzidentelle Aspiration von halogenierten Kohlenwasserstoffen (z. B. Lampenöl-Intoxikation).

Prädisponiert für eine Aspiration sind auch Kinder mit angeborenen Fehlbildungen (Atresien und Stenosen im Gastrointestinaltrakt, ösophagotracheale Fisteln) und funktionellen Störungen des Schluckmechanismus (ZNS-Störungen).

Klinik. In Abhängigkeit von Art und Menge des aspirierten Materials kann das klinische Bild sehr variabel sein. Es reicht von völliger Symptomlosigkeit über Husten und Dyspnoe bis zur akuten respiratorischen Insuffizienz. Rezidivierend können pneumonische Befunde beobachtet werden.

Diagnose. Die entscheidende diagnostische Maßnahme ist die Anfertigung eines Thoraxröntgenbildes sowie die Erkennung der eventuell vorhandenen Grundkrankheit.

Therapie. Je nach Ausprägung des Befundes sind die Sicherung der Vitalfunktion und eine antibiotische Therapie erforderlich. Daneben sollte möglichst die Grundkrankheit behandelt werden.
Ist eine normale Ernährung nicht gefahrlos möglich, muss eine Nahrungszufuhr per Magensonde oder PEG erwogen werden.

\subsection{Thoraxtrauma und Erkrankungen der Pleura}

W. Leupold

Thoraxtraumata sind im Kindesalter selten und kommen bei Verkehrsunfällen, direktem Schlag oder iatrogen (Reanimation, Pleuradrainage, diagnostische Eingriffe) vor. Meist sind kombinierte Verletzungen der intrathorakalen Strukturen vorhanden.

\subsubsection{Geschlossene Brustkorbverletzungen}

Commotio und Contusio thoracis. Durch kurzzeitige Einwirkung stumpfer Gewalt entsteht eine Druckwelle, die zu einer Erschütterung der intrathorakalen Organe führt und reflektorisch ein Schockgeschehen auslösen kann. Contusionen sind darüber hinaus durch Verletzungen der Brustwand und pathologisch-anatomische Organveränderungen gekennzeichnet.

Rippenfrakturen. Einzelfrakturen sind als so genannte pathologische Frakturen im Rahmen von pathologischen Knochenprozessen möglich. Bei einem Trauma kommt es öfter aufgrund der großen Elastizität zu Infraktionen, aber auch Serienfrakturen sind möglich. Bei letzteren treten paradoxe respiratorische Bewegungen des Thorax auf (Innenbewegung der Thoraxwand bei Inspiration, Außenbewegung bei Exspiration). Schmerzen und Atemnot sind die wesentlichsten Symptome. Eine Ruhigstellung der Thoraxwand (elastischer Verband) genügt meistens.

\subsubsection{Pneumothorax}

Pathogenese und Klinik. Aufgrund des Entstehungsmechanismus unterscheidet man einen inneren und einen äußeren Pneumothorax:

- Defekt der Pleura visceralis $\rightarrow$ innerer Pneumothorax,

- Defekt der Pleura parietalis $\rightarrow$ äußerer Pneumothorax.

Ein Pneumothorax kann traumatisch bedingt sein (dabei oft auch ein Hämatothorax vorliegend), aber auch Punktionen und Biopsien an Pleura und Lunge führen gelegentlich zum iatrogenen Pneumothorax. Auch andere ärztliche Maßnahmen (Gefäßpunktionen der A. subclavia, Beatmung mit hohen Drücken) können Ursache dieses Ereignisses sein.

Ein primärer Spontanpneumothorax hat seine Ursache meistens in bisher unbekannten, apikal gelegenen, subpleuralen Zysten oder Bullae, wobei Beziehungen zu Schwankungen des atmosphärischen Drucks bestehen. Der Pneumothorax entwickelt sich meistens unter Ruhebedingungen bzw. im Rahmen von Hustenattacken. Die Patienten spüren gelegentlich einen leichten Schmerz und sind vielleicht etwas dyspnoisch. Bei der klinischen Untersuchung beobachtet man lediglich eine mäßige Tachykardie, und die Atembeweglichkeit auf der befallenen Seite ist geringer. Perkutorisch hört man hypersonoren Klopfschall, die Atemgeräusche sind vermindert oder aufgehoben. Bei primärem Spontanpneumothorax besteht ein deutlich erhöhtes Rezidivrisiko. 
Ein sekundärer Spontanpneumothorax kann im Rahmen chronischer Lungenerkrankungen (Asthma bronchiale, Mukoviszidose) oder bei einer akuten Infektion im Sinne einer (Pleuro)pneumonie auftreten.

Eine Sonderform ist der Spannungspneumothorax, bei dem aufgrund eines Ventilverschlusses im Bereich der Fistel zwar jeweils Luft bei der Einatmung in den Pleuraraum einströmt, diese aber bei der Ausatmung nicht mehr entweichen kann. Der zunehmende Überdruck verdrängt Herz und Mediastinum nach der Gegenseite, sodass die Blutzirkulation in den großen Gefäßen und die Ventilation der gesunden Seite erheblich beeinträchtigt werden.

Diagnose. Die Röntgenaufnahme des Thorax - möglichst in voller Exspiration - lässt in der Regel Art und Ausdehnung des Pneumothorax erkennen. Im Zweifelsfalle sollte eine Computertomographie erfolgen, die vor allem zur Suche von Zysten und Bullae wichtig ist. Bei Säuglingen und jungen Kindern kann auch die Durchleuchtung mit einer zentrierten starken Lichtquelle (Diaphanoskopie) diagnostisch hilfreich sein.

Therapie. Bei geringer Ausdehnung des Pneumothorax (20-25\% der Lunge betroffen), normaler Atemfrequenz und fehlender $\mathrm{Zu}$ nahme kann eine abwartende Haltung eingenommen werden. Durch kontinuierliche $\mathrm{O}_{2}$-Applikation (Nasensonde) kann der Stickstoffpartialdruck in der Lunge gesenkt und damit die $\mathrm{N}_{2}$-Absorption aus der pleuralen Luftansammlung verbessert werden.

> Bei symptomatischen Patienten, bei ausgedehnterem Pneumothorax und natürlich sofort beim Spannungspneumothorax muss eine Saugdrainage gelegt werden.

Führt diese innerhalb von 7 Tagen nicht zum gewünschten Effekt, sind invasivere Methoden indiziert (Thorakoskopie, u. U. mit Verklebung der Fistel oder Entfernung weiterer Bullae).

Prognose. Nicht selten gelangt bei einem Pneumothorax Luft durch das Lungeninterstitium in das Mediastinum und von dort bis in die Halsweichteile (Mediastinal- und Weichteilemphysem). An der Einstichstelle für den Pleurakatheter kann es ebenfalls zum Hautemphysem in der Thoraxwand kommen. Bedeutsam ist die relativ hohe Rezidivrate - bis $\mathrm{zu} 50 \%$ sowohl beim Spontan- wie vor allem beim sekundären Pneumothorax.

\subsubsection{Pleuritis}

Im Kindesalter dominieren sekundäre Miterkrankungen der Pleura bei Prozessen an anderen Organen (Lunge, Herz, Abdominalorgane) bzw. im Rahmen von Systemerkrankungen (z.B. Lupus erythematodes visceralis).

Pleuritis sicca. Diese Form der Entzündung ist gekennzeichnet durch eine geschwollene, mit Fibrinauflagerungen bedeckte Pleura, die bei den Atembewegungen aneinander reibt und typische Symptome hervorruft:

- Schmerzen bei der Atmung (einseitig),

- verminderte Atemexkursion der betroffenen Seite,

- typisches in- und exspiratorisches Reibegeräusch (Verstärkung durch Druck auf Thoraxwand, keine Beeinflussung durch Husten).
- Tabelle 22.19. Ursachen von Exsudat und Transsudat im Pleuraraum

\begin{tabular}{l|l|}
\hline Exsudat & Transsudat \\
\hline Infektiös & Herzinsuffizienz \\
Tuberkulose & Hypoproteinämie \\
- Viral, bakteriell & Leberzirrotisches Syndrom \\
\hline Pilzbedingt & Pneumothorax mit Erguss \\
Maligne & Atelektase mit Erguss \\
- Lymphome & Peritonealdialyse \\
\hline Karzinome & latrogen \\
\hline Kollagenoumien & \\
Urämie & \\
Abszess (subphrenisch) & \\
Pankreatitis & \\
Chylothorax & \\
Hämatothorax & \\
Nach Bestrahlung & \\
Sarkoidose & \\
Medikamentös &
\end{tabular}

Der Befund kann sich zurückbilden, aber auch in eine exsudative Pleuritis übergehen. Pleurareiben und Schmerz verschwinden dann oft.

Pleuritis exsudativa. Zu einer Flüssigkeitsansammlung im Pleuraraum ohne Trauma kann es entweder durch eine Erhöhung des hydrostatischen Druckes, durch eine Erniedrigung des onkotischen Druckes oder durch beide Mechanismen kommen. Flüssigkeit, die so entsteht, heißt Transsudat. Veränderungen der Pleuraoberfläche durch Entzündung, Tumor oder Infiltrationen können ohne Mitbeteiligung des onkotischen oder hydrostatischen Druckes zu einem Erguss führen. Solche Ergüsse heißen Exsudat.

Eine Übersicht über mögliche Ursachen von Exsudaten und Transsudaten gibt • Tabelle 22.19. Die größte Bedeutung haben infektiös hervorgerufene Exsudate. Dabei können die Erreger sich primär direkt an der Pleura ansiedeln und - wie bei der tuberkulösen Pleuritis - unter Vermittlung einer hyperergen Reaktion zu einem serösen Erguss führen. Häufiger liegt aber ein parapneumonischer Erguss vor, unter dem wir eine pleurale Flüssigkeitsansammlung verstehen, die topographisch und zeitlich mit einer Pneumonie, einem Lungenabszess oder Bronchiektasen assoziiert ist. Dabei kann die einfachste Form als steriler pleuraler Begleiterguss auftreten. Der komplizierte parapneumonische Erguss (Anzüchtung eines pathogenen Keimes aus der Pleuraflüssigkeit) und das Pleuraempyem (Nachweis von Eiter im Pleuraraum) gehen auf eine Invasion des Pleuraraumes durch Bakterien oder andere Erreger zurück.

Klinik. Typische Symptome und Befunde sind:

- atemabhängige, einseitige Schmerzen,

- Atemnot (inspiratorisches Stöhnen),

- Fieber,

- verminderte Atemexkursion der betroffenen Seite (Schonhaltung),

- Pleuritis sicca: atemsynchrones Reibegeräusch,

- Pleuritis exsudativa: Klopfschalldämpfung. Atemgeräusch aufgehoben oder abgeschwächtes bronchovesikuläres (»Kompressions-«) Atemgeräusch. Abschwächung der Schallleitung (Bronchophonie und Stimmfremitus). 


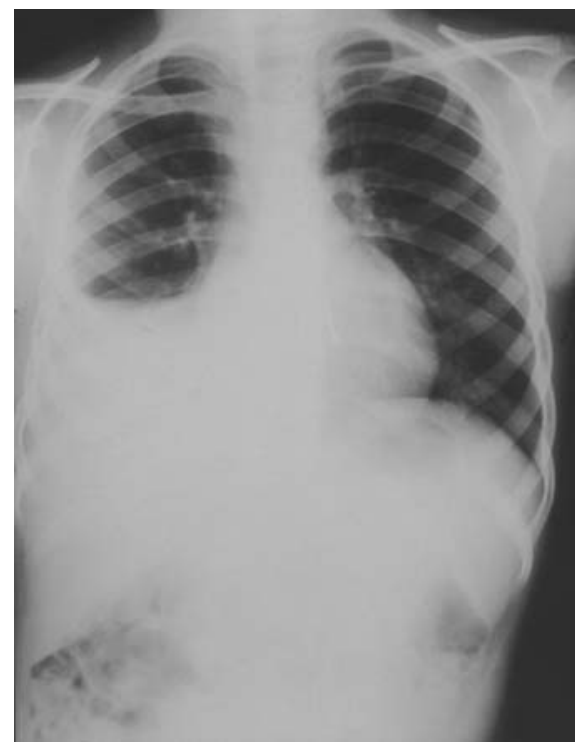

- Abb. 22.12. Pleuropneumonie im rechten Unterfeld mit Pleuraerguss bei einem Patienten mit Muskeldystrophie, Fieber, Husten, Dyspnoe

Diagnose. Im Vordergrund steht die p.-a. und seitliche Thoraxröntgenaufnahme im Stehen oder Sitzen (• Abb. 22.12). Beim frischen, nicht abgekapselten Erguss findet man meist eine seitlich ansteigende Verschattung des Lungenfeldes, die von unten nach oben abnimmt und fließend in die normale Lungenzeichnung übergeht. Aber auch nur ein kleiner Winkelerguss (bei dann meist gut sichtbarer pneumonischer Infiltration) oder aber eine homogene Totalverschattung einer Seite sind mögliche Befunde. Ein horizontaler Ergussspiegell mit darüber liegender Luftblase zeigt eine Fistel zum Bronchialsystem an.

Abgekapselte Ergüsse lassen sich mit Hilfe eines Computertomogramms besser darstellen. Dabei gelingt auch eine Abgrenzung pleuraler von pulmonalen Prozessen. Mit der Pleurasonographie kann die Ausdehnung des Ergusses (auch beliebig oft) kontrolliert und damit die günstigste Stelle für die Einlage der Pleuradrainage festgelegt werden.

Die Pleurozentese (diagnostisch oder im Rahmen der Therapie) dient der differenzialdiagnostischen Exploration des Ergusses. Zuerst muss entschieden werden, ob es sich um ein
Transsudat oder Exsudat handelt (• Tabelle 22.20). Parallel dazu müssen Erregerdiagnostik (Gramfärbung und Kultur), laborchemische Analyse (pH-Wert, Glukose, LDH, Eiweißgehalt, spezifisches Gewicht, Zellzahl und Differenzierung) veranlasst werden.

Differenzialdiagnose. Durch die Analyse der Punktionsflüssigkeit sind ein Hämatothorax und ein Chylothorax auszuschließen (- Tabelle 22.20). Die Abgrenzung eines Lungenabszesses von einem Empyem gelingt meist durch das Computertomogramm.

Therapie. Kleinere parapneumonische Ergüsse bedürfen keiner Punktion oder Drainage. Über einen Randwinkelerguss hinausgehende Flüssigkeitsansammlungen sollten zur weiteren Diagnostik punktiert werden. Die Entscheidung zur Anlage einer Thoraxdauerdrainage kann dann anhand des makroskopischen Bildes (Eiter?), der mikrobiellen sowie der laborchemischen Analyse der Ergussflüssigkeit gefällt werden. Bei kompliziertem parapneumonischem Erguss bzw. Empyem liegt eine entsprechende Indikation vor. Dabei kann auch eine Spül-Saug-Drainage sinnvoll sein.

Die antibiotische Grundbehandlung richtet sich nach dem nachgewiesenen oder vermuteten Erreger des pleuropneumonischen Prozesses.

Prognose. Die Prognose - selbst des Pleuraempyems - ist im Kindesalter meist gut, wenn die Grundkrankheit behandelbar ist. Pleuraschwarten, die anfangs durchaus zu Skoliosen führen können, bilden sich in der Regel sehr gut zurück. Dekortikationen sind praktisch nicht mehr nötig.

\subsection{Tumoren der Lunge und der Pleura}

$$
\text { M. Kopp }
$$

Primäre Tumoren der Lunge und der Pleura sind im Kindesalter sehr selten.

\subsubsection{Gutartige Neoplasien}

Das Fibroxanthom ist ein entzündlicher Pseudotumor. Der Altersgipfel liegt zwischen 8 und 12 Jahren. Nur etwa die Hälfte der

- Tabelle 22.20. Differenzialdiagnose der Flüssigkeitsansammlung im Thorax

\begin{tabular}{l|l|l|l|l} 
& \multicolumn{2}{l}{ Hydrothorax } & Hämatothorax & Chylothorax \\
& Transsudat & Exsudat & & Milchig \\
\hline Farbe & Durchsichtig & Trüb & Blutig & Lymphozyten \\
\hline Zellzahl & $<1.000 / \mathrm{mm}^{3}$ & $>1.000 / \mathrm{mm}^{3}$ & Viele & $2-6 \mathrm{~g} / \mathrm{dl}$ \\
\hline Gesamteiweiß & $<3 \mathrm{~g} / \mathrm{dl}$ & $>3 \mathrm{~g} / \mathrm{dl}$ & $4-8 \mathrm{~g} / \mathrm{dl}$ & $>1.016$ \\
\hline Spez. Gewicht & $<1.016$ & $>1.016$ & $>1.016$ & $>0,5$ \\
\hline Eiweißquotient ${ }^{\mathrm{a}}$ & $<0,5$ & $>0,5$ & $>0,5$ & Serumwert \\
\hline LDH & $<200 \mathrm{IU}$ & $>200 \mathrm{IU}$ & Serumwert & $>0,6$ \\
\hline LDH-Quotient ${ }^{\mathrm{b}}$ & $<0,6$ & $>0,6$ & $>0,6$ &
\end{tabular}




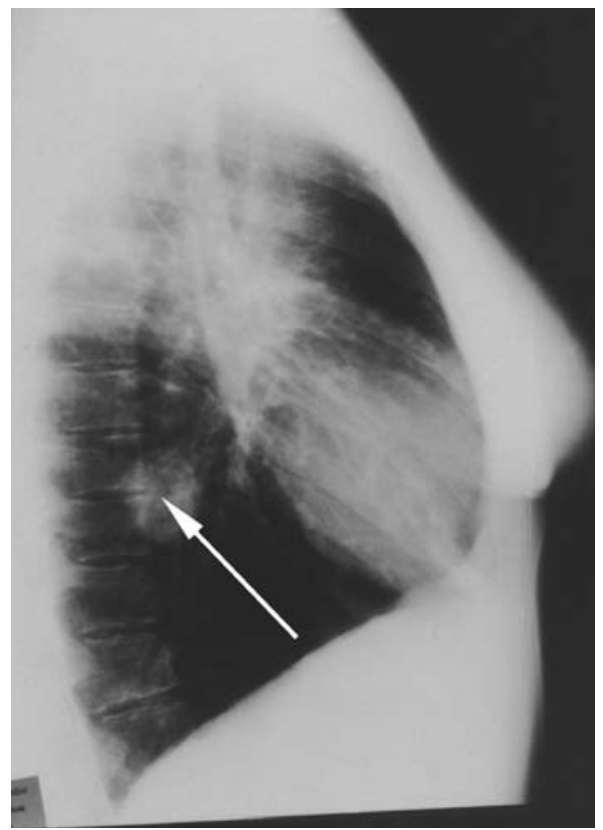

- Abb. 22.13. Metastase eines Lymphoms in der Lunge, Rö-Thorax, rechtsseitig anliegend

Kinder entwickelt Symptome mit Husten, Fieber, einer Anämie und Thrombozytose. Auf dem Röntgenbild sieht man einen solitären Tumor, der oft Verkalkungen zeigt. Die Pathogenese der Erkrankung ist bislang nicht geklärt. Die Therapie besteht in einer chirurgischen Exzision, die Prognose ist nach der Operation sehr gut.

\subsubsection{Maligne Tumoren}

Bei den malignen Tumoren der Lunge handelt es sich überwiegend um Metastasen, z. B. bei Wilms-Tumor, dem Hepatoblastom, Osteosarkom, Ewing-Sarkom und Rhabdomyosarkom. In der Regel werden die Lungenmetastasen im Rahmen der Primärdiagnostik entdeckt, selten sind sie klinisch symptomatisch.

Auch Tumoren der Pleura sind vorwiegend Metastasen im Rahmen der oben aufgeführten Tumorerkrankungen. Hier kommt es öfter zur Ausbildung eines Pleuraergusses mit atemabhängigen Schmerzen, Dyspnoe und Husten. Sehr selten im Kindesalter ist das maligne Pleuramesotheliom.

( Nicht selten werden Raumforderungen im Thoraxbereich als Zufallsbefund einer Röntgen-Thoraxuntersuchung gefunden. Sie müssen mit allen zur Verfügung stehenden bildgebenden Verfahren bis hin zur offenen operativen Exploration abgeklärt werden.

\section{Literatur}

Nolte D (1998) Asthma, 7. Aufl. Urban Schwarzenberg, München Reinhardt D (2007) Asthma bronchiale im Kindesalter, 3. Aufl. Springer, Berlin Heidelberg New York Tokio

Rieger C, von der Hardt H, Sennhauser FH, Wahn U, Zach M (Hrsg) (2004) Pädiatrische Pneumologie. Springer, Berlin Heidelberg New York Rühle KH (2002) Pleura-Erkrankungen. Kohlhammer, Stuttgart Berlin Köln

Taussig LM, Landau LF, LeSouef PN, Sly PD (1999) Pediatric respiratory medicine. Mosby, USA 